\title{
EFFECTS OF SODIUM CHLORIDE AND POLYETHYLENE GLYCOL ON THE WATER RELATIONS, GROWTH, AND MORPHOLOGY OF CITRUS ROOTSTOCK SEEDLINGS
}

By

MONGI ZEKRI

A DISSERTATION PRESENTED TO THE GRADUATE SCHOOL OF THE UNIVERSITY OF FLORIDA IN PARTIAL FULFILLMENT OF THE REQUIREMENTS FOR THE DEGREE OF DOCTOR OF PHILOSOPHY

UNIVERSITY OF FLORIDA

1987 
In the name of God,

Most Gracious,

Most Merciful.

"It is He Who has let free the two bodies of flowing water: one palatable and sweet and the other salt and bitter: yet has He made a barrier between them, a partition that is forbidden to be passed."

Glorious Quran

Sura XXV (Furquan), or The Criterion

Verse \#53

\author{
In the name of God \\ Most Gracious, \\ Most Merciful.
}

"It is He who sendeth down rain from the

skies: with it We produce vegetation of all

kinds: from some We produce green (crops), out of which we produce grain, heaped up (at harvest); out of the date-palm and its sheaths (or spathes) (come) clusters of dates hanging low and near: and (then there are) gardens of grapes, and olives, and pomegranates, each similar (in kind) yet different (in variety): when they begin to bear fruit, feast your eyes with the fruit and the ripeness thereof. Behold! in these things there are signs for people who believe.

Yet they make the Jinns equals with God, though God did create the Jinns; and they falsely, having no knowledge, attribute to Him sons and daughters. Praise and glory be to Him! (for He is) above what they attribute to Him!

To him is due the primal origin of the heavens and the earth: how can He have a son when He hath no consort? He created all things, and He hath full knowledge of all things.

That is God, your Lord! There is no god but He, The Creator of all things: then worship ye Him: and He hath power to dispose of all affairs."

Glorious Quran

Sura VI (An'am), or Cattle

Verses \#99-102 
ACKNOWLEDGMENTS

The author expresses his deepest appreciation to his wife, Leila, for her assistance, encouragement, and patience. He also wishes to express his sincere gratitude to his mother and to all the family in Tunisia for their patience and understanding through the years the author was away from home.

The author expresses his profound gratitude to Dr. L.R. Parsons, chairman of the supervisory committee, for his valuable advice and helpful suggestions in the course of conducting the research and in the preparation of the manuscript.

Sincere thanks re extended to Dr. R. C. J. Koo and to Dr.W. S. Castle for their advice and for providing greenhouse space.

A special debt of gratitude is acknowledged to Dr. D. L. Myhre and to Dr. A. G. Smajstrla for their helpful suggestions and comments and for kindly serving on the supervisory committee.

The author is also grateful to Dr. J. P. Syvertsen and Mr. M. L. Smith, Jr., for providing equipment and for the use of their laboratory facilities.

The author's most sincere gratitude is extended to the coordinators of the Tunisia Agricultural Technology Transfer Project for continuous encouragement and financial support. 
TABLE OF CONTENTS

$\underline{\text { Page }}$

ACKNOWLEDGEMENTS. . . . . . . . . . . . . . . . . . . . . . . . . i i i

LIST OF TABLES . . . . . . . . . . . . . . . . . . . . . . $v \mathrm{vi}$

LIST OF FIGURES . . . . . . . . . . . . . . . . . . . . . . . ix

ABSTRACT. . . . . . . . . . . . . . . . . . . . xi

INTRODUCTION. . . . . . . . . . . . . . . . . . . 1

LITERATURE REVIEW . . . . . . . . . . . . . . . . . . 3

Salts....................... . . . . . 3

Mechanisms of Salt Tolerance in Plants. . . . . . . . . 3

Mechanisms of Salt Injury.... . . . . . . . . . . . 4

Osmotic Effect................. . . . . 4 4

Ion Toxic Effect . . . . . . . . . . . . . . . 5

Nutritional Imbalance. . . . . . . . . . . . . 6

Plant Responses to Salinity . . . . . . . . . . . . . . 7

Salinity and Citrus... . . . . . . . . . . . . 8

Citrus Salinity Research . . . . . . . . . . . . 8

Citrus Tolerance to Salinity. . . . . . . . . . . . 11

Scion . . . . . . . . . . . . . . . . . . 11

Rootstock................. . . 11

Salt exclusion . . . . . . . . . . . . . 12

Ion concentration . . . . . . . . . . . . . . 12

Citrus Responses to Saline Conditions . . . . . . . . . 13

Photosynthesis . . . . . . . . . . . 13

Yield . . . . . . . . . . . . . . 14

Leaf injury . . . . . . . . . . . . . . 14

Salinity and high water table......... 15

Irrigation . . . . . . . . . . . . . . . 15

Reducing Salt Damage . . . . . . . . . . . . . . . 17

Role of Calcium. . . . . . . . . . . . . . . 17

Genetic Improvement . . . . . . . . . . . . . 18

MATERIALS AND METHODS . . . . . . . . . . . . . . . . . 20

General Procedures . . . . . . . . . . . . . . . 20

Experiment 1: Effects of $\mathrm{NaCl}$ and PEG on the Root

Conductivity and Leaf Ion Content of Seedlings

of 7 Citrus Rootstocks... . . . . . . . . . . . . . 21

Experiment 2: Water Relations of Sour Orange and Cleopatra
Mandarin Seedlings under $\mathrm{NaCl}$ and PEG Stresses. 
Experiment 3: Fibrous Root Density and Distribution of Sour Orange Seedlings under $\mathrm{NaCl}$ and PEG Stresses . . . . .

Experiment 4: Response of Split-Root Sour 0range Seedlings to Salinity

Experiment 5: Effects of Calcium on Sour Orange Seedlings Grown under Saline Conditions . . . . . . . . . . 32

RESULTS

Experiment 1: Effects of $\mathrm{NaCl}$ and PEG on the Root Conductivity and Leaf Ion Content of Seedlings of 7 Citrus Rootstocks.

Experiment 2: Water Relations of Sour Orange and Cleopatra Mandarin Seedlings under $\mathrm{NaCl}$ and PEG Stresses . . . .

Experiment 3: Fibrous Root Density and Distribution of Sour Orange Seedlings under $\mathrm{NaCl}$ and PEG Stresses . . . . .

Experiment 4: Response of Split-Root Sour Orange Seedlings to Salinity

Experiment 5: Effects of Calcium on Sour Orange Seedlings Grown under Saline Conditions . . . . . . . . . . . .

Comparison of Citrus Seedling Responses to $\mathrm{NaCl}$ and PEG Treatments

DISCUSSION

Leaf Ion Content and Salinity Tolerance . . . . . . . . 82

Rootstock Tolerance . . . . . . . . . . . . 82

Ion Exclusion and Accumulation . . . . . . . . . . . 83

Leaf Ion Content and Ion Toxicity . . . . . . . . . . . 84

Importance of Calcium under Saline Conditions . . . . . 85

Physiological Effects of $\mathrm{NaCl}$ and PEG . . . . . . . . . . 86

Effect of $\mathrm{NaCl}$ on Root Conductivity . . . . . . . . 86

Effect of PEG on Root Conductivity . . . . . . . . 87

Effect of $\mathrm{NaCl}$ on Stomatal Conductance . . . . . . . 88

Effect of PEG on Stomatal Conductance . . . . . . . . 89

Effect of $\mathrm{NaCl}$ and PEG on Chlorophyll . . . . . . . 89

Effect of $\mathrm{NaCl}$ on Leaf Thickness and Succulence . . . . 90

Growth of Citrus Rootstock Seedlings under $\mathrm{NaCl}$ and

PEG Stresses . . . . . . . . . . . . . . . . . 90

Relationship of Leaf Damage Symptoms to

Root Growth and Distribution under $\mathrm{NaCl}^{\cdot} \cdot{ }^{*} \cdot{ }^{*} \cdot$ and PEG Stresses ................ 91

Effects of Non-Uniform Salinity and Water Stress... . 92

Comparative Effects Between $\mathrm{NaCl}$ and PEG. . . . . . . . . 93

SUMMARY AND CONCLUSIONS . . . . . . . . . . . . . . . . 95

APPENDIX . . . . . . . . . . . . . . . . . . . . 100

LITERATURE CITED. . . . . . . . . . . . . . . . . . . . 116

BIOGRAPHICAL SKETCH . . . . . . . . . . . . . . . . 132 
LIST OF TABLES

Table

1. Salt treatments and chemical properties of the different

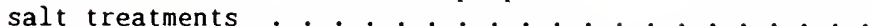

2. Shoot dry weight of seedlings of 7 rootstocks grown for 5 months under different $\mathrm{NaCl}$ and PEG concentrations . . . . . . . . . . . . . . . . .

3. Root dry weight of seedlings of 7 rootstocks grown for 5 months under different $\mathrm{NaCl}$ and PEG concentrations . . . . . . . . . . . . . . . . .

4. Specific fibrous root weight of seedlings of 7 rootstocks grown under different $\mathrm{NaCl}$ concentrations. .

5. Root length, root conductivity, water flow rate, and osmotic potential of inot exudate of seedlings of 7 rootstocks under non-stressed conditions . . . . . .

6. Visible injury in seedlings of 7 rootstocks after 5 months of $\mathrm{NaCl}$ treatments ............

7. Leaf sodium content of seedlings of 7 rootstocks grown for 5 months under different $\mathrm{NaCl}$ and $\mathrm{PEG}$ concentrations . . . . . . . . . . . . . . . .

8. Leaf chloride content of seedlings of 7 rootstocks grown for 5 months under different $\mathrm{NaCl}$ and PEG concentrations . . . . . . . . . . . . . . . . . . .

9. Ion exclusion and accumulation in leaves of citrus rootstock seedlings . . . . . . . . . . . . . .

10. Leaf calcium content of seedlings of 7 rootstocks grown for 5 months under different $\mathrm{NaCl}$ and PEG concentrations . . . . . . . . . . . . . . . . .

11. Monthly new flush growth--area/leaf--of sour orange seedlings .. . . . . . . . . . . . . . . . 
12. Monthly new flush growth--leaf number--of sour orange seedlings . . . . . . . . . . . . . . .

13. Leaf succulence of seedlings of 2 rootstocks grown for 6 months under different $\mathrm{NaCl}$ and PEG

concentrations . . . . . . . . . . . . . . . . . . . .

14. Total chlorophyll of seedlings of 2 rootstocks grown for 6 months under different $\mathrm{NaCl}$ and PEG concentrations . . . . . . . . . . . . . . . .

15. Fibrous root length in the 3 compartments of the root boxes for seedlings under different $\mathrm{NaCl}$ and PEG concentrations . . . . . . . . . . . . . . . .

16. Shoot and root dry weight of split-root sour orange seedlings under $\mathrm{NaCl}$ and PEG stresses . . . . . . .

17. Midday leaf water, osmotic, and turgor potentials of split-root sour orange seedlings under $\mathrm{NaCl}$ and PEG

18. Midday stomatal conductance and transpiration of split-root sour orange seedlings under $\mathrm{NaCl}$ and $\mathrm{PEG}$ stresses . . . . . . . . . . . . . . . . .

19. Root and shoot dry weight of sour orange seedlings under different salt treatments . . . . . . . . 75

20. Total plant dry weight and leaf succulence of sour orange seedlings under different salt treatments....

21. Leaf mineral analysis of sour orange seedlings under different salt treatments . . . . . . . . . .

22. Summary of citrus rootstock responses to $\mathrm{NaCl}$ and PEG as compared to a no salt control . . . . . . .

23. Shoot root ratio of seedlings of 7 rootstocks grown for 5 months under different $\mathrm{NaCl}$ and PEG

24. Total plant dry weight of seedlings of 7 rootstocks grown for 5 months under different $\mathrm{NaCl}$ and PEG concentrations . . . . . . . . . . . . . . . . . . 
25. Stem cross sectional area of seedlings of 7

rootstocks grown for 5 months under different $\mathrm{NaCl}$

and PEG concentrations............. 102

26. Leaf magnesium content of seedlings of 7 rootstocks

grown for 5 months under different $\mathrm{NaCl}$ and PEG

concentrations . . . . . . . . . . . . . 103

27. Leaf potassium content of seedlings of 7 rootstocks

grown for 5 months under different $\mathrm{NaCl}$ and $\mathrm{PEG}$

concentrations... . . . . . . . . . . . 104

28. Leaf phosphorus content of seedlings of 7 rootstocks grown for 5 months under different $\mathrm{NaCl}$ and PEG

concentrations . . . . . . . . . . . . 105

29. Leaf $z$ inc content of seedlings of 7 rootstocks grown

for 5 months under different $\mathrm{NaCl}$ and PEG

concentrations.............. . . 106

30. Leaf manganese content of seedlings of 7 rootstocks grown for 5 months under different $\mathrm{NaCl}$ and PEG

concentrations ................ 107

31. Seedling height of seedlings of 2 rootstocks grown

for 6 months under different $\mathrm{NaCl}$ and PEG

concentrations . . . . . . . . . . . . . 108

32. Total leaf area of seedlings of 2 rootstocks grown

for 6 months under different $\mathrm{NaCl}$ and PEG

concentrations . . . . . . . . . . . 109

33. Specific leaf weight of seedlings of 2 rootstocks grown for 6 months under different $\mathrm{NaCl}$ and PEG

concentrations . . . . . . . . . . . . . . 


\section{LIST OF FIGURES}

1. Osmotic potential versus $\mathrm{NaCl}$ concentration as determined by vapor pressure (VPD) and freezing point depression (FPD) . . . . . . . . . . 22

2. Osmotic potential versus PEG concentration as determined by vapor pressure (VPD) and freezing point depression (FPD) . . . . . . . . . . . . 23

3. Sour orange seedlings with a split-root system . . . . 30

4. Effect of $3 \mathrm{NaCl}$ concentrations on the total fibrous root length, root hydraulic conductivity, and water flow rate for seedlings of 7 citrus rootstocks .... . . . . . . . . . . . . .

5. Relationship between root hydraulic conductivity and specific root weight of seedlings of 7 citrus rootstocks under non-stressed conditions . . . . . .

6. Effect of $\mathrm{NaCl}$ at an osmotic potential of -0.35 $\mathrm{MPa}$ on the 7 rootstocks after 5 months of salinity treatments

7. Relationship between water flow rate and osmotic potential of root exudate of sour orange and Cleopatra mandarin seedlings . . . . . . . . . . . . .

8. Relationship between midday stomatal conductance and root conductivity of sour orange and Cleopatra mandarin seedlings

9. Midday stomatal conductance of sour orange seedlings irrigated with nutrient solution containing no salt (NS) or with added $\mathrm{NaCl}$ or PEG . . . 58

10. Relationship of time of day to stomatal conductance of sour orange seedlings irrigated with nutrient solution containing no salt (NS) or with added $\mathrm{NaCl}$ or $\mathrm{PEG}$ during 2 consecutive days . . . 
11. Growth of sour orange seedlings irrigated with nutrient solution containing no salt (NS) or with added $\mathrm{NaCl}$ or PEG . . . . . . . . . . . . . 60

12. Fibrous root length of sour orange seedlings irrigated with nutrient solution containing no salt (NS) or with added $\mathrm{NaCl}$ or PEG

13. Fluctuations in shoot and root growth of sour orange seedlings irrigated with nutrient solution containing no salt (NS) or with added $\mathrm{NaCl}$ or PEG

14. Root density and distribution of sour orange seedlings growing in root boxes under non-stressed (NS) and stressed ( $\mathrm{NaCl}, \mathrm{PEG}$ ) conditions

15. Root development of split-root sour ornage seedlings under uniform and non-uniform $\mathrm{NaCl}$ and PEG stress ...................

16. Leaf water, osmotic, and turgor potential of sour orange seedlings irrigated with nutrient solution containing no salt (NS) or with $\mathrm{NaCl}$ added to both root halves . . . . . . . . . . . . . . .

17. Relationship between transpiration and stomatal conductance of sour orange seedlings . . . . . . . . . 72

18. Cross sections of sour orange leaves . . . . . . . . . 74

19. Sour orange leaves from non-stressed (control) and stressed ( $\mathrm{NaCl}, \mathrm{PEG})$ seedlings... . . . . . . .

20. Effect of $3 \mathrm{NaCl}$ concentrations on the osmotic potential of root exudate collected from seedlings of 7 citrus rootstocks. .

21. Relationship of time of day to stomatal conductance of sour orange seedlings irrigated with nutrient solution containing no salt (NS) or with added $\mathrm{NaCl}$ during 3 consecutive days . . . . .

22. Relationship of time of day to stomatal conductance of Cleopatra mandarin seedlings irrigated with nutrient solution containing no salt (NS) or with added $\mathrm{NaCl}$ during 3 consecutive days . 
23. Relationship of time of day to stomatal conductance of sour orange seedlings irrigated with nutrient solution containing no salt (NS) or with added PEG during 3 consecutive days . . . . . . . 114

24. Relationship of time of day to stomatal conductance of Cleopatra mandarin seedlings irrigated with nutrient solution containing no salt (NS) or with added PEG during 3 consecutive days................... . . 115 
Abstract of Dissertation Presented to the Graduate School of the University of Florida in Partial Fulfillment of the Requirements for the Degree of Doctor of Philosophy EFFECTS OF SODIUM CHLORIDE AND POLYETHYLENE GLYCOL ON THE WATER RELATIONS, GROWTH, AND MORPHOLOGY OF CITRUS ROOTSTOCK SEEDLINGS

By

MONGI ZEKRI

December 1987

Chairman: Dr. Lawrence R. Parsons

Major Department: Horticultural Science (Fruit Crops)

The effects of sodium chloride $(\mathrm{NaCl})$ and polyethylene glycol (PEG) on the growth, water relations, and leaf mineral content of citrus rootstocks were investigated. Significant growth reduction and physiological disturbances occurred even at $\mathrm{NaCl}$ and PEG concentrations of $-0.10 \mathrm{MPa}$. Growth reduction and physiological changes were found to precede visible damage. Growth was reduced up to $30 \%$ without being accompanied by visible leaf injury symptoms. Leaf burn symptoms developed only after a threshold value of chloride accumulation (1\%) was reached. Leaf burn symptoms developed too slowly to accurately evaluate salt damage. Root conductivity correlated better with salinity tolerance among rootstocks than did total fibrous root length.

Sodium chloride usually caused less damage than PEG. Unlike PEG, $\mathrm{NaCl}$ significantly increased leaf thickness and succulence along with leaf sodium and chloride concentrations, but reduced calcium and zinc contents in the leaves. Both $\mathrm{NaCl}$ and PEG reduced leaf magnesium and potassium contents but increased leaf phosphorus and manganese contents. 
Differences in sodium and chloride exclusion capacities among rootstocks were found. Sour orange, rough lemon, and Milam were sodium and chloride accumulators. Poncirus trifoliata, Swingle citrumelo, and Carrizo citrange were sodium excluders but chloride accumulators. Cleopatra mandarin was a chloride excluder but a sodium accumulator. Differences in $\mathrm{NaCl}$ sensitivity among rootstocks were also found. Cleopatra mandarin and sour orange were the least sensitive, Milam and Poncirus trifoliata were the most sensitive, and rough lemon, Swingle citrumelo, and Carrizo citrange were intermediate in sensitivity. Cleopatra mandarin tolerated high concentrations of $\mathrm{NaCl}$ by partial exclusion of chloride while sour orange tolerated $\mathrm{NaCl}$ even though it accumulated sodium and chloride in its leaves. Sour orange might have the ability to compartmentalize these ions and exclude them from the cytoplasm where they may inhibit metabolic processes.

Seedlings receiving $\mathrm{NaCl}$ or PEG produced small and shallow root systems with the majority of the roots occurring in the top layer. Addition of calcium sulfate to saline irrigation water was found to be beneficial in overcoming the detrimental effects of $\mathrm{NaCl}$ on citrus. The split-root experiment showed that citrus could withstand substantial amounts of stress as long as half of the root system was growing in a non-stressed environment. 


\section{INTRODUCTION}

It is well established that salt can impair the performance of many agricultural plants. Salts present in the soil and irrigation water are a serious problem for commercial agriculture particularly in arid and semi-arid regions. However, the potential for salinity damage also exists in humid climates. Controlling or reducing salt injury is usually achieved either through soil management practices and irrigation with good quality water or by combining these practices with the use of salt-tolerant plants.

Citrus is a fruit crop of international significance. It is grown in over 50 countries and ranks among the top 3 tree fruit crops in world production. In certain areas where citrus is grown, salinity is already a problem of some importance. In other areas, the future of citriculture is threatened by salinity largely because agriculture is being forced to use lower quality land and water for irrigation. In agricultural areas with salinity problems, citrus is particularly vulnerable because there is relatively little salt tolerance in the genus.

Salinity studies have shown that among species, cultivars, and various selections, only 2 rootstocks, Cleopatra mandarin and Rangpur lime, have a limited capacity to tolerate certain salts. However, rootstocks are usually selected for other attributes such as yield and fruit quality. Rootstocks deficient in these characteristics are not likely to be commercially used despite favorable salt tolerance. 
In Florida, there are many citrus plantings located in coastal areas where saline water is being used for irrigation. Citrus planting in these and other southern Florida areas has been accelerated by extensive freeze damage in more northern areas. These changes in the citrus industry, as well as the diseases triteza and blight, have greatly affected interest in rootstock characteristics including salt tolerance.

In the past, virtually all evaluations of citrus response to salinity were based on visual leaf injury and correlations with leaf chloride content. There were no root system observations recorded and no detailed physiological studies conducted. Such observations and measurements of physiological responses are necessary for a complete understanding of salt injury and tolerance in plants. This information is particularly valuable for efficient breeding and screening of new germplasm for salt tolerance.

The objectives of this research are the following:

1. To compare the salt tolerance of citrus rootstocks commercially important in Florida and to determine which rootstocks are salt excluders or salt accumulators.

2. To determine the salt concentrations at which growth is depressed, water balance is disturbed, and leaves are injured.

3. To separate specific ion effects of salts from their osmotic effects by comparing growth, water relations, and plant chemical analyses under $\mathrm{NaCl}$ and PEG stresses.

4. To measure the effects of several $\mathrm{NaCl}$ and PEG concentrations on root growth and distribution.

5. To study citrus growth and water relations under non-uniform salinity (split-root system).

6. To examine the importance of calcium in reducing $\mathrm{NaCl}$ damage. 


\section{LITERATURE REVIEW}

\section{$\underline{\text { Salts }}$}

Many hectares of land throughout the world are too saline for profitable agriculture (Carter, 1975). Large amounts of arable lands are being removed from crop production every year due to increasing soil salinity (Chapman, 1975; Epstein et al., 1980). Saline irrigation water combined with fertilizer application are the factors most responsible for increasing soil salinity (Epstein et al., 1980; Jones et al., 1952; Stewart et al., 1977).

The ions in soil waters which contribute significantly to salinity problems are principally sodium, chloride, calcium, magnesium, sulfate, potassium, bicarbonate, carbonate, nitrate, and occasionally borate ions (Bernstein and Hayward, 1958; Peck, 1975; Shainberg, 1975). However, most salinity research has involved $\mathrm{NaCl}$ because it is the most common salt in saline soils and irrigation waters.

\section{Mechanisms of Salt Tolerance in Plants}

Salt-tolerant plants are generally thought to be protected from salt stress by either ion accumulation or ion exclusion. Accumulation of high concentrations of ions in halophyte leaves has been known to be a salt tolerance mechanism (Flowers et al., 1977; Greenway and Munns, 1980). Salts can be tolerated because ions are compartmentalized in the vacuole and not in the cytoplasm. Hence, metabolic processes are not inhibited. These ions in the vacuoles balanced with neutral organic solutes in the cytoplasm lower the leaf osmotic potential. This allows 
the plant to extract water from saline solutions. However, salt tolerance in glycophytes (nonhalophytes) is related to ion exclusion because of the plant's inability to compartmentalize toxic ions in a useful way and to adjust osmotically (Greenway and Munns, 1980).

\section{Mechanisms of Salt Injury}

Salt damage to plants is caused by the decrease in the water potential of the soil solution or by the toxicity of specific ions. Some workers attribute most of the salt damage to osmotic stress (Bernstein, 1961, 1963; Bernstein and Hayward, 1958; Bielorai et al., 1978, 1983; Bohn et al., 1979). Others favor the idea that toxic effects of specific ions predominate in restricting growth and yields (Babaeva et al., 1968; Gollek, 1973; Strogonov, 1964).

A common method of distinguishing between osmotic and ion toxic effects of salts is to compare the effects of isosmotic solutions of the salt with those of non-toxic organic substances. If the salt injury is simply osmotic, all solutes should produce the same injury at the same osmotic potential (Levitt, 1980). Polyethylene glycol (PEG), a non-ionic compound, has been successfully used as an osmoticum for subjecting plants and plant tissues to known levels of water stress (Janes, 1966; Kaufmann and Eckard, 1971; Kawasaki et al., 1983a, b). Osmotic Effect

Water is osmotically more difficult to extract from saline solutions. Pair et al. (1975) pointed out that the addition of $0.4 \%$ salts had the effect of reducing the total available water in the soil by approximately 33\%. Salt addition is analogous to soil drying since both result in reduced water uptake. In extreme circumstances, salinity can prevent water uptake even when the soil is at field capacity (Hartz, 1984). Water uptake by mature grapefruit trees, mature Valencia orange 
trees, and Valencia orange seedlings was reduced as salinity increased (Bielorai et al., 1983; Hayward and Blair, 1942; Plessis, 1985). Ion Toxic Effect

Ion toxic effect of salt is attributed to excess accumulation of certain ions in plant tissues and to nutritional imbalances caused by such ions. Ion excess has been defined as a condition where high internal ion concentrations reduced growth (Greenway and Munns, 1980). In many crops, salt injury increases with increased salt uptake. Raspberries were found to accumulate chloride ions more rapidly and consequently were more severely injured than blackberry (Ehlig, 1964). Tagawa and Ishizaka (1963) found that the primary cause of injury to rice by $\mathrm{NaCl}$ was chloride accumulation in the shoots. When treated with $\mathrm{NaCl}$, a less resistant barley variety accumulated higher levels of chloride and sodium than a more resistant variety (Greenway, 1962).

Salt damage to citrus has been mainly attributed to excessive accumulation of chloride and sodium in the leaves (Abdel-Messih et al., 1979; Chapman et al., 1969; Cooper, 1961; Cooper et al., 1951; 1952b; Cooper and Peynado, 1953; El-Azab et al., 1973; Furr and Ream, 1968; Grieve and Walker, 1983). Goell (1969) suggested that salt ions such as chloride in citrus leaves might shorten the life span of leaves by increasing chlorosis (loss of chlorophyll and photosynthetic potential) and by promoting senescence and abscission. Sulfate and other ions also caused damage to citrus (Bhambota and Kanwar, 1970; Bingham et al., 1973; Cerda et al. 1979; Hewitt and Furr, 1965a; Peynado and Young, 1964). It has been suggested that the accumulation of ions in large amounts in the leaves is the main factor causing leaf burn and inhibition of certain metabolic processes. 
Sodium can also cause injury to plants through its deleterious effect on the soil. When the proportion of exchangeable sodium is relatively high, clay particles in the soil tend to disperse and block the pores through which water flows. This phenomenon decreases the hydraulic conductivity of the soil (Bohn et al., 1979; Shainberg, 1975) and causes poor aeration. Studies by Aldrich et al. (1945) demonstrated that inferior performance of orange trees was caused primarily by poor water penetration resulting from sodium accumulation on the exchange complex.

\section{Nutritional Imbalance}

Salt can also damage plants by causing nutritional imbalances. High sodium levels can lead to calcium and magnesium deficiencies (Bohn et al., 1979). In spinach and lettuce, sodium salts decreased dry matter production as well as leaf potassium, magnesium, and calcium contents (Matar et al., 1975). Pumpkin and sweet clover plants subjected to $\mathrm{NaCl}$ showed potassium deficiency (Solov'ev, 1969). A decrease in potassium uptake at higher concentrations of sodium was found in sugarcane (Nimbalker and Joshi, 1975) and rice (Paricha et al., 1975). With increased salinity, potassium and phosphorus uptake decreased in grapes, guava, and olive plants (Taha et al., 1972), in wheat (Sharma and Lal, 1975), and in barley (Kawasaki et al., 1983b).

In citrus, nutritional imbalance has been also attributed to depressed absorption of some nutrients. A decrease in the concentration of calcium, magnesium, and sometimes potassium was found when salt concentration in the irrigation water was increased (Jones et al., 1957; Patil and Bhambota, 1980; Pearson et al., 1957). 


\section{Plant Responses to Salinity}

Salinity has been known to adversely affect all stages of plant development such as germination, vegetative growth, and fruiting: Salinity has also been found to depress chlorophyll content, photosynthesis, stomatal conductance, root conductivity, and transpiration of many crops. For example, growth of citrus (Furr and Ream, 1968), Vicia faba (Helal and Mengel, 1981), pepper (Hoffman et al., 1980), alfalfa (Keck et al., 1984), bean (Meiri and Poljakoff-Mayber, 1970), and corn (Siegal et al., 1980) was significantly depressed under saline conditions.

Yield of grapefruit (Bielorai and Levy, 1971; Bielorai et al., 1978, 1983), orange (Bingham et al., 1973, 1974; Chapman et al., 1969), celery (Francois and West, 1982), and muskmelon (Shannon and Francois , 1978) was severely reduced due to salinity stress. Salinity was found to alter fruit quality by decreasing the "pack out" of oranges at a commercial packing shed (Bingham et al., 1974) and by decreasing the marketable yield of tomato and melon (Mizrahi and Pasternak, 1985; Shannon and Francois, 1978). It was found that the relative amount of the premium grade fruit decreased with use of saline water even though there was a trend toward higher soluble solids and better taste (Bingham et al., 1974; Mizrahi and Pasternak, 1985; Shannon and Francois, 1978).

Salinity reduced leaf chlorophyll content in grapevine, bean, barley, citrus and mangrove (Downton and Millhouse, 1985), spinach (Downton et al., 1985), and Acacia saligna (Shaybany and Kashirad, 1978). Leaf chlorophyll content declined only when certain amounts of salt ions accumulated in the leaves. Salinity reduced photosynthesis in spinach (Downton et al., 1985), rice (Flowers et al., 1985), Xanthium strumarium (Schwarz and Gale, 1983), beans (Seemann and Critchley, 
1985), and Acacia saligna (Shaybany and Kashirad, 1978). Under most circumstances, photosynthetic reduction was attributed to ion accumulation in the leaves and to reduction in stomatal conductance.

Salinity was found to reduce root conductivity in white lupin (Munns and Passioura, 1984) and beans (0'Leary, 1969; 1974). However, salinity did not affect root conductivity in barley (Munns and Passioura, 1984), sunflower and tomato plants (Shalhevet et al., 1976). Reduced hydraulic conductivity of roots has been attributed to root suberization and to reduced root membrane permeability.

\section{Salinity and Citrus}

Citrus is generally classified as a salt sensitive crop because physiological disturbances and growth and fruit yield reductions can occur at relatively low salinity levels (Bernstein, 1969; Bielorai et al., 1978, 1983; Boaz, 1978; Cherif et al., 1982; Cooper and Shull, 1953; Francois and Clark, 1980; Furr et al., 1963; Kirkpatrick and Bitters, 1969; Marsh, 1973; Patil and Bhambota, 1980; Pehrson et al., 1985; Walker et al., 1982).

\section{Citrus Salinity Research}

The response of citrus to salinity is a topic of concern in many regions where citrus is grown especially the United States, Israel, Egypt, India, Spain, and Tunisia. In the United States, salinity studies essentially began in Texas during the 1940s. Investigations were led by W.C. Cooper with emphasis on differences in salinity tolerance among citrus rootstocks (Cooper, 1948; Cooper and Gorton, 1952; Cooper and Peynado, 1959; Cooper and Shull, 1953; Cooper et al., 1951). The work was conducted mostly on young budded trees grown in the field. Salinity treatments consisted of $\mathrm{NaCl}+\mathrm{CaCl}_{2}$ added to Rio Grande river water. These studies led to the observation that chloride 
exclusion was strongly correlated with salt tolerance. Chloride accumulation or exclusion and leaf injury symptoms were used to classify salt tolerant and salt sensitive rootstocks.

Salinity studies on citrus were started in California in the 1950's (Harding et al., 1958a; Janes et al., 1952; Pearson and Goss, 1953), in Israel in the 1970s (Bielorai et al., 1973; Heller et al., 1973), and in Australia in the 1970s (Cole and Till, 1977). Most of these studies were conducted in the field on mature citrus trees and were focused on yield reduction and fruit quality alteration as a function of salt concentration in irrigation waters (Bielorai et al., 1978, 1983; Bingham et al., 1973, 1974; Boaz, 1978; Francois and Clark, 1980; Levy et al., 1979; Pehrson et al., 1985; Shalhevet et al., 1974).

Recent salinity work in Israel was directed to plant breeding using cell culture techniques (Ben-Hayyim and Kochba, 1983; Ben-Hayyim et al., 1985). Recent work in Australia was conducted mainly with young rootstock seedlings grown in pots under glasshouse conditions (Behboudian et al., 1986; Grieve and Walker, 1983: Walker and Douglas, 1983; Walker et al., 1982, 1983, 1984, 1986). Salinity treatments consisted of $\mathrm{NaCl}$ added to a nutrient solution. These studies were focused on sodium and chloride exclusions mechanisms, water relations, and photosynthesis. Photosynthesis was severely reduced and photosynthetic reduction was attributed to a loss of turgor in salt excluder rootstocks and to chloride accumulation in salt accumulator roots tocks.

Some salinity work on citrus conducted in Egypt (Abdel-Messih et al., 1979; Minessy et al., 1973), India (Bhambota and Kanwar, 1970; Patil and Bhambota, 1980), Spain (Cerda et al., 1979; Guillen et al., 1978), and Tunisia (Cherif et al., 1981; 1982; Zid, 1975; Zid and 
Grignon, 1985, 1986) on budded trees and rootstock seedlings involved ion analysis and nutrient absorption. These studies showed that salinity caused nutritional imbalance, growth reduction, and leaf burn. Growth reduction was attributed to potassium deficiency and foliar necrosis to sodium accumulation in the leaves.

Salinity is of increasing concern in Florida. Salt water intrusion into groundwater in areas where citrus is grown has increased the need for salinity studies in Florida. Many citrus rootstocks are being used in Florida such as sour orange, Swingle citrumelo, Carrizo citrange, and Milam without knowing their salt tolerance. As a result, there is an incentive to study the salinity tolerance of these and other rootstocks which are commercially important.

Physiologists of ten concentrate on the activities of shoots and neglect roots because they are out of sight and more difficult to study than shoots (Kramer, 1983). Roots play an important role in the growth and development of the entire plant. Their health, vigor and activity can be an index of the functioning of the above-ground parts (Crider, 1927). It is important to investigate root growth and distribution because roots are directly in contact with salts in the soil. Detailed information on the growth behavior and morphological development of citrus root systems under salt conditions is not available.

The two major resistances to water movement through the soil-plant-atmosphere continuum are the roots and the stomata (Kramer, 1969; Kriedemann and Barrs, 1981). Root conductivity and stomatal conductance are important variables to be monitored in salinity studies because they can provide information on the water balance disturbance caused hy salt. Root conductivity of some in citrus rootstocks under salinity stress has not been previously studied. Furthermore, 
information relating root conductivity to stomatal conductance and transpiration as a function of different osmotic concentrations is lacking .

Under field conditions, the roots of an individual plant grow in soil which varies in water content and salt concentration both in space and with time. In assessing the suitability of water for irrigation, it is usually assumed that plants respond to the mean root zone salinity (Shalhevet and Bernstein, 1968). However, some workers suggest that the least saline part of the rooting zone controls the overall plant growth and yield (Lunin and Gallatin, 1965). Responses of citrus to non-uniform salinity or to zonal salinization are not known. Citrus Tolerance to Salinity

Scion. Differences in salt tolerance among citrus varieties or scions have been shown. Boaz (1978) concluded that Valencia orange had a lower tolerance to salinity than grapefruit on sweet orange rootstock. Bernstein (1969) reported that lemon was more sensitive to salinity than orange which was more sensitive than grapefruit. Miwa et al. (1957) also found that lemon was the most susceptible variety to foliar spray injury from sea water. Results of Pearson and Huberty (1959) showed that navel orange trees were more sensitive to irrigation water quality than Valencia orange trees. Budded on rough lemon, salt tolerance decreased in the following order: Hamlin, Valencia, Pineapple and Blood red sweet orange (Bhambota and Kanwar, 1969). Valencia seemed to be more sensitive to salinity than Shamouti when both were grafted on sour orange rootstock (Shalhevet et al., 1974).

Rootstock. Some studies have indicated a wide range in salt tolerance among citus rootstocks (Cooper, 1948: Cooper and Edwards, 1950; Cooper et al., 1952b, 1958). Cooper et al. (1951) found that 
Cleopatra mandarin and Rangpur lime are relatively salt-tolerant rootstocks. They classified sour orange, rough lemon, sweet lemon, tangelo and sweet lime as sensitive rootstocks and Florida sweet .orange and trifoliate orange as very sensitive. In another study, Cleopatra mandarin and Rangpur lime were also found to be the most tolerant rootstocks and Carrizo citrange was the most sensitive rootstock (Joolka and Singh, 1979; Patil and Bhambota, 1978). Trifoliate orange and rough lemon were found to be very salt sensitive (Bhambota and Kanwar, 1969). Although some selections of sour orange differed in salt tolerance, Ream and Furr (1976) found that none of them was as salt tolerant as Cleopatra mandarin.

Salt Exclusion. Exclusion of certain ions has been demonstrated in some citrus rootstocks. Rangpur lime and Cleopatra mandarin appear to be chloride excluders (Cooper, 1961; Cooper and Gorton, 1952; Cooper and Peynado, 1959; Douglas and Walker, 1983; Grieve and Walker, 1983; Hewitt and Furr, 1965b; Walker, 1986; Walker et al., 1983; Wutscher et al., 1973). Trifoliate orange appears to be a sodium excluder (Elgazzar et al., 1965; Grieve and Walker, 1983; Walker, 1986) and Citrus macrophylla a boron excluder (Cooper and Peynado, 1959; Embleton et al. 1962). This suggests the existence of a blocking mechanism in the transport of these ions (Fernandez et al., 1977). It also indicates the existence of apparently separate mechanisms which regulate the uptake and transport of ions (chloride and sodium) in salt-stressed citrus (Fernandez et al., 1977; Grieve and Walker, 1983; Walker et al., 1983). Ion concentration. Citrus is a nonhalophyte, and its tolerance to salinity is correlated with its ability to restrict the entry of ions into the shoots (Greenway and Munns, 1980). Injury to citrus from $\mathrm{NaCl}$ has been attributed to excess chloride accumulation (Ben-Hayyim and 
Kochba, 1983; Cooper, 1961; Cooper and Gorton, 1952; Furr and Ream, 1969). In an effort to screen young citrus trees for salt tolerance, Hewitt et al. (1964) found that the leaves could be analyzed for . chloride after 3 to 4 weeks of treatment with highly saline irrigation water. Fernandez et al. (1977) considered foliar chloride content as a suitable index of the soil salinity status and toxicity levels. However, Ben-Hayyim et al. (1985) showed the difficulty in determining if any particular ion could serve as a reliable marker for salt tolerance in citrus. Citrus Responses to Saline Conditions

Photosynthesis. Photosynthetic rates were reduced by 50 to $75 \%$ after 70 days of $\mathrm{NaCl}$ stress (Behboudian et al., 1986; Walker et al., 1982). A decrease in photosynthesis is often caused by a drop in leaf turgor, but studies have shown different turgor responses to salinity. In one study with Rangpur lime, photosynthesis reduction was attributed to low turgor pressures in rangpur lime and not to leaf chloride or sodium concentrations since there was no significant difference in concentrations of these ions between salt-stressed and control leaves. In contrast to Rangpur lime, photosynthetic reduction during salt treatment in Etrog citron was associated with a marked increase in leaf chloride since turgor was not reduced. Their work established that a plant's capacity for salt exclusion alone or turgor maintenance alone was unable to protect citrus seedlings against photosynthetic reduction. Therefore, to improve salt tolerance in citrus, studies need to be focused not only on salt exclusing rootstocks but also on the ability of scions to maintain turgor. It appears that the inability to osmotically adjust and exclude toxic ions is related to citrus sensitivity to salinity (Zid and Grignon, 1986). 
Yield. Citrus yield has been related to salt concentration in the soil (Bielorai et al., 1978; Harding et al., 1958b). According to Boaz (1978) and Maas and Hoffman (1977), the threshold salinity is an . electrical conductivity of the soil saturation extract of $1.8 \mathrm{dS} / \mathrm{m}(1.8$ mmhos $/ \mathrm{cm}$ ) for oranges and grapefruit. Above this threshold, yield is reduced at a rate of $16 \%$ per $\mathrm{dS} / \mathrm{m}$. Pehrson et al. (1985) stated that 10 and $50 \%$ yield reductions for citrus were associated with electrical conductivities of the soil saturation extract of 2.3 and $4.8 \mathrm{dS} / \mathrm{m}$, respectively.

Salinity was found to significantly reduce citrus yield without visual symptoms (Pehrson et al., 1985). The use of moderately saline irrigation water $(2.5 \mathrm{dS} / \mathrm{m})$ decreased orange yield by about $30 \%$ without any visible leaf injury symptoms (Bingham et al., 1974). Within a concentration range of 2 to $2.7 \mathrm{dS} / \mathrm{m}, 9$ to $18 \%$ yield reduction in grapefruit occurred without apparent te-icity symptoms (Bielorai et al., 1978, 1983). When irrigated with moderately saline water (15 to $30 \mathrm{mM}$, $\mathrm{CaCl}_{2}+\mathrm{Na}_{2} \mathrm{SO}_{4}+\mathrm{MgSO}_{4}$ ), Valencia orange had yield reductions of 34 to $54 \%$ with no visible leaf injury symptoms (Francois and Clark, 1980).

Leaf injury. Salinity effects develop slowly so that leaf injury symptoms appear after a certain period of time. However, the length of this time period is shortened by higher salt concentrations. Grown in the field, two-year-old Ruby red grapefruit on sour orange rootstock irrigated with salt solutions of $2500 \mathrm{mg} / \mathrm{L}\left(50: 50 \mathrm{NaCl}\right.$ and $\left.\mathrm{CaCl}_{2}\right)$ showed no visible symptoms of salt injury during a one year period. Trees irrigated with $4000 \mathrm{mg} / \mathrm{L}$ salt solution developed leaf bronzing within 1 month and marginal burning of the leaves within 2 months. Trees irrigated with $5000 \mathrm{mg} / \mathrm{L}$ salt solution were completely defoliated within a one year period (Cooper, 1961; Cooper et al., 1952a). 
Salinity and high water table. Relatively few studies have been conducted to investigate the effects of a combination of water table and salinity on citrus even though this condition exists in many parts of the world. Studying the effects of salinity and water table on the growth and mineral composition of young grapefruit trees, Pearson and Goss (1953) found that the rates of defoliation and twig dieback due to salinity were greatly accelerated by a frequently fluctuating water table. In a more detailed report of the same study, Pearson et al. (1957) concluded that the salinity factor accounted for approximately 90\% of the variance in growth while the water table factor accounted for only about $4 \%$. They found that sodium and chloride accumulated in toxic amounts in the leaves and were responsible for the decrease in growth. However, while investigating the effect of different water table depths and salinity levels on sweet orange, Kanwar and Bhambota (1969) observed that the adverse effect of water table was more pronounced than that of salinity. Both studies agreed that the interaction of water table and salinity affected the trees more severely than either condition alone.

The fact that Cleopatra mandarin is more sensitive to flooding (Ford, 1964) but more salt tolerant (Cooper et al., 1951) than sour orange raises the question about the performance of these two rootstocks under saline conditions associated with high water table or flooding problems.

Irrigation. Citrus is relatively sensitive to salinity, but can withstand high salt concentrations depending on the variety, rootstock, and irrigation management. Good irrigation management should consider the salinity factor in the irrigation water, in the soil, and in the root zone (Boaz, 1978). Methods of irrigation scheduling which do not account for salinity are not sufficiently accurate for scheduling 
irrigation in areas with a saline high water table. Irrigation water containing about $250 \mathrm{mg}$ chloride per liter reduced grapefruit yield by 28 to $32 \%$ when trees were irrigated at intervals of 40 days compared to intervals of 18 days (Bielorai and Levy, 1971; Bielorai et al., 1973). These studies demonstrated that the effect of salinity is more severe at lower soil water content.

overhead sprinkler irrigation should be avoided when using water containing high levels of salts because salt residues can accumulate on the foliage and seriously injure plants. Navel orange accumulated injurious amounts of chloride and sodium from sprinkler-applied water having 500 to $900 \mathrm{ppm}$ total dissolved solids (Harding et al., 1958a). Considerable leaf burn and defoliation of these trees were found to be correlated with excessive amounts of sodium and chloride and lower amounts of potassium in the leaves. Leaf injury of navel orange trees developed at concentrations of 5 to $10 \mathrm{mmol} / \mathrm{L}$ of $\mathrm{NaCl}, \mathrm{CaCl}_{2}$ or $\mathrm{Na}_{2} \mathrm{SO}_{4}$ in the sprinkler-applied waters (Ehlig and Bernstein, 1959). Salt content of up to $1300 \mathrm{mg} / \mathrm{L}$ caused defoliation of sprinkler-irrigated citrus trees in Texas (Lyons, 1977). In Australia, during periods of high salinity in the irrigation water, foliar absorption of sodium and chloride occurred when using overhead sprinklers on citrus. It was believed that this problem caused poor tree health, low yield, and possibly poor fruit quality in citrus (Cole and Till, 1977).

Frequency rather than duration of sprinkler irrigation is perhaps more important in foliar absorption of salts. Salt injury was higher under higher evaporation conditions and with short and frequent periods of overhead sprinkling (Eaton and Harding, 1959; Ehlig and Bernstein, 1959; Harding et al., 1958a). 
Micro-irrigation is gaining in popularity not only in arid regions but also in humid subtropical areas. Micro-irrigation refers to both drip and microsprinkler irrigation. Micro-irrigation enables the use of poorer quality water that cannot be tolerated with overhead sprinklers. Direct foliar uptake of salts, and hence leaf injury, is avoided with drip irrigation (Calvert and Reitz, 1966). Nevertheless, saline water cannot be used indiscriminately with micro-irrigation systems. Comparative studies between overhead sprinklers and drip systems using saline water showed that vegetative growth, root development, and yield were greater with drip than with sprinkler irrigation (Goldberg and Shmueli, 1971; Shmueli and Goldberg, 1971). In a comparison of flood and drip systems, water high in chloride and boron was applied to young grapefruit trees on many rootstocks (Wutscher et al., 1973). More chloride and boron accumulation was found in trees that were flood irrigated than in tho " that were micro-irrigated.

Drip irrigation at frequent intervals maintains a low soil water tension and prevents salt accumulation within the wetted zone. Consequently, water with higher salinity levels may be used without significantly affecting the yield. Nevertheless, salt accumulation under drip irrigation must be considered because salts may accumulate both at the periphery of the wetted zone and on the soil surface (Bielorai, 1977, 1985; Goldberg et al., 1976; Hoffman et al., 1985; Yaron et al., 1973).

\section{Reducing Salt Damage}

Role of Calcium

Calcium has been known to have an ameliorating effect on the growth of plants under saline conditions (Deo and Kanwar, 1969; Epstein, 1972; Hyder and Greenway, 1965). This effect has been attributed to calcium 
preventing the uptake of the sodium ion to injurious levels, and allowing the uptake of potassium (Waisel, 1962). In the presence of adequate concentrations of calcium, bean plants were able to exclude sodium and to withstand the effects of relatively high $\mathrm{NaCl}$ concentrations (LaHaye and Epstein, 1969, 1971). In barley, inhibition of the absorption and translocation of potassium and phosphorus by $\mathrm{NaCl}$ was found to recover dramatically in the presence of calcium (Kawasaki et al., 1983b). Application of gypsum to the soil or in the irrigation water markedly reduced the percentage of soluble sodium in the soil (Harding et at., 1958b) and reduced the percentage of sodium in citrus leaves and roots (Jones et al., 1952; Pearson and Huberty, 1959).

Calcium amendments are commonly used for replacement of exchangeable sodium (Richards, 1954). Calcium can flocculate soil in which clay particles and aggregates have been dispersed by sodium. Salt-affected soils can therefore be made productive by chemical amendment, drainage, and irrigation with high quality water, but sometimes the cost of these operations exceeds the expected returns from the land.

\section{Genetic Improvement}

In recent years, adapting plants to saline environments through breeding and genetic manipulation have been attempted (Epstein et al., 1980). The genetic basis for salt tolerance, using information from studies with whole plants, has allowed the identification of plants with increased salt tolerance. Another approach is to increase salt tolerance through cell culture (Croughan et al., 1981).

In some species, the variability in salt tolerance may not be adequate for a successful breeding program because it may not be possible to find salt-tolerant wild relatives and use them as sources of germplasm. Suspension of cells from salt-sensitive plants in solutions 
having various degrees of osmotic stress was found to be a promising technique to select salt-tolerant cells from salt-sensitive cells. This implies that the genetic information for growth in a saline environment may be present in salt-sensitive cells but is not expressed. Selection of salt-tolerant cells may provide genetic material that will help improve our understanding of salinity resistance at the cellular level. 
MATERIALS AND METHODS

\section{General Procedures}

This study consisted of 5 experiments involving citrus seedlings grown in greenhouses in central Florida. Seeds were sown in plastic trays composed of individual cells. The trays were filled with PROMIX BX [60\% Canadian peat, $20 \%$ perlite, and $20 \%$ vermiculite with dolomitic limestone, superphosphate, calcium nitrate and fritted trace elements added]. The seeds were irrigated with tap water twice a week until emergence. Seedlings were irrigated with tap water every other day and fertilized with 20-20-20 (N,P,K) fertilizer once a week. The temperature and $\mathrm{r} r$ ative humidity in the greenhouses were controlled by both heating and evaporative cooling systems with conventional end-wall air circulation fans. The minimum and maximum temperature and relative humidity ranged from 20 to $35^{\circ} \mathrm{C}$ and from 40 to $100 \%$, respectively.

Three to 6 months after emergence, uniform seedlings were selected and transplanted into pots or wooden boxes containing fine sand taken from the top $30 \mathrm{~cm}$ of a citrus orchard soil. The soil was Astatula fine sand (hyperthermic, uncoated Typic Quartzipsamments) with a pH of 6.5 and a field capacity and a wilting percentage of $7.2 \%$ and $1.2 \%$ (volume basis), respectively. Seedlings were irrigated every 2 to 3 days with half strength Hoagland's solution \#1 (Hoagland and Arnon, 1950) for at least one month before starting salt and polyethylene glycol (PEG) treatments. Treatments were started by adding NaCl, PEG, or other salts to the Hoagland solution. 
The water holding capacity of the soil in the containers was about 18\% (volume basis). The irrigation frequency was 2 to 3 days. The amount of solution added each time was based on bringing the soil to slightly more than the water holding capacity of the soil in the containers to prevent salt accumulation in the growth medium and to prevent plants from undergoing a drought stress.

Standard curves (Fig. 1, 2) of osmotic potential versus solute concentration were developed for $\mathrm{NaCl}$ and PEG 4000 by measuring vapor pressure and freezing point depression. The values obtained were similar to those of Steuter et al. (1981) who compared freezing point depression and vapor pressure methods for determination of water potential of PEG solutions. Electrical conductivities of the different treatments were determined with a conductivity meter. Electrical conductivity values were converted to TDS (Richards, 1954).

Sodium chloride and PEG treatments were continued for at least 4 months, after which the plants were harvested and the roots were washed briefly with tap water to free them of sand particles. Shoots were separated into stems and leaves, and roots were separated into taproots, lateral roots, and fibrous roots (roots less than $2 \mathrm{~mm}$ in diameter). The material was oven-dried for 3 days at $60^{\circ} \mathrm{C}$, weighed, ground, and retained for ion analysis.

Analysis of variance (F-test) was used to determine significant differences and Duncan's multiple range test was employed for mean comparison at $\mathrm{P}<0.05$.

Experiment 1: Effects of $\mathrm{NaCl}$ and PEG on the Root Conductivity and Leaf Ion Content of Seedlings of 7 Citrus Rootstocks

The objective of this experiment was to compare the growth, ion content, and water relations of 7 rootstocks treated with different 


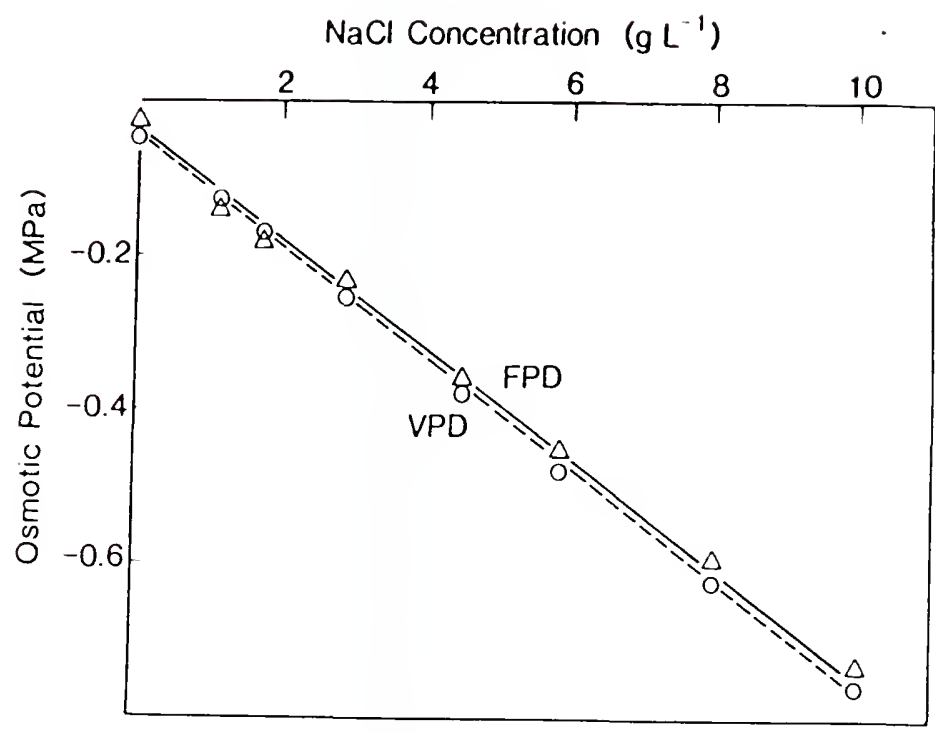

Fig. 1. Osmotic potential versus $\mathrm{NaCl}$ concentration as determined by vapor pressure (VPD) and freezing point depression (FPD). 


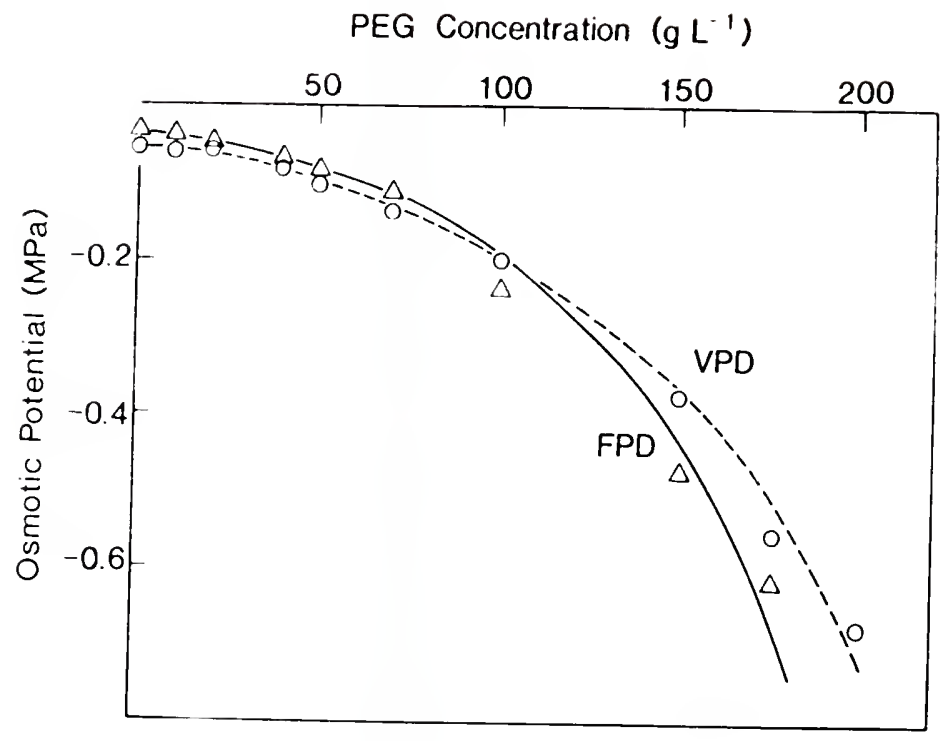

Fig. 2. 0smotic potential versus PEG concentration as determined by vapor pressure (VPD) and freezing point depression (FPD). 
levels of $\mathrm{NaCl}$ and PEG. On 0ctober 20, 1985, 5-month-old uniform seedlings of 7 rootstock cultivars were transplanted into $33 \mathrm{~cm}-\mathrm{tall}$ black plastic pots containing about $2.2 \mathrm{~L}$ of fine sand. Rootstocks studied were the following: sour orange (Citrus aurantium), Cleopatra mandarin (C. reshni), Swingle citrumelo (‥ paradisi $x$ Poncirus

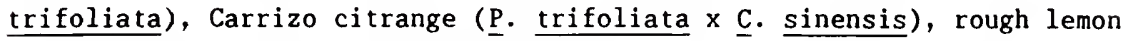
(C. jambhiri), Milam (‥ jambhiri variant) and trifoliate orange (P. trifoliata). The plants were watered with a half strength Hoagland's solution and were grown with this control solution for 2 months. Sodium chloride and PEG treatments were started on December 19, 1985, and nutrient solutions for treated plants were identical to that of the control plants except for the addition of $\mathrm{NaCl}$ and PEG. Sodium chloride and PEG were added to the half strength Hoagland's solution to achieve final concentrations of $-0.10,-0.20$, and $-0.35 \mathrm{MPa}$. The basic nutrient solution (control) had an osmotic potential (OP) of $-0.05 \mathrm{MPa}$.

Treatments were as follows:

$\underline{\text { Treatment }}$

$\frac{\mathrm{TDS}}{\left(\mathrm{mg} \mathrm{L^{-1 }}\right)} \frac{\mathrm{OP}}{(\mathrm{MPa})} \frac{\mathrm{EC}}{\left(\mathrm{dS} \mathrm{\textrm {m } ^ { - 1 }}\right)} \frac{\mathrm{NaCl}}{(\mathrm{mmol})}$

1. NS control : th Hoagl. sol. $550-0.05 \quad 1.1$

2. $\mathrm{NaCl}(0.10): 1.0 \mathrm{~g} \mathrm{NaCl} / \mathrm{L}$ th Hoagl. sol. $1600 \quad-0.10 \quad 3.1 \quad 17$

3. PEG (0.10) : $55 \mathrm{~g}$ PEG/L H/2 Hoagl. sol. $460-0.10 \quad 0.9 \quad 0$

4. $\mathrm{NaCl}(0.20): 2.2 \mathrm{~g} \mathrm{NaCl} / \mathrm{L}$ 位 Hoagl. sol. $3000 \quad-0.20 \quad 5.4 \quad 38$

5. PEG (0.20) : $105 \mathrm{~g} \mathrm{PEG/L} \mathrm{H2} \mathrm{Hoagl.} \mathrm{sol.} 400-0.20 \quad 0.8 \quad 0$

6. $\mathrm{NaCl}(0.35): 4.2 \mathrm{~g} \mathrm{NaCl} / \mathrm{L}$ th Hoagl. sol. $4900 \quad-0.35 \quad 8.8 \quad 72$

7. PEG (0.35) : $144 \mathrm{~g} \mathrm{PEG/L} \mathrm{th} \mathrm{Hoagl.} \mathrm{sol.} 350-0.35 \quad 0.7 \quad 0$ Plants were adjusted to their final $\mathrm{NaCl}$ and PEG concentrations through a progression of $-0.10,-0.20$, and $-0.35 \mathrm{MPa}$ solutions at 2-day intervals to avoid osmotic shock. Plants were then maintained at their 
final osmotic levels for 5 months. The experimental unit was a single seedling arranged in a split plot with 4 replications. The 7 salt treatments were assigned to the main plots and the 7 rootstocks to the subplots.

At the end of the experiment, root hydraulic properties were evaluated while in situ on 4 seedlings of each rootstock as previously described (Graham and Syvertsen, 1984, 1985; Levy et al., 1983; Syvertsen and Graham, 1985). Before measuring, the soil was wetted to field capacity to minimize possible differences in soil hydraulic conductivity and equilibrated to $25^{\circ} \mathrm{C}$ in the laboratory. Each pot and intact plant were placed in a pressure chamber. The stem was then cut $10 \mathrm{~cm}$ above the soil and the chamber was sealed around the cut stem. The pressure within the chamber was increased gradually to a constant value of $0.5 \mathrm{MPa}$. After an initial equilibration time of 10 minutes, the weight of the liquid $x$ xuded from the cut end was measured at least 5 times at 1 minute intervals. Osmotic potential of the exudate was measured by a Wescor vapor pressure osmometer calibrated with $\mathrm{NaCl}$ solutions.

Each root system was washed free of soil, and the total length of fibrous roots of each plant was determined by the line-intersect method (Tennant, 1975). Water flow per root system measured in this way included a soil conductivity component and was expressed as weight of exudate per unit time and pressure (ug $\mathrm{s}^{-1} \mathrm{MPa}^{-1}$ ). Root conductivity for each rootstock was calculated by dividing the water flow by the total fibrous root length. Thus, the root conductivity was expressed in ug/s/MPa per meter of fibrous roots (ug m $\mathrm{m}^{-1} \mathrm{~s}^{-1} \mathrm{MPa}^{-1}$ ).

Prior to measuring root conductivity, the trunk circumference of each seedling was measured at a point $5 \mathrm{~cm}$ above the soil surface and 
converted to stem cross sectional area. Dry weights of leaves, stems, fibrous roots, and tap roots were determined. Shoot root ratio and specific root weight (root weight per unit length) were calculated. Leaf chloride content was measured using a Buchler-Cotlove chloridometer after extracting the leaf samples with a nitric-acetic acid solution. Measurement of leaf $\mathrm{Na}, \mathrm{Ca}, \mathrm{Mg}, \mathrm{K}, \mathrm{P}, \mathrm{Zn}, \mathrm{Mn}, \mathrm{Cu}$, and $\mathrm{Fe}$ content was performed using an inductively coupled argon plasma spectrophotometer after a wet digestion of the samples in a nitric-perchloric acid mixture.

Experiment 2: Water Relations of Sour Orange and Cleopatra Mandarin Seedlings under $\mathrm{NaCl}$ and PEG Stresses

The objective of this experiment was to study the effects of $\mathrm{NaCl}$ and PEG on the root conductivity, plant growth, stomatal conductance, and chlorophyll content of seedlings of 2 rootstocks differing in chloride accumulation characteristics, sour orange and Cleopatra mandarin (Cooper et al., 1951).

Six-month-old uniform seedlings of sour orange and Cleopatra mandarin were transplanted on November 13, 1985, into 19-cm tall black plastic pots containing $5.5 \mathrm{~L}$ of Astatula fine sand. Plants were then watered to excess every 2 to 3 days with half strength Hoagland's solution for one month before $\mathrm{NaCl}$ and PEG treatments were started. The treatments were the same as in Experiment 1. The treatments were replicated 7 times in a split plot design with 2 main plots (rootstocks) and 7 subplots (solutions). All variables measured in Experiment 1 with the exception of the chemical analysis were also measured similarly in this experiment. Seedling height from the soil surface to the terminal bud was measured every 2 weeks. Leaf conductance to water vapor was measured on abaxial leaf surfaces with a Li-cor 1600 steady state 
porometer at 2-hour intervals from 0700 to 1700 hours for 3 consecutive days.

After 5 months of $\mathrm{NaCl}$ and PEG treatments, two 1-cm diameter disks were removed from the central area of 2 mature leaves per seedling to determine leaf chlorophyll content using $\mathrm{N}, \mathrm{N}$-dimethyl formamide as a solvent (Moran and Porath, 1980; Syvertsen and Smith, 1984). Two millimeters of $\mathrm{N}, \mathrm{N}$-dimethyl formamide were placed in a small bottle and the 2 leaf disks which were removed from the same seedling were weighed and then immersed in the solvent. The bottles were firmly closed and stored in the dark in a freezer for 2 months. The bottles were then removed from the freezer and left in the dark to equilibrate to the temperature of the laboratory prior to spectrophotometer examination. One millimeter of the chlorophyll extract from each bottle was diluted with deionized water and examined by means of a scanning spectrophotometer. The optical density of the extract was measured at wavelengths of both $663 \mathrm{mu}$ and $644 \mathrm{mu}$, and chlorophyll content was calculated following the equations used by Arnon (1949). Leaf chlorophyll content was expressed as mg of leaf chlorophyll per gram fresh weight.

New shoot growth was determined by counting leaf number and measuring leaf area over a 3 -month period. The plants were harvested after 6 months of $\mathrm{NaCl}$ and PEG treatments. Total leaf area was measured by a Li-cor leaf area meter. Fresh and dry weights of leaves were determined. Specific leaf weight (SLW), expressed on a fresh and dry weight basis per unit of leaf area, was calculated. Leaf succulence was expressed as grams of water per gram of leaf dry weight. 
Experiment 3: Fibrous Root Density and Distribution of Sour Orange Seedlings under NaCl and PEG Stresses

The objective of this experiment was to determine the effect of $\mathrm{NaCl}$ and PEG on the root growth and distribution of sour orange seedlings. Five-month-old seedlings were transplanted on 0ctober 1, 1985, into root boxes filled with Astatula fine sand. The root boxes were similar to those described by Bevington and Castle $(1982,1985)$. Each container consisted of one plexiglas sheet $(6.4 \mathrm{~mm}$ thick) attached to the front of a wooden box. The plexiglas was covered with a removable metal shutter to exclude light. The internal dimensions of a root box were $87 \mathrm{~cm}$ high, $27 \mathrm{~cm}$ wide, and $5 \mathrm{~cm}$ thick. The viewing surface was $23 \mathrm{dm}^{2}$ and the volume was about $11.5 \mathrm{~L}$. Drainage was provided by 3 mesh-covered outlets in the bottom of the box. The boxes were vertically oriented. Seedlings were allowed to adjust in their containers for 2 months. During this period, they were watered every other day with half strength Hoagland's solution. Plants were then treated with 2 concentrations of $\mathrm{NaCl}$ and PEG (total osmotic potential equal to -0.12 and $-0.24 \mathrm{MPa}$ ). The experimental design was a randomized complete block with 3 replications using a single seedling per box. Treatments were as follows :

\section{Treatment}

1. NS control : Ho Hoagland's sol.

2. $\mathrm{NaCl}(0.12): 1.1 \mathrm{~g} \mathrm{NaCl} / \mathrm{L}$ th Hoagl. sol. 1700

3. PEG (0.12) : $60 \mathrm{~g} \mathrm{PEG/L} \mathrm{t/2} \mathrm{Hoagl.} \mathrm{sol}$

4. $\mathrm{NaCl}(0.24): 2.8 \mathrm{~g} \mathrm{NaCl} / \mathrm{L}$ th Hoagl. sol. 3300

5. PEG $(0.24): 110 \mathrm{~g}$ PEG/L $1 / 2$ Hoagl. sol.

$\frac{\mathrm{TDS}}{\left(\mathrm{mg} \mathrm{L^{-1 }}\right)} \frac{\mathrm{OP}}{(\mathrm{MPa})} \frac{\mathrm{EC}}{\left(\mathrm{dS} \mathrm{m}^{-1}\right)} \frac{\mathrm{NaCl}}{(\mathrm{mmol})}$

$550-0.05$

1.1

$-0.12$

3.3 19

$450-0.12$

0.9

$-0.24$

5.9 48

$390 \quad-0.24$

0.8 0 
Root growth was recorded at 2 -week intervals by using colored pencils to trace the root system onto transparent acetate sheets. Plant height was measured at 2-week intervals. Stomatal conductance was measured about every 2 weeks and for 2 consecutive days at 2-hour intervals from 0700 to 1700. After 6 months of $\mathrm{NaCl}$ and PEG treatments, the plants were taken from their boxes by removing the plexiglas wall and inserting a needle board to hold the root system in place. Leaves, stems, and roots were separated and roots were divided in place into 3 equal compartments (top, middle, and bottom). Shoot and root dry weight, shoot root ratio, leaf number, plant height, root length, specific root weight, and stomatal conductance were determined as described in Experiment 2.

Experiment 4: Response of Split-Root Sour 0range Seedlings to Salinity The objective of this experiment was to determine and quantify the growth and water relations of sour orange seedlings when only a portion of the root system was exposed to $\mathrm{NaCl}$ or PEG. A split-root system was initiated using the technique of Koch and Johnson (1984). The tap root of each seedling at the 3-leaf stage was cut to a $1 \mathrm{~cm}$ length and all other roots were removed. The remaining portion of the tap root was dipped into a $50 \%$ ethanol solution containing 5 grams of IBA (indolebutyric acid) per liter. Seedlings were then placed in PROMIX BX, watered daily and fertilized weekly for 2 months. Seedlings which had 2 uniform adventitious root systems were selected and transplanted when 5 months old into $2.2 \mathrm{~L}$ square plastic containers stapled together along one side (Fig. 3). These seedlings were left to adjust in their double pots for 1 month before $\mathrm{NaCl}$ and PEG treatments were imposed. The treatments were replicated 4 times in a randomized complete block design and are shown below: 


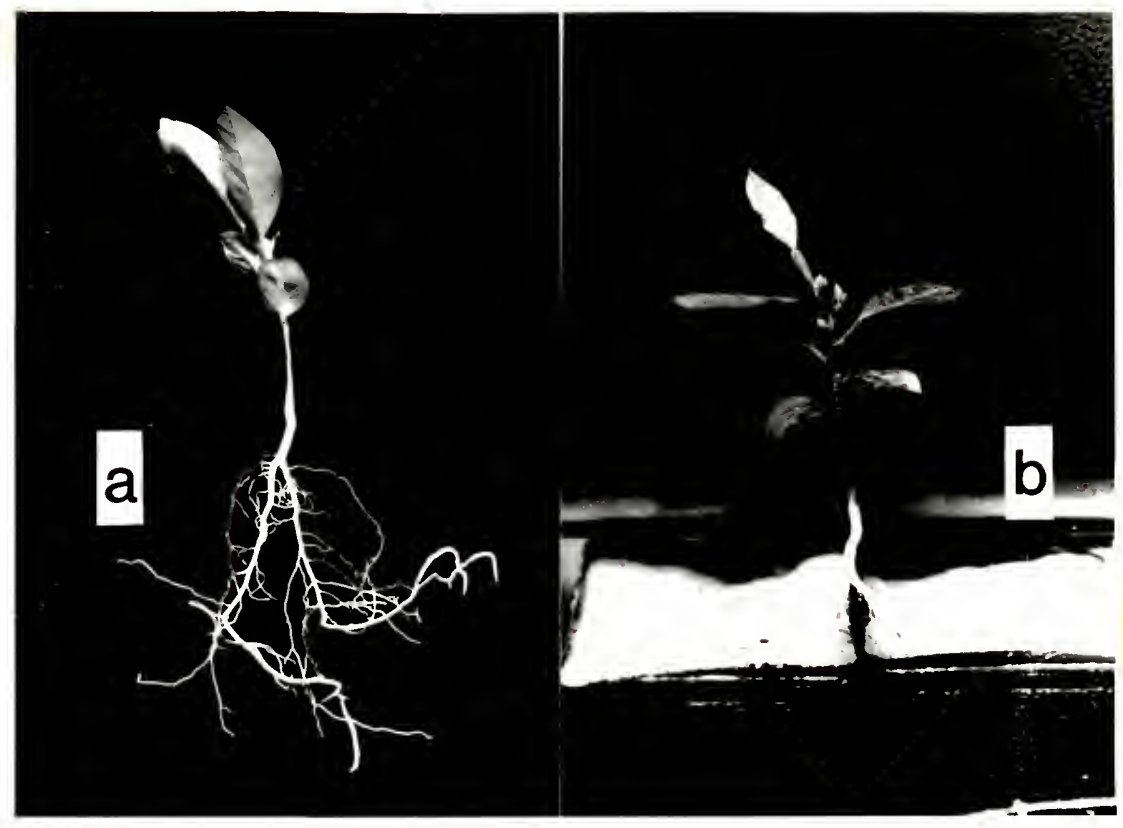

Fig. 3. Sour orange seedlings with a split-root system. a. Root development after 2 months.

b. Container system used to grow split-root seedlings. 
Treatment

1. NS/NS (no salt)

2. $\mathrm{NS} / \mathrm{NaCl}(0.10)$

3. $\mathrm{NaCl}(0.10) / \mathrm{NaCl}(0.10)$

4. NS/NaCl $(0.20)$

5. $\mathrm{NaCl}(0.20) / \mathrm{NaCl}(0.20)$

6. NS/NaCl $(0.35)$

7. $\mathrm{NaCl}(0.35) / \mathrm{NaCl}(0.35)$

8. NS/PEG (0.20)

9. PEG $(0.20) /$ PEG $(0.20)$

$$
\frac{\mathrm{TDS}}{\left(\mathrm{mg} \mathrm{L}^{-1}\right)}
$$$$
550 / 550
$$$$
550 / 1600
$$$$
1600 / 1600
$$$$
550 / 3000
$$$$
3000 / 3000
$$$$
550 / 4900
$$$$
4900 / 4900
$$$$
550 / 400
$$$$
400 / 400
$$

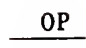

(MPa)

$-0.05 /-0.05$

$-0.05 /-0.10$

$-0.10 /-0.10$

$-0.05 /-0.20$

$-0.20 /-0.20$

$-0.05 /-0.35$

$-0.35 /-0.35$

$-0.05 /-0.20$

$-0.20 /-0.20$
$\mathrm{EC}$

$\left(\mathrm{dS} \mathrm{m}^{-1}\right.$ )

$1.1 / 1.1$

$1.1 / 3.1$

$3.1 / 3.1$

$1.1 / 5.4$

$5.4 / 5.4$

$1.1 / 8.8$

$8.8 / 8.8$

$1.1 / 0.7$

$0.7 / 0.7$

Water relations variables were monitored on 4 successive days during the fourth month of salt treatment. Leaf water potential was measured at sunrise and at midday on fully expanded leaves using a pressure chamber. Leaves were then removed from the chamber, wrapped in double plastic bags and rapidly frozen at $-20^{\circ} \mathrm{C}$. Leaves were subsequently thawed after 48 hours and their osmotic potential was determined with a vapor pressure osmometer. Turgor potential was obtained by subtracting the osmotic potential value from the water potential value. Morning and midday stomatal conductance and leaf transpiration rates were measured with a steady state porometer. For anatomical study, 2 mature leaves per plant from NS/NS and $\mathrm{NaCl}(0.35) / \mathrm{NaCl}(0.35)$ treatments were selected from about half-way between the first leaf and the shoot apex. Two small rectangles were cut at mid-lamina of each leaf, frozen immediately, and cut by a Cryostat minot rotary microtome in sections 10 microns thick. Sections were then thawed in a phosphate buffer saline solution. Twenty randomly selected leaf cross sections per treatment were fixed for a light microscopy study. 
After 4 months of $\mathrm{NaCl}$ and PEG treatment, the plants were harvested, and shoot and root dry weights were determined.

Experiment 5: Effects of Calcium on Sour Orange Seedlings Grown under Saline Conditions

The objective of this experiment was to determine if the addition of calcium to saline irrigation water would reduce salt damage.

Three-month-old sour orange seedlings were transplanted on August 10 , 1986, into the same pots used in Experiment 2. Salt treatments (Table 1 ) were started after 1 month of adjustment, and seedlings were irrigated every 2 to 3 days for 4 months. The treatments were replicated 8 times in a randomized complete block design. The plants were watered the night before harvest and leaves were removed the following morning. Fresh and dry weights of leaves, stems, and roots were recorded. The succulence of new and old leaves was computed. The dried, mature, fully expanded leaves were ground and their mineral content was determined as in Experiment 1. 


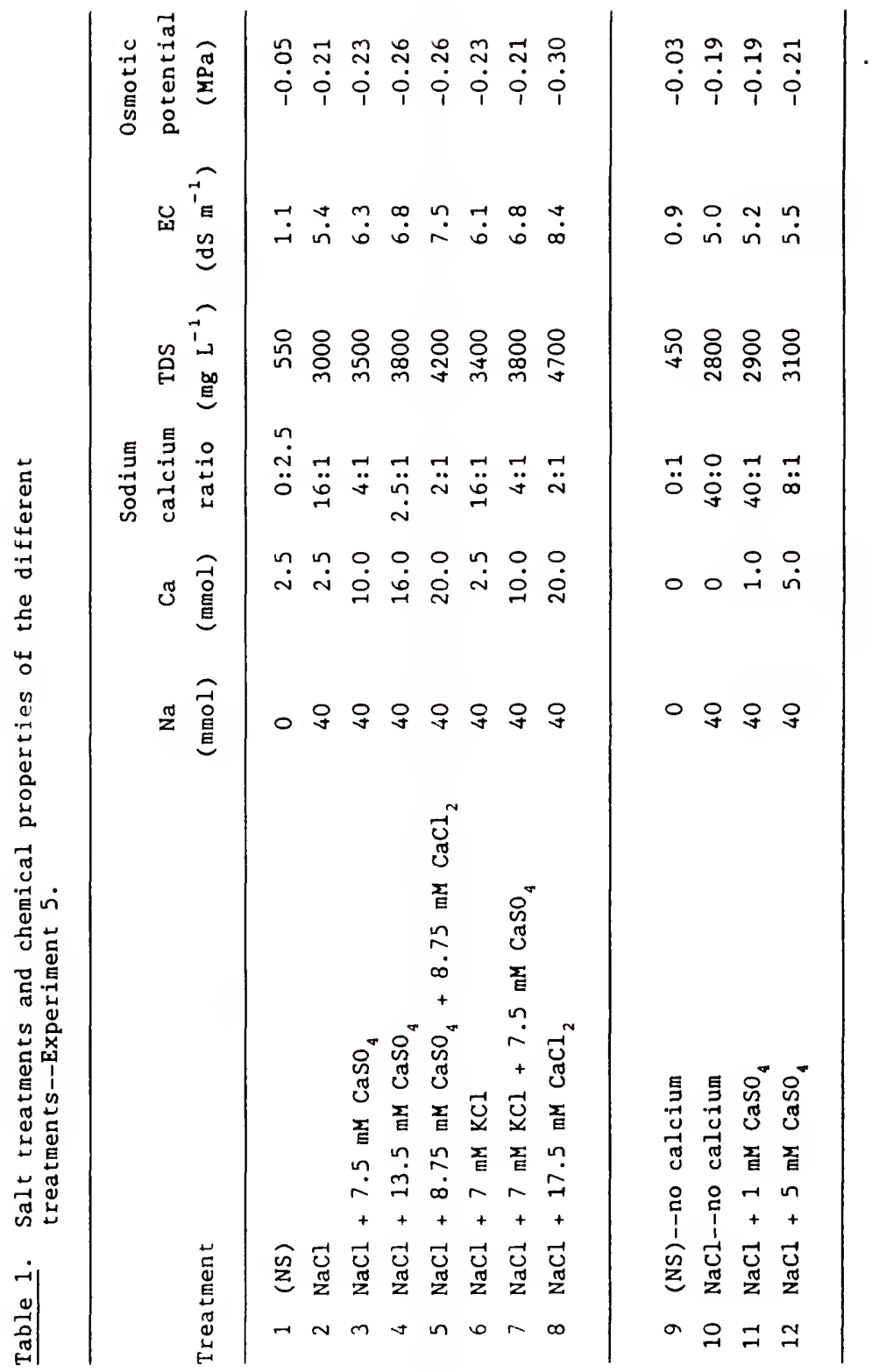


RESULTS

Experiment 1: Effects of NaCl and PEG on the Root Conductivity and Leaf Ion Content of Seedlings of 7 Citrus Rootstocks

The results of the analysis of variance showed that salt treatments and rootstocks were significant and independent factors; i.e., the interaction of these 2 factors was not significant.

Significant differences in growth due to NaCl and PEG treatments were found among rootstocks. Shoot dry weight generally decreased as $\mathrm{NaCl}$ and PEG concentration increased in the nutrient solution (Table 2). Shoot dry weight at the low, medium, and high $\mathrm{NaCl}$ concentrations was 18 to $36 \%, 30$ to $55 \%$, and 58 to $82 \%$ lower, respectively, than the control plants. Shoot dry weight of sour orange (SO) and Cleopatra mandarin (CM) seedlings was the least affected while Milam (ML) and Poncirus trifoliata (PT) seedlings showed the greatest response. Sodium chloride and PEG effects on root dry weight were similar to those on shoot dry weight (Table 3). However, roots were less affected than shoots so that the shoot-root ratio decreased with increasing $\mathrm{NaCl}$ and PEG concentration (Table 23, Apendix). Total plant dry weight (Table 24, Appendix) and stem cross sectional area (Table 25, Appendix) were proportionally reduced by $\mathrm{NaCl}$ and $\mathrm{PEG}$ concentrations and reductions were usually greater with PEG than with NaCl. Fibrous root length was also reduced by $\mathrm{NaCl}$ (Fig. 4) but specific root weight (SRW, dry weight per unit length) increased with increasing $\mathrm{NaCl}$ concentration (Table 4). 


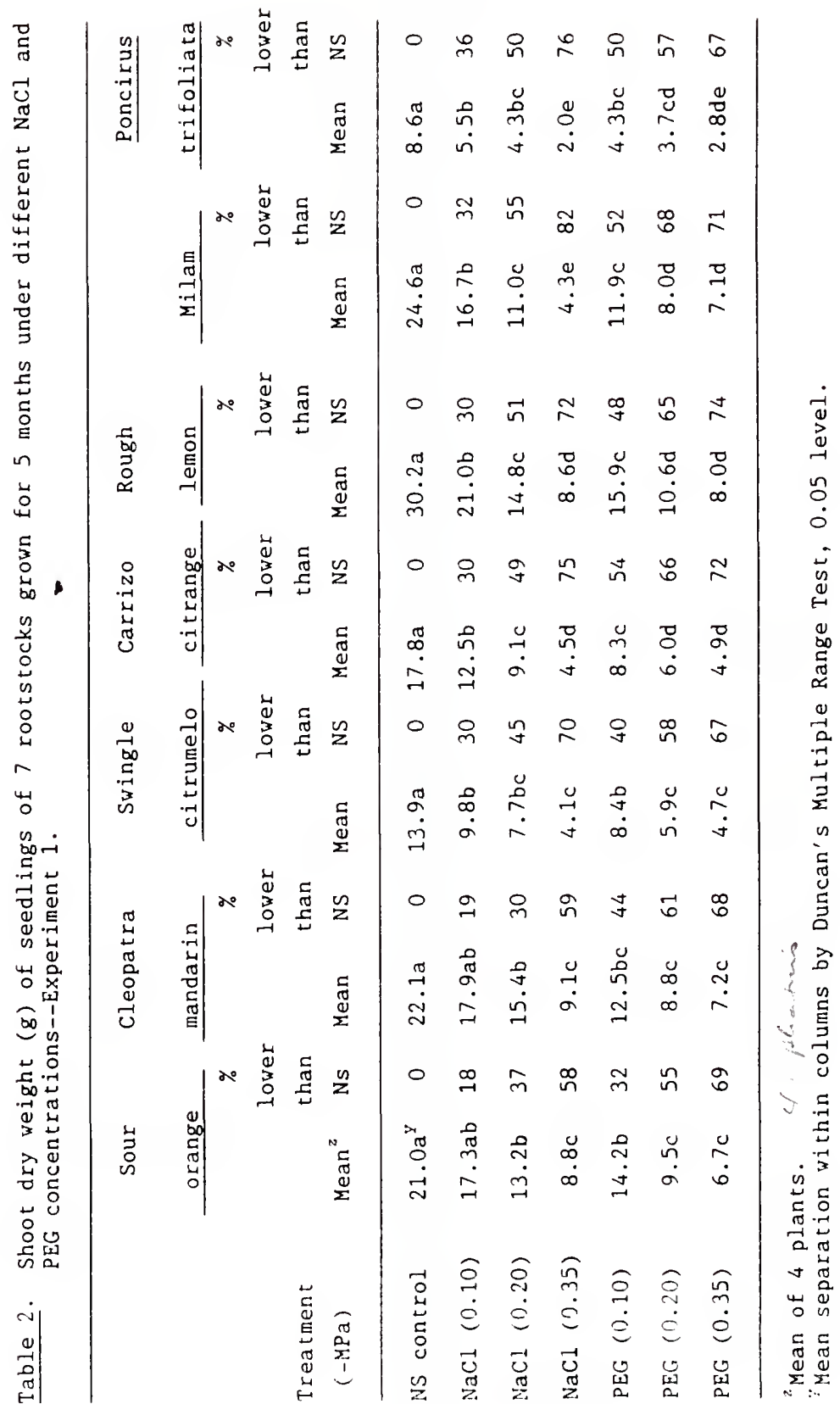




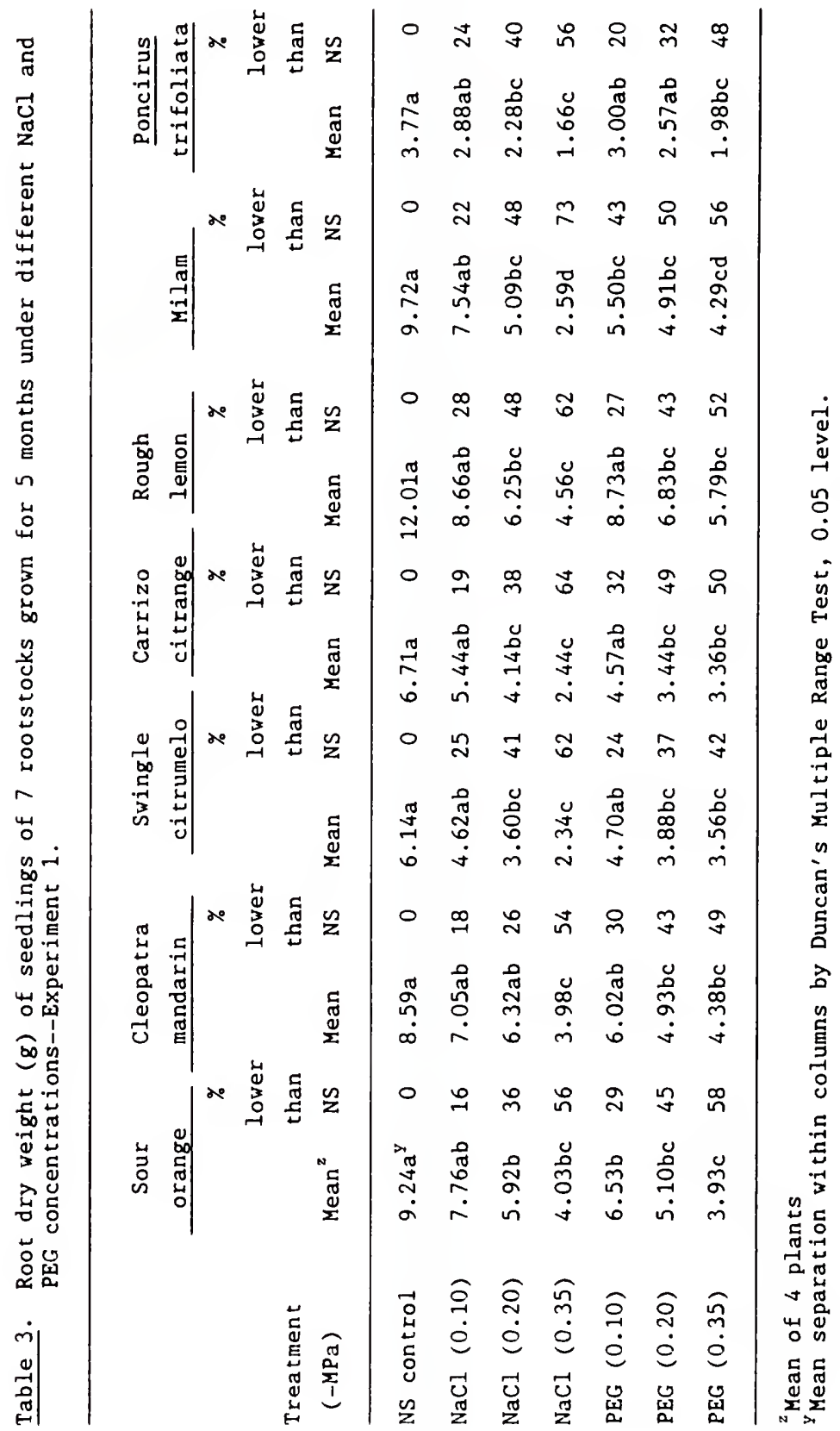




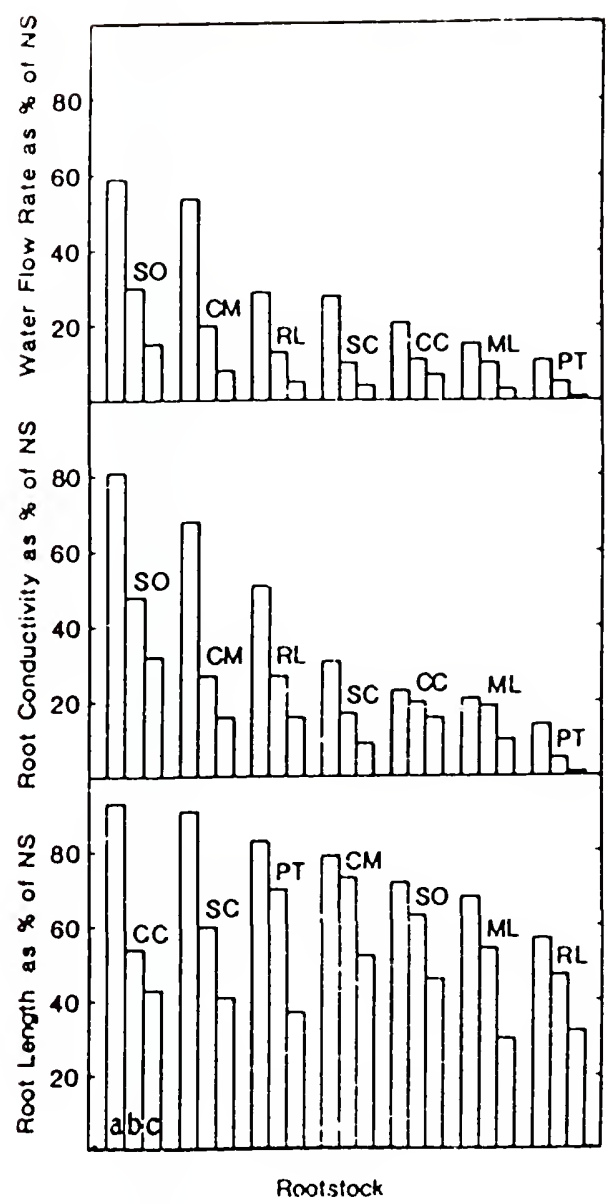

Fig. 4. Effect of $3 \mathrm{NaCl}$ concentrations $(a=-0.10 \mathrm{MPa}$, $b=-0.20 \mathrm{MPa}, c=-0.35 \mathrm{MPa}$ ) on the total fibrous root length, root hydraulic conductivity, and water flow rate for seedlings of 7 citrus roots tocks. 


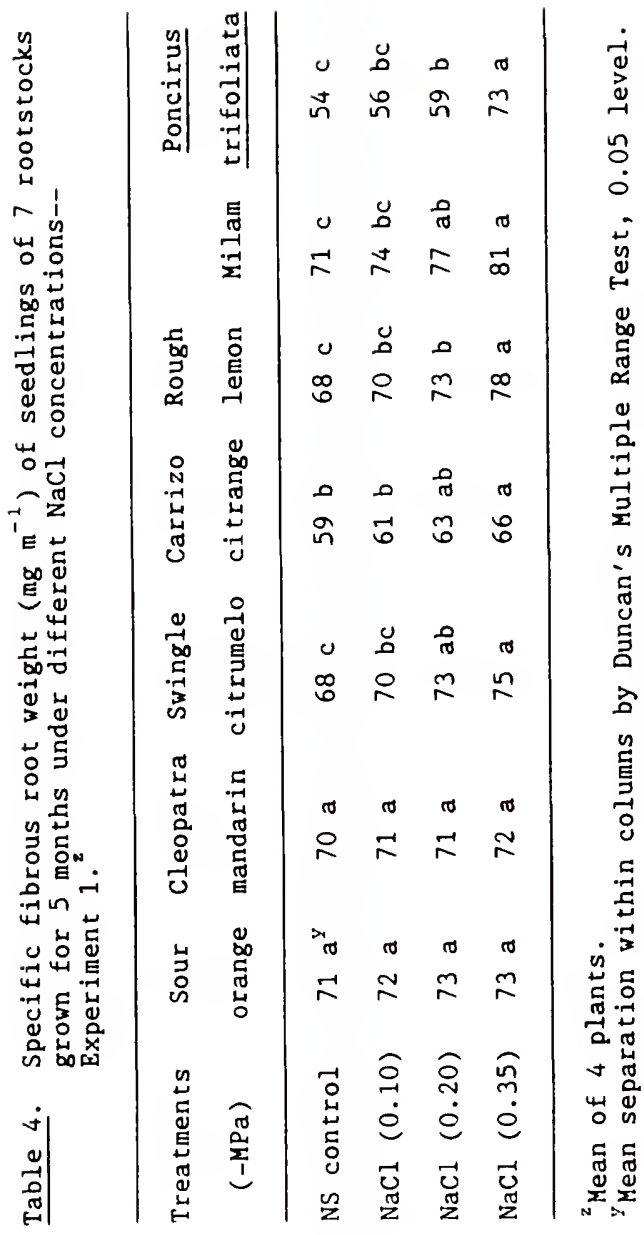


The increase in SRW of rough lemon (RL), ML, and PT was greater than that of the other rootstocks.

Root hydraulic variables were affected by rootstock and NaCl. Significant differences in root conductivity among rootstocks were found under non-stresed conditions (Table 5) as well as under NaCl stress conditions (Fig. 4). Sour orange and $\mathrm{CM}$ had the smallest reduction in hydraulic conductivity and ML and PT had the greatest. There was a significant negative relationship between root hydraulic conductivity and SRW of the 7 rootstocks studied (Fig. 5). As root weight per unit length increased, conductivity decreased.

Water flow through the root system decreased as much as 41 to $89 \%$ at the first $\mathrm{NaCl}$ level (Fig. 4). Osmotic potential of root exudate due to $\mathrm{NaCl}$ stress followed the same trend as root hydraulic conductivity (Fig. 20, Appendix). Water flow and osmotic potential of root exudate were reduced the least in SO and CM and the most in ML and PT. However, when $\mathrm{NaCl}$ was not added to the irrigation water, PT and Swingle citrumelo (SC) had the highest osmotic potential of root exudate, and so and $C M$ had the lowest potentials (Table 5).

Leaf burn symptoms appeared in the $\mathrm{NaCl}(0.35)$ treatment in PT and ML after 5 weeks. In RL, SC, Carrizo citrange (CC), and So, leaf burn symptoms occurred after 6 weeks at the highest $\mathrm{NaCl}$ concentration $(-0.35$ MPa). Just before harvest, final evaluation of the different rootstocks based on tree appearance and performance was made (Table 6, Fig. 6).

Leaf ion content of the seedlings of the 7 rootstocks was affected by the NaCl and PEG concentrations. Sodium (Table 7) and chloride (Table 8 ) contents in the leaves of all rootstocks increased with increasing $\mathrm{NaCl}$ in the nutrient solution. Cleopatra mandarin accumulated the least chloride while PT, SC, and CC accumulated the 


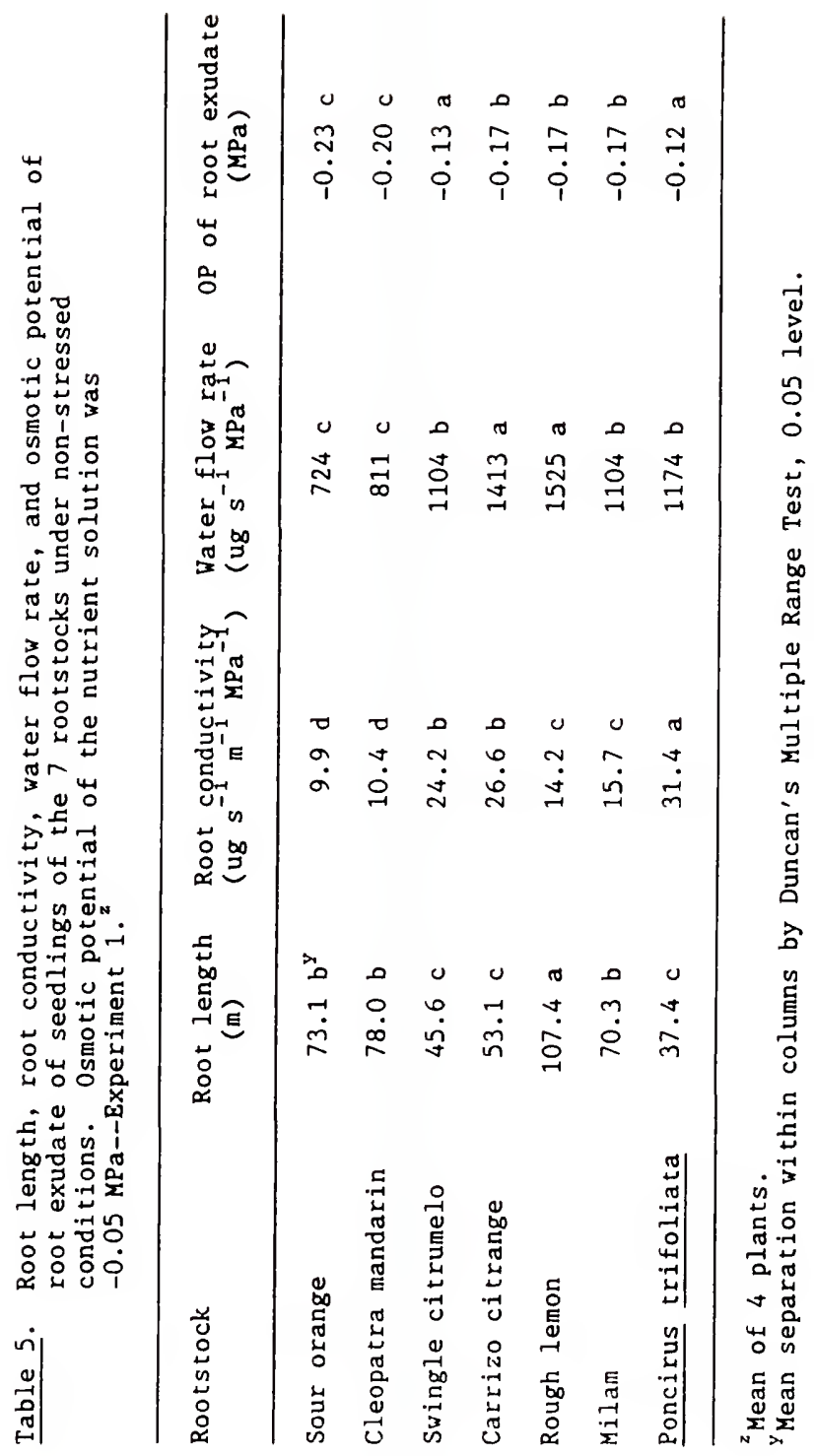




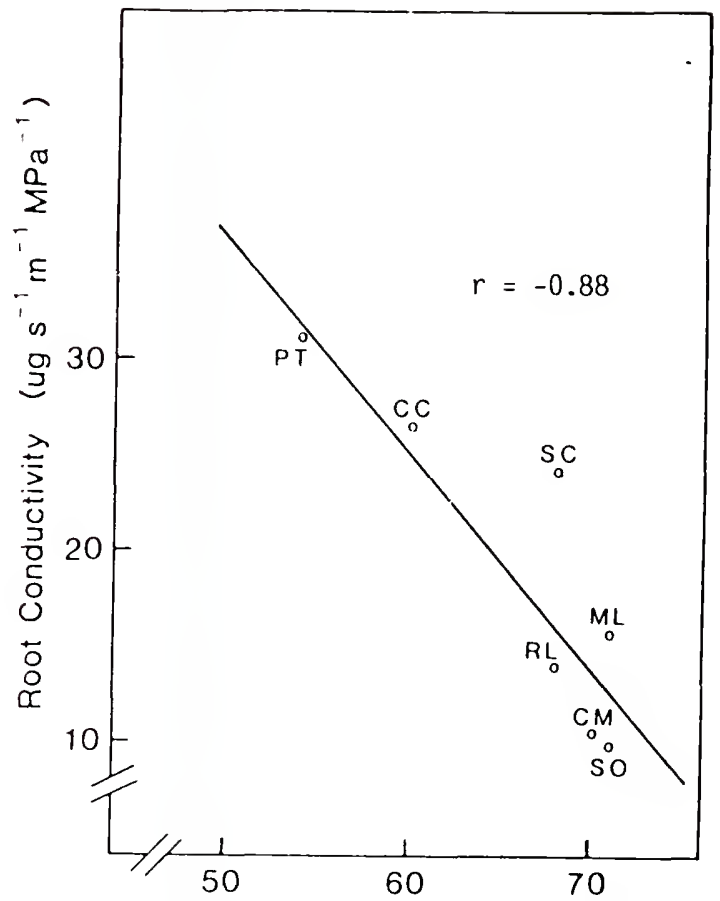

Specific Root Wt $\left(\mathrm{mg} \mathrm{m}^{-1}\right)$

Fig. 5. Relationship between root hydraulic conductivity and specific root weight of seedlings of 7 citrus rootstocks under non-stressed conditions. 


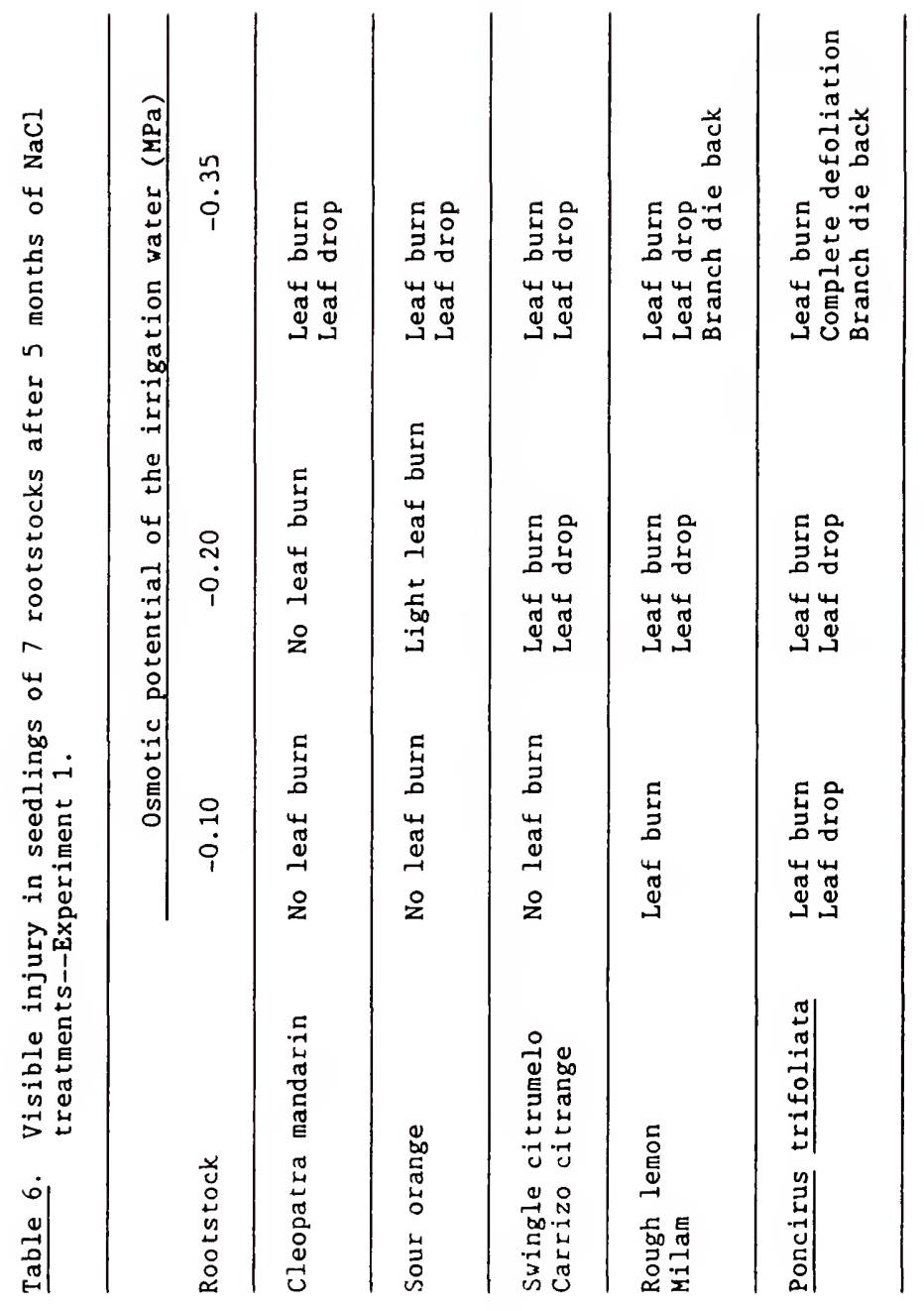




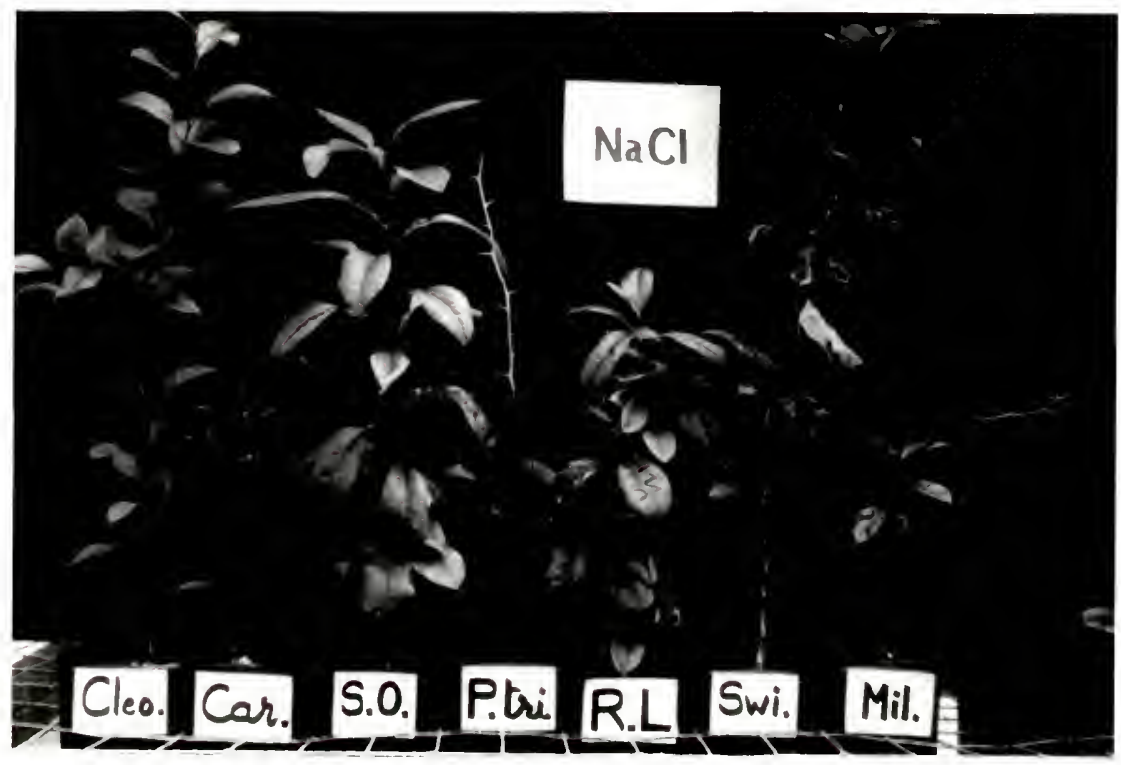

Fig. 6. Effect of $\mathrm{NaCl}$ at an osmotic potential of $-0.35 \mathrm{MPa}$ on the 7 rootstocks after 5 months of salinity treatments. 


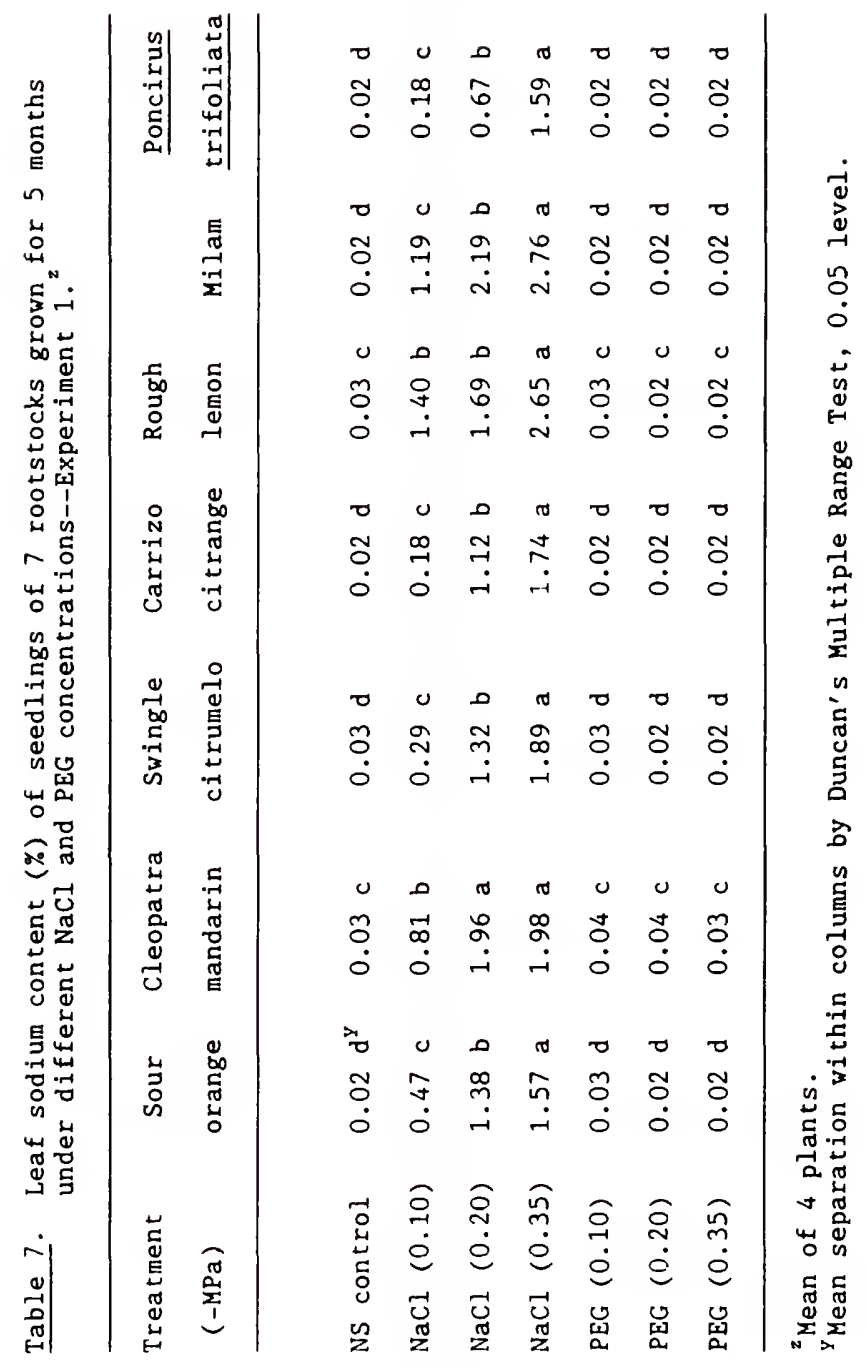




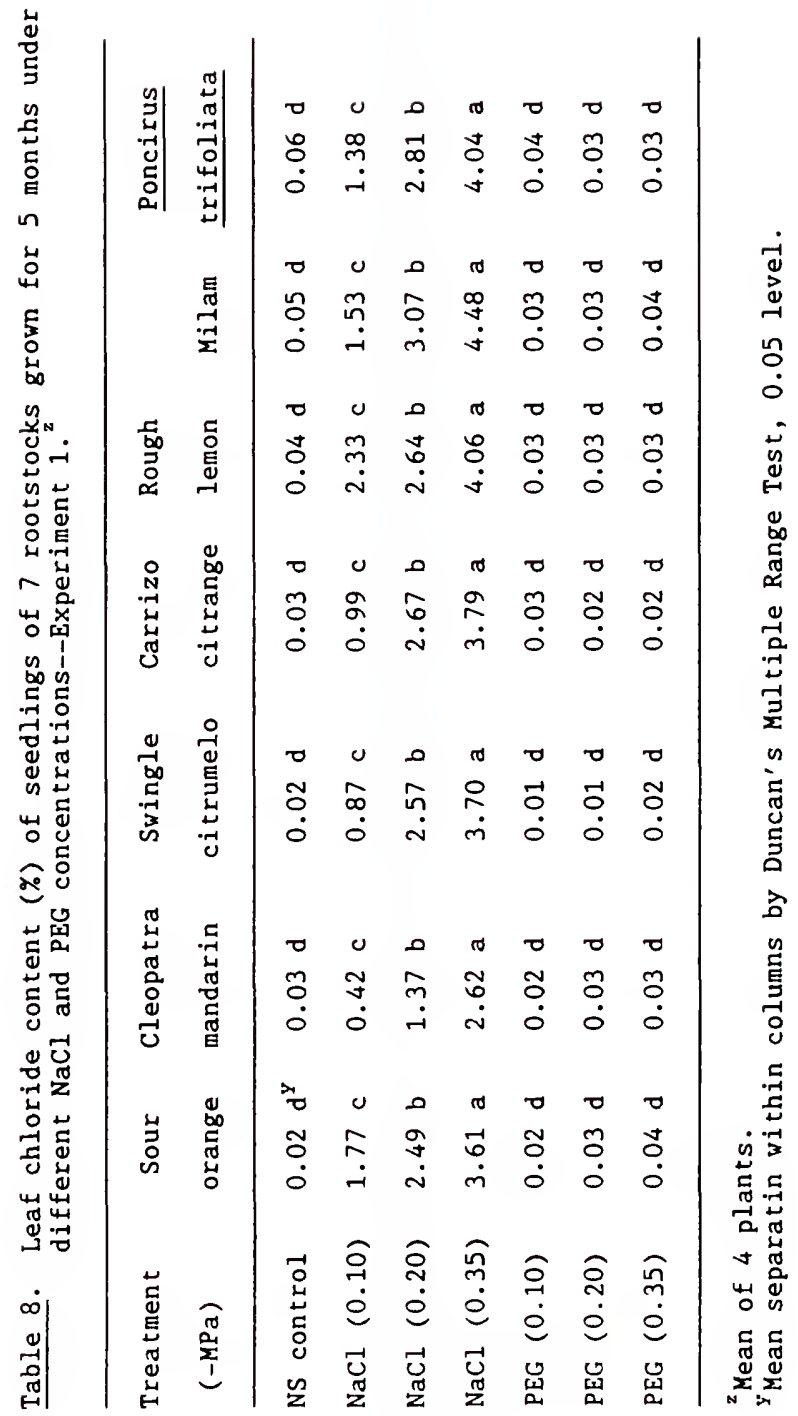


least sodium. Even at a relatively low NaCl concentration (-0.10 MPa), large amounts of chloride were accumulated in SO, RL, ML, and PT leaves. Large amounts of sodium were also accumulated in RL and ML leaves. The accumulation or exclusion characteristics of sodium and chloride for each rootstock are summarized in Table 9.

Sodium chloride at $-0.35 \mathrm{MPa}$ reduced leaf calcium of all rootstocks 10 to $40 \%$ with the exception of PT while PEG generally increased calcium content (Table 10). Both $\mathrm{NaCl}$ and PEG reduced magnesium (Table 26, Appendix). Magnesium reduction varied among rootstocks and ranged from 28 to $50 \%$ and from 22 to $41 \%$ under $\mathrm{NaCl}$ and PEG, respectively.

Potassium decreased significantly in SO, CM, RL, and $\mathrm{ML}$ but did not in SC, CC, and PT with NaCl treatments (Table 27, Appendix). Potassium seemed to be more strongly reduced in PEG treatments than in $\mathrm{NaCl}$ treatments.

Both NaCl and PEG had similar effects on leaf phosphorus content but the effect was more pronounced with PEG (Table 28, Appendix). Sodium chloride and PEG significantly increased phosphorus in CM, SC, CC, RL, and ML, reduced phosphorus in PT, and did not affect phosphorus in So.

Both zinc and manganese were significantly increased under PEG stress. In some rootstocks, PEG more than doubled the zinc and manganese levels. Zinc was reduced in SC, CC, RL, ML, and PT but was not in SO and $\mathrm{CM}$ under $\mathrm{NaCl}$ stress (Table 29, Appendix). Manganese tended to increase in the leaves of $\mathrm{NaCl}$-treated plants except for $\mathrm{RL}$ (Table 30, Appendix). 


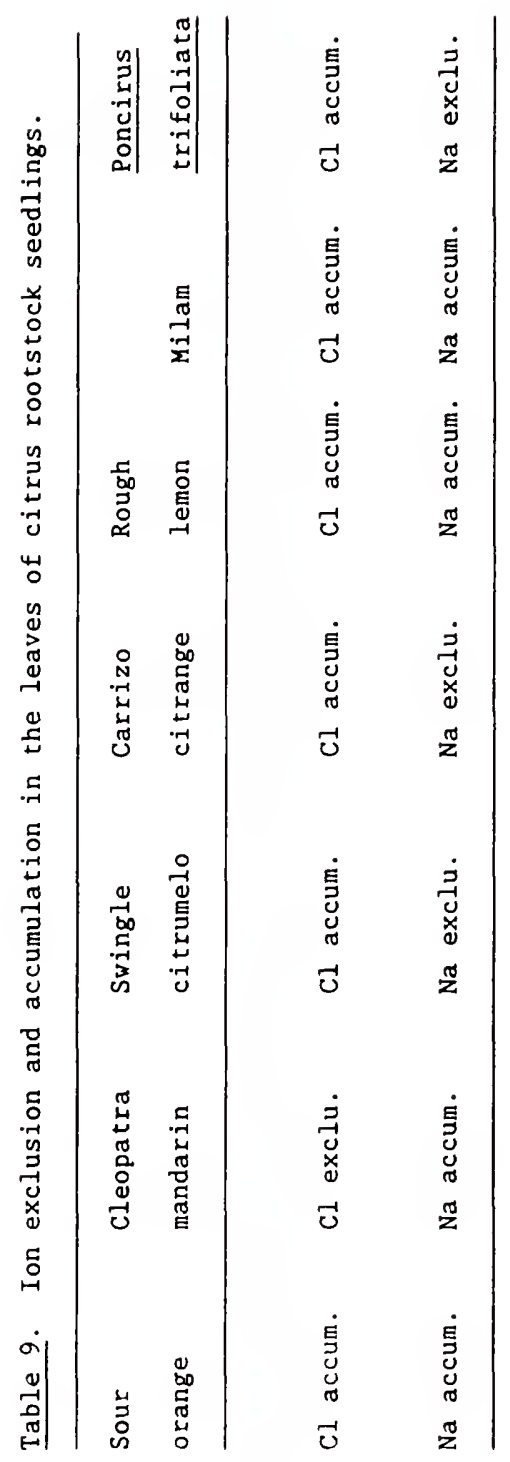




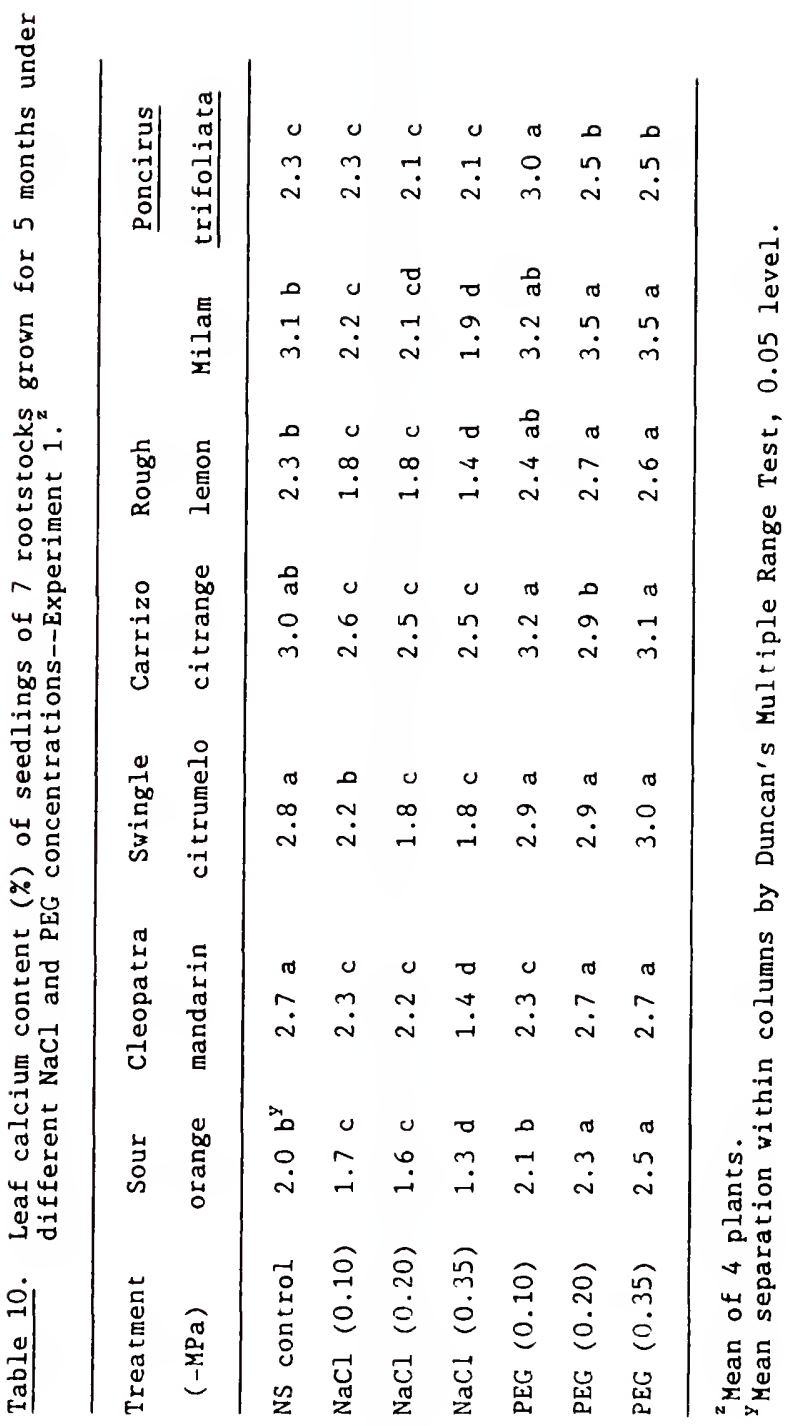


Experiment 2: Water Relations of Sour Orange and Cleopatra Mandarin Seedlings under $\mathrm{NaCl}$ and PEG Stresses

As in Experiment 1, the results of the analysis of variance showed significant differences among salt treatments and between rootstocks but there were no significant interactions between these 2 factors.

The growth rate of SO and CM seedlings was significantly reduced with increasing $\mathrm{NaCl}$ and PEG concentrations in the nutrient solution. A $\mathrm{NaCl}$ concentration as low as $-0.10 \mathrm{MPa}\left(1600 \mathrm{mg} \mathrm{L}^{-1}\right)$ reduced shoot and root dry weight, root length, and stem cross sectional area by 508 after 6 months of treatment (data not presented). For both rootstocks, seedling height was 26 to 398 and 33 to 508 lower, respectively, at the first $2 \mathrm{NaCl}$ concentrations (Table 31, Appendix). Total leaf area was reduced by more than $40 \%$ at the $-0.10 \mathrm{MPa}$ NaCl level (Table 32, Appendix). All these growth variables were more severely reduced under PEG than under NaCl stress.

No significant difference in growth reduction was found between so and CM. Similar to Experiment 1, shoot root ratio decreased and SRW increased with increasing $\mathrm{NaCl}$ and particularly PEG in the nutrient solution (data not shown).

Sodium chloride reduced new shoot growth of So (Tables 11, 12). Leaf size of new shoots was smaller for salt-treated plants than for control plants (Table 11). Sodium chloride-treated plants had 59 to $86 \%$ fewer leaves than those grown without salt (Table 12).

Root hydraulic conductivity and water flow of the 2 rootstocks were reduced at the first salinity level by about $50 \%$ and more than $70 \%$, respectively. Water flow through the root system to the shoot in the PEG treatment was reduced by more than 958 (data not shown). Similar to Experiment 1, no significant differences in root conductivity, water 


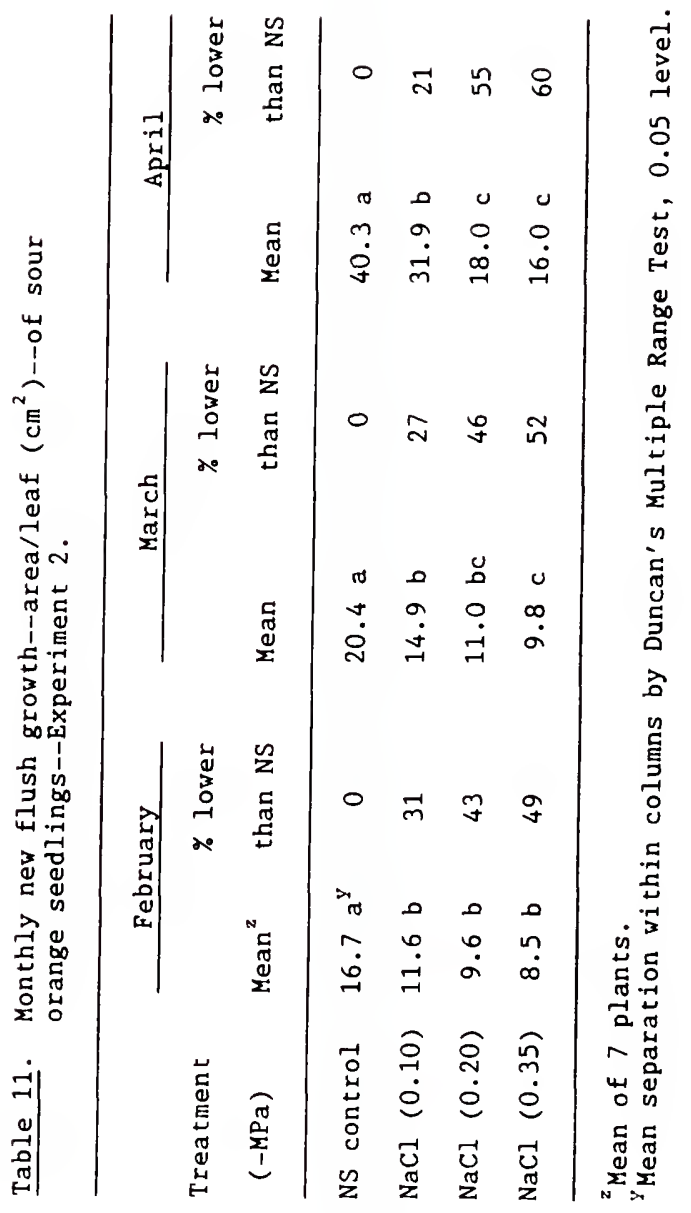




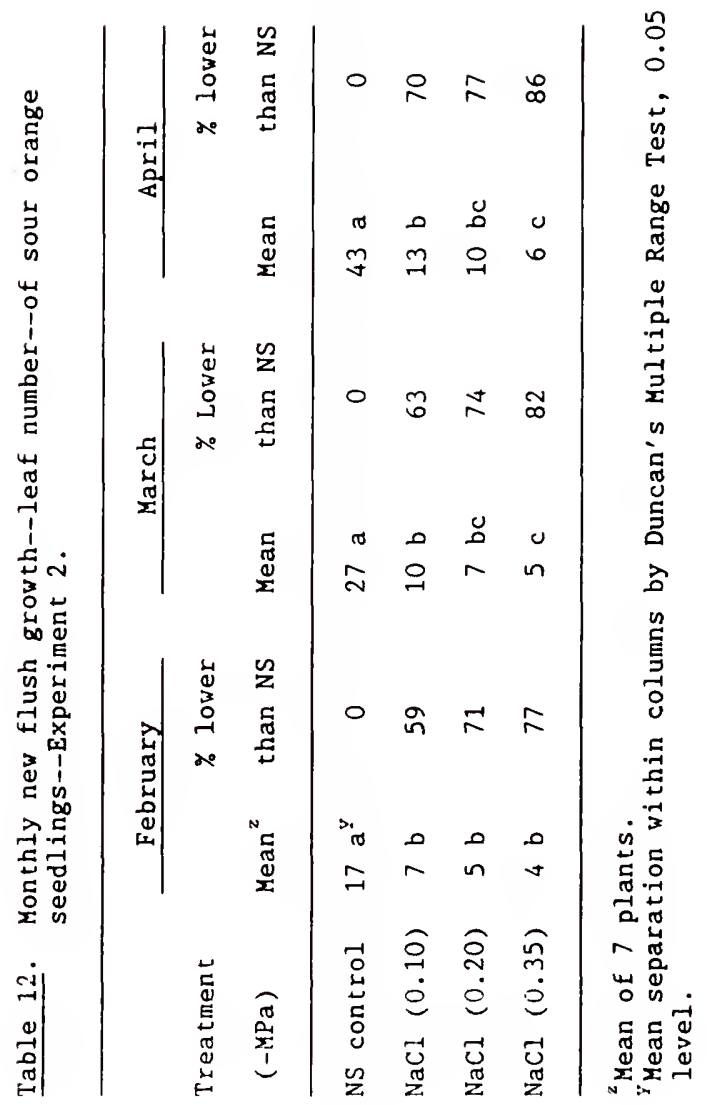


flow and osmotic potential of root exudate were found between so and CM. There was a positive correlation between water flow through the root system and osmotic potential of root exudate (Fig. 7). With NaCr, less water flow corresponded to higher ion concentrations in the root exudate and consequently to a lower osmotic potential of the root exudate. Both $\mathrm{NaCl}$ and PEG increased SLW when expressed on a dry weight basis (Table 33, Appendix). However, unlike NaCl, PEG decreased SLW when expressed on a fresh weight basis. Consequently, leaf succulence was decreased by PEG and increased by NaCl (Table 13). Among PEG treatments, succulence was more reduced in SO than in CM seedlings.

Leaf chlorophyll content was reduced by $\mathrm{NaCl}$ and PEG treatments. A significant difference in chlorophyll content due to $\mathrm{NaCl}$ was found between SO and CM with a greater reduction occurring in SO (Table 14). Polyethylene glycol generally reduced chlorophyll level in cM more than did $\mathrm{NaCl}$.

Stomatal conductance was also affected by NaCl (Figs. 21, 22, Appendix) and PEG (Figs. 23, 24, Appendix). No significant difference in stomatal conductance was found between SO and $\mathrm{CM}$ under $\mathrm{NaCl}$ and PEG stresses. Again, the effect of PEG was more pronounced on this variable than that of $\mathrm{NaCl}$. There was a significant positive linear correlation between root hydraulic conductivity and midday stomatal conductance (Fig. 8).

Addition of $\mathrm{NaCl}$ and PEG to the nutrient solution reduced seedling water use or evapotranspiration. Water use could be approximated because the amount of water added each time was based on bringing the soil to slightly more than field capacity. Estimated water use for $\mathrm{NaCl}$ $(0.10), \mathrm{NaCl}(0.20), \mathrm{NaCl}(0.35), \operatorname{PEG}(0.10), \operatorname{PEG}(0.20)$, and PEG $(0.35)$ 


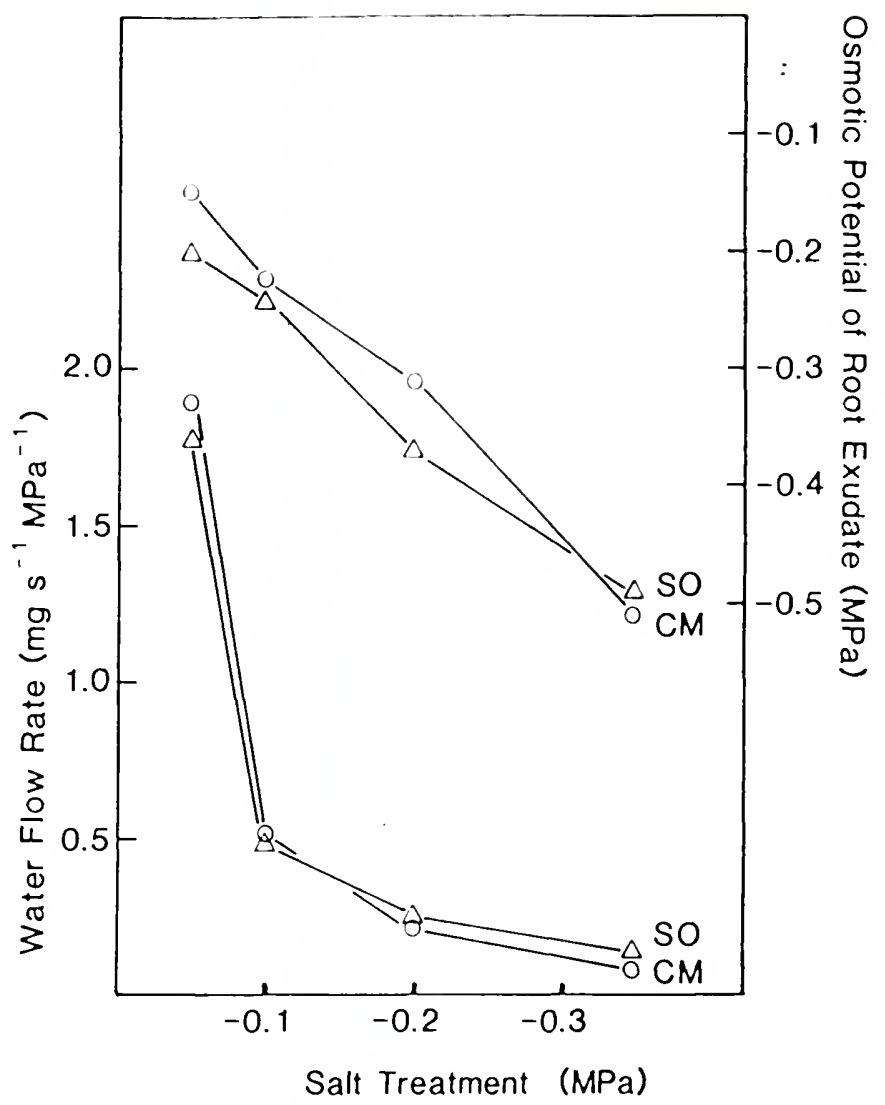

Fig. 7. Relationship between water flow rate and osmotic potential of root exudate of sour orange and Cleopatra mandarin seedlings. 
Table 13. Leaf succulence [ ( $g$ water/g dry wt) $x$ 100] of seedlings of 2 rootstocks grown for 6 months under different $\mathrm{NaCl}$ and PEG concentrations--Experiment 2.

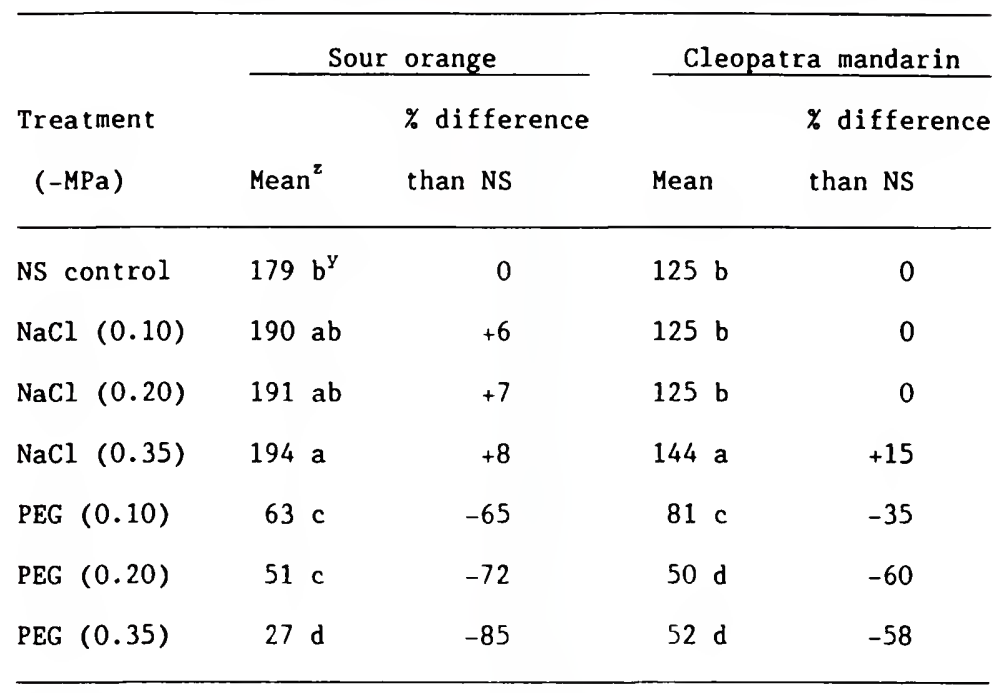

zMean of 7 plants.

'Mean separation within columns by Duncan's Multiple Range Test, 0.05 level. 
Table 14. Total chlorophyll ( $\mathrm{mg} \mathrm{g}^{-1}$ fresh wt) of seedlings of 2 rootstocks grown for 6 months under different $\mathrm{NaCl}$ and PEG concentrations--Experiment 2 .

\begin{tabular}{|c|c|c|c|c|}
\hline \multirow[b]{2}{*}{$\begin{array}{l}\text { Trea tment } \\
(-\mathrm{MPa})\end{array}$} & \multicolumn{2}{|c|}{ Sour orange } & Cleopatra & \multirow{2}{*}{$\begin{array}{l}\text { mandarin } \\
\text { \% lower } \\
\text { than NS }\end{array}$} \\
\hline & $\operatorname{Mean}^{2}$ & $\begin{array}{l}\% \text { lower } \\
\text { than NS }\end{array}$ & Mean & \\
\hline NS control & $1.99 \mathrm{a}^{\mathrm{Y}}$ & 0 & $2.42 \mathrm{a}$ & 0 \\
\hline $\mathrm{NaCl}(0.10)$ & $0.88 \mathrm{~b}$ & 56 & $2.15 \mathrm{a}$ & 11 \\
\hline $\mathrm{NaCl}(0.20)$ & $0.61 \mathrm{c}$ & 69 & $1.64 \mathrm{~b}$ & 32 \\
\hline $\mathrm{NaCl}(0.35)$ & $0.59 \mathrm{c}$ & 70 & $1.12 \mathrm{c}$ & 54 \\
\hline PEG $(0.10)$ & $0.88 \mathrm{~b}$ & 56 & $1.20 \mathrm{c}$ & 50 \\
\hline PEG $(0.20)$ & $0.58 \mathrm{c}$ & 71 & $0.95 \mathrm{c}$ & 61 \\
\hline PEG $(0.35)$ & $0.56 \mathrm{c}$ & 72 & $0.83 \mathrm{c}$ & 66 \\
\hline
\end{tabular}

${ }^{z}$ Mean of 7 plants.

'Mean separation within columns by Duncan's Multiple Range Test, 0.05 level. 


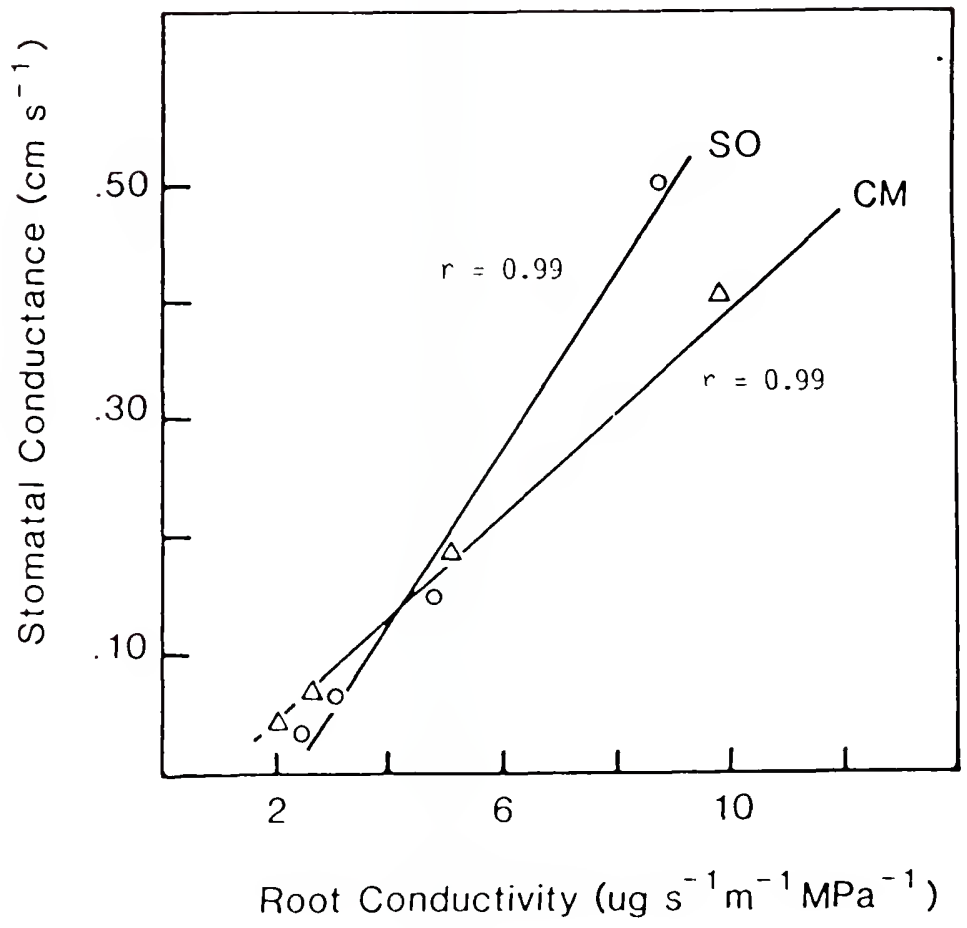

Fig. 8. Relationship between midday stomatal conductance and root conductivity of sour orange and Cleopatra mandarin seedlings. 
treatments were, respectively, 50, 25, 17, 25, 12, and 128 of that for the control (NS) treatment.

Experiment 3: Fibrous Root Density and Distribution of Sour Orange Seedlings under NaCl and PEG Stresses

Plant responses in this experiment to $\mathrm{NaCl}$ and PEG treatments were similar to those obtained in Experiment 2. Shoot and root dry weight, shoot root ratio, and leaf number generally decreased with increasing $\mathrm{NaCl}$ and PEG concentrations in the nutrient solution (data not shown). Significant differences among treatments were found in stomatal conductance during different months (Fig. 9) as well as in daily stomatal conductance (Fig. 10). Stomatal conductance also decreased as leaf age increased (Fig. 9). Throughout the growing period, shoot and root growth rate increased with time, but the growth rate of stressed seedlings was less than that of non-stressed seedlings. After 4 weeks, measurements of seedling height (Fig. 11) and root length (Fig. 12) showed a significant reduction in plant growth due to $\mathrm{NaCl}$ and PEG treatments. Cycling between shoot and root growth was noticed under stressed and non-stressed conditions (Fig. 13).

When the portion of the root system in each compartment (top, middle, and bottom) of the root box was compared, root density decreased with depth and was significantly higher in the top compartment than in either of the lower 2 sections (Table 15, Fig. 14). Seedlings receiving $\mathrm{NaCl}$ or PEG treatments developed a shallow root system as compared to the control (Fig. 14). Stressed seedlings had a higher percentage of the total root system in the top of the root boxes. About $65 \%$ of the roots of the PEG-stressed seedlings, but less than $50 \%$ of the roots of control seedlings, were located in the upper section (Table 15). In the 


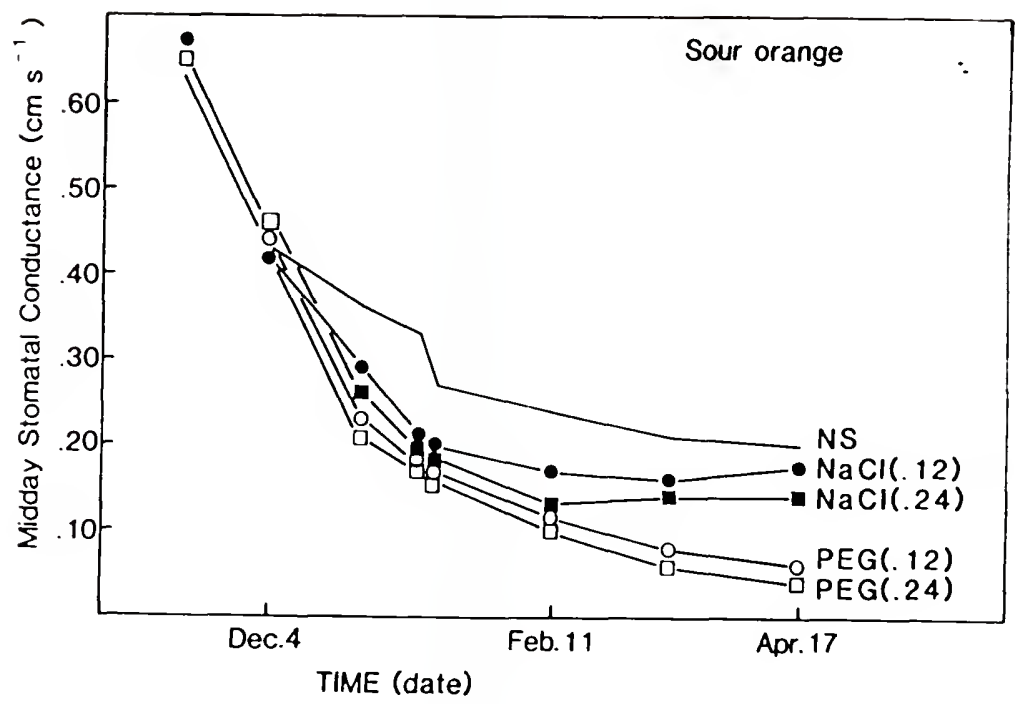

Fig. 9. Midday stomatal conductance of sour orange seedlings irrigated with nutrient solution containing no salt (NS) or with added $\mathrm{NaCl}$ or PEG. 


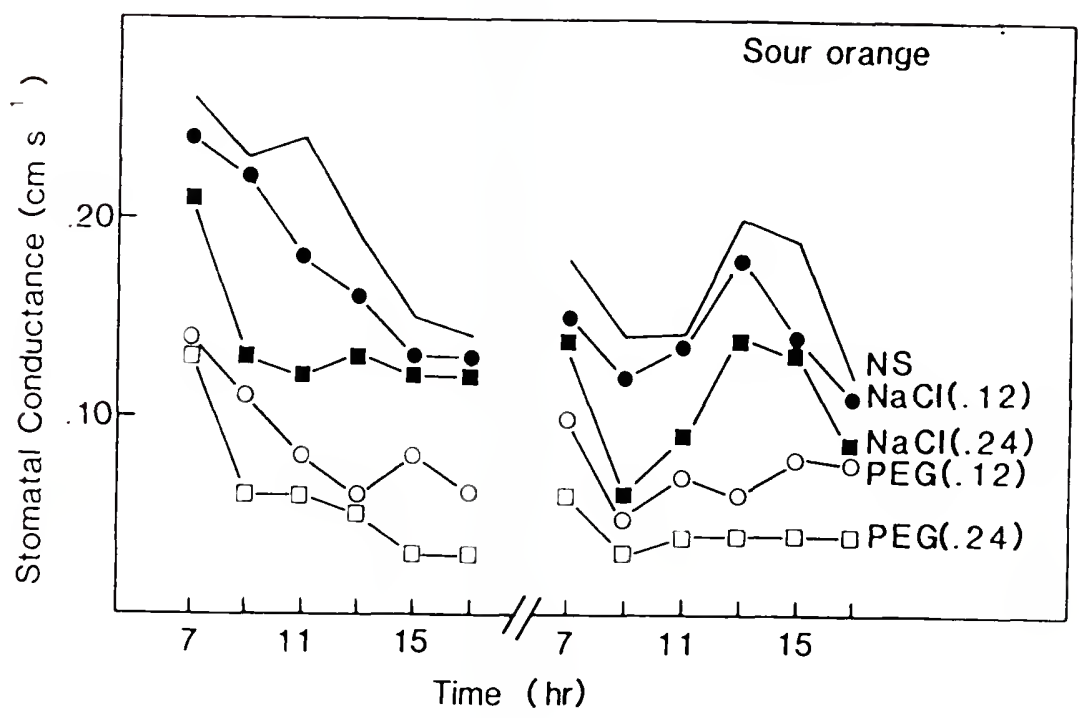

Fig. 10. Relationship of time of day to stomatal conductance of sour orange seedlings irrigated with nutrient solution containing no salt (NS) or with added NaCl or PEG during 2 consecutive days. Measurements were started on April 17, 1986. Seedlings were irrigated the day before measurements were started and not irrigated until after measurements were completed on Day 2. 


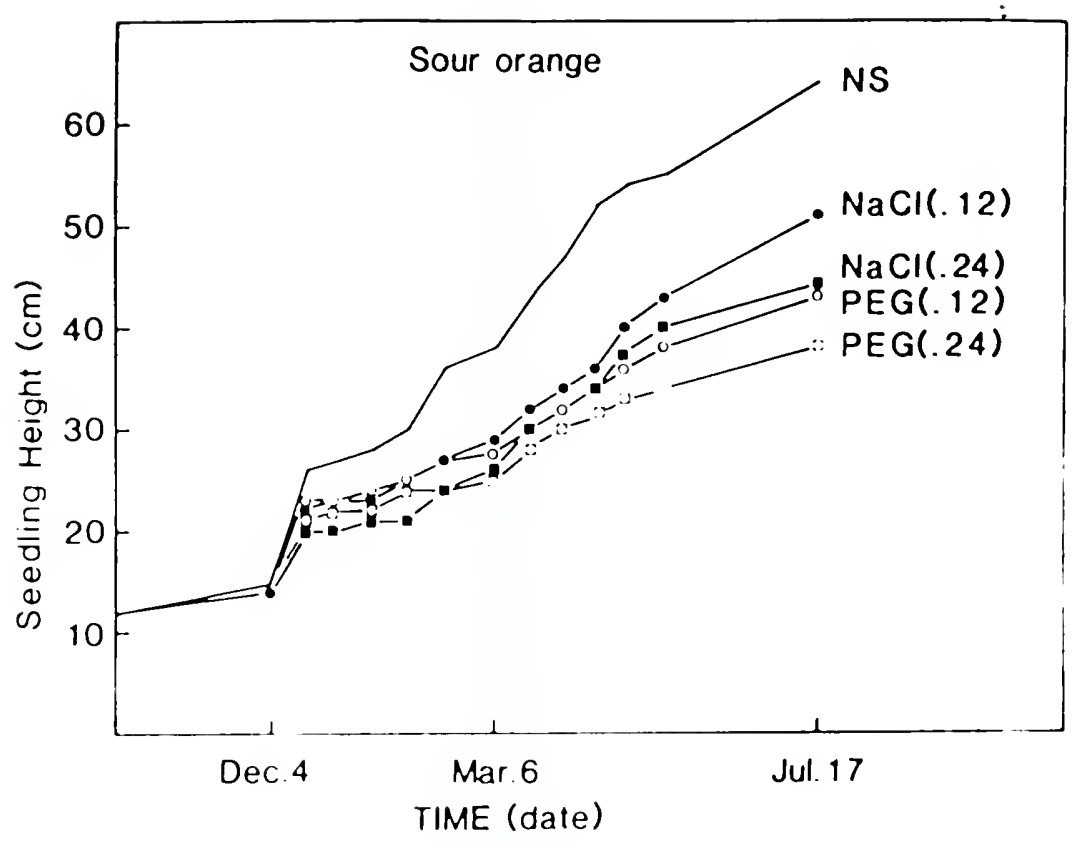

Fig. 11. Growth of sour orange seedlings irrigated with nutrient solution containing no salt (NS) or with added $\mathrm{NaCl}$ or PEG. 


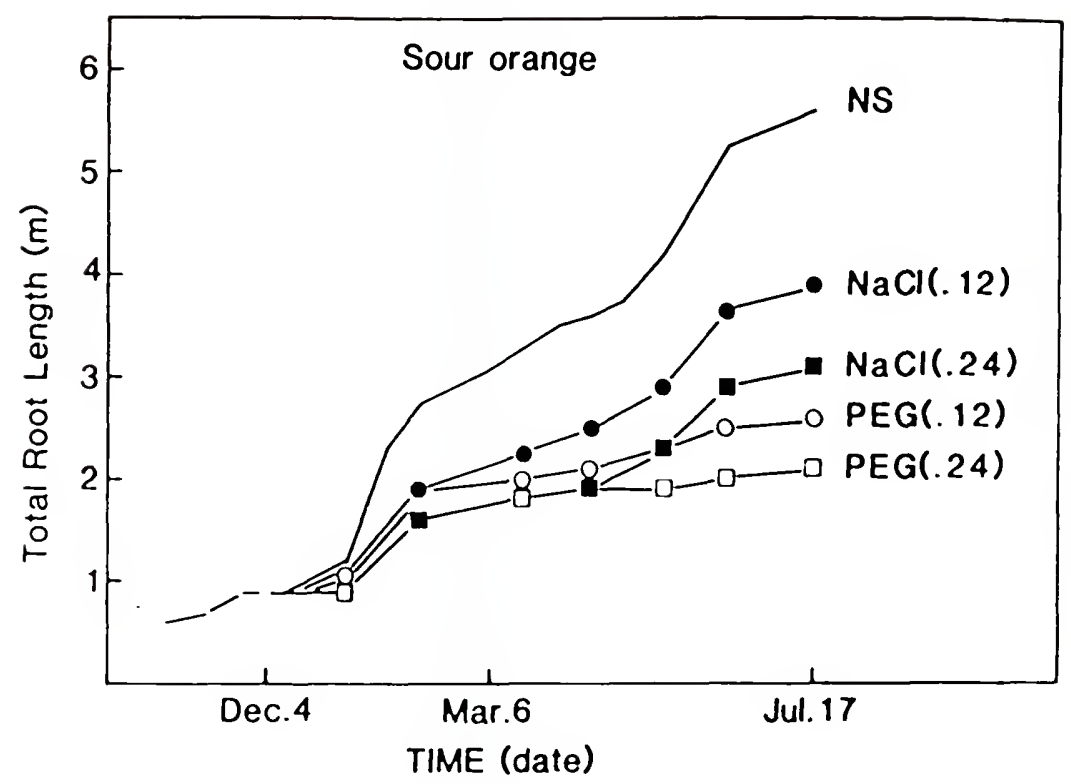

Fig. 12. Fibrous root length of sour orange seedlings irrigated with nutrient solution containing no salt (NS) or with added $\mathrm{NaCl}$ or PEG. 


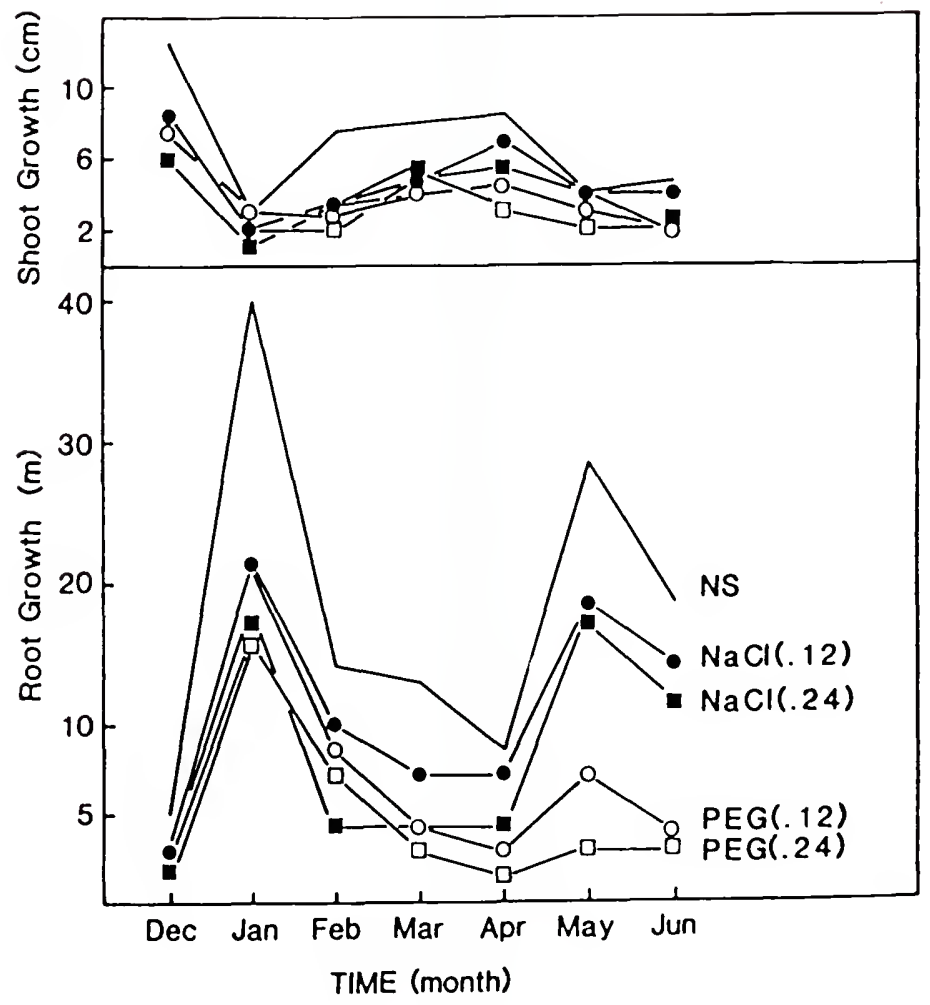

Fig. 13. Fluctuations in shoot and root growth of sour orange seedlings irrigated with nutrient solution containing no salt (NS) or with added NaCl or PEG. 


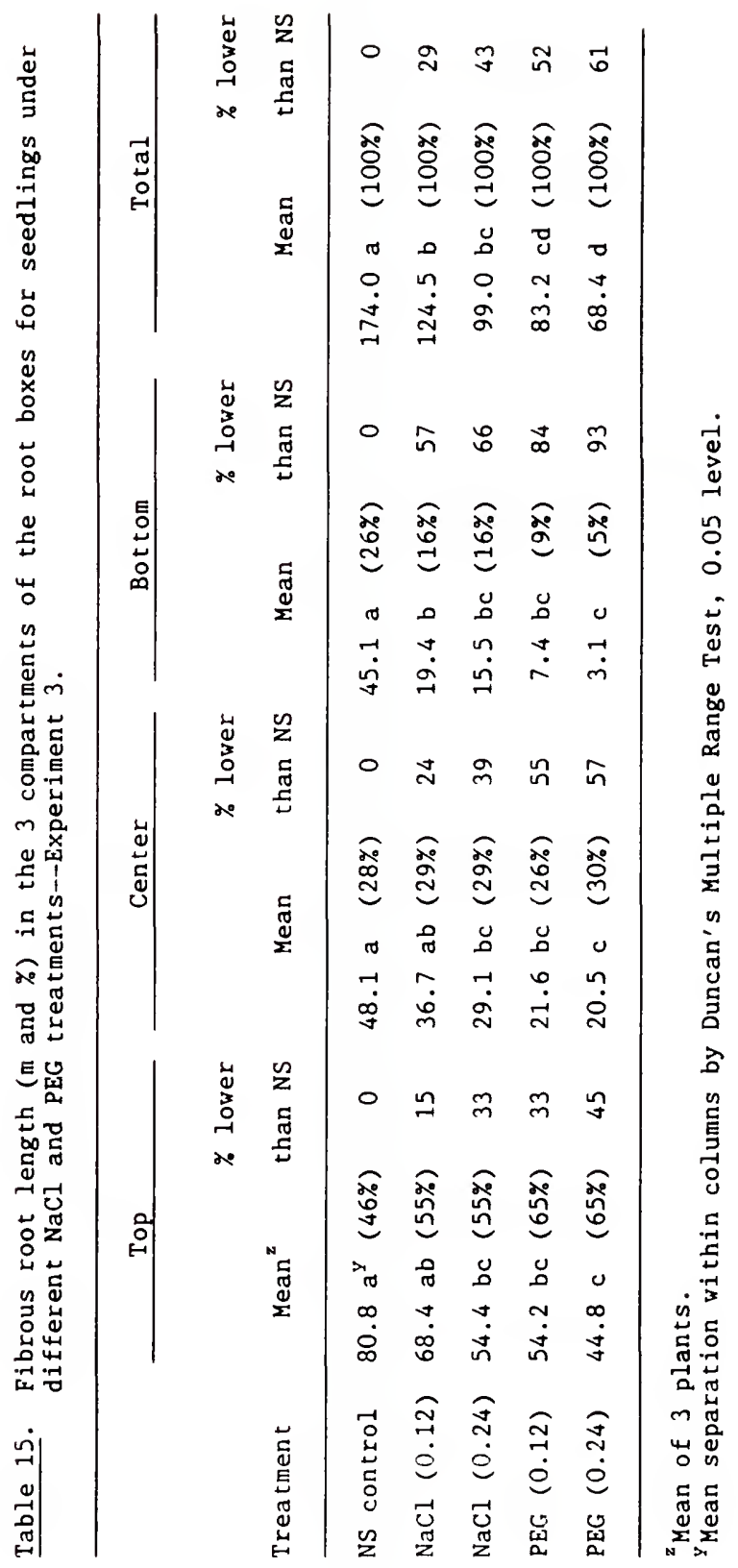



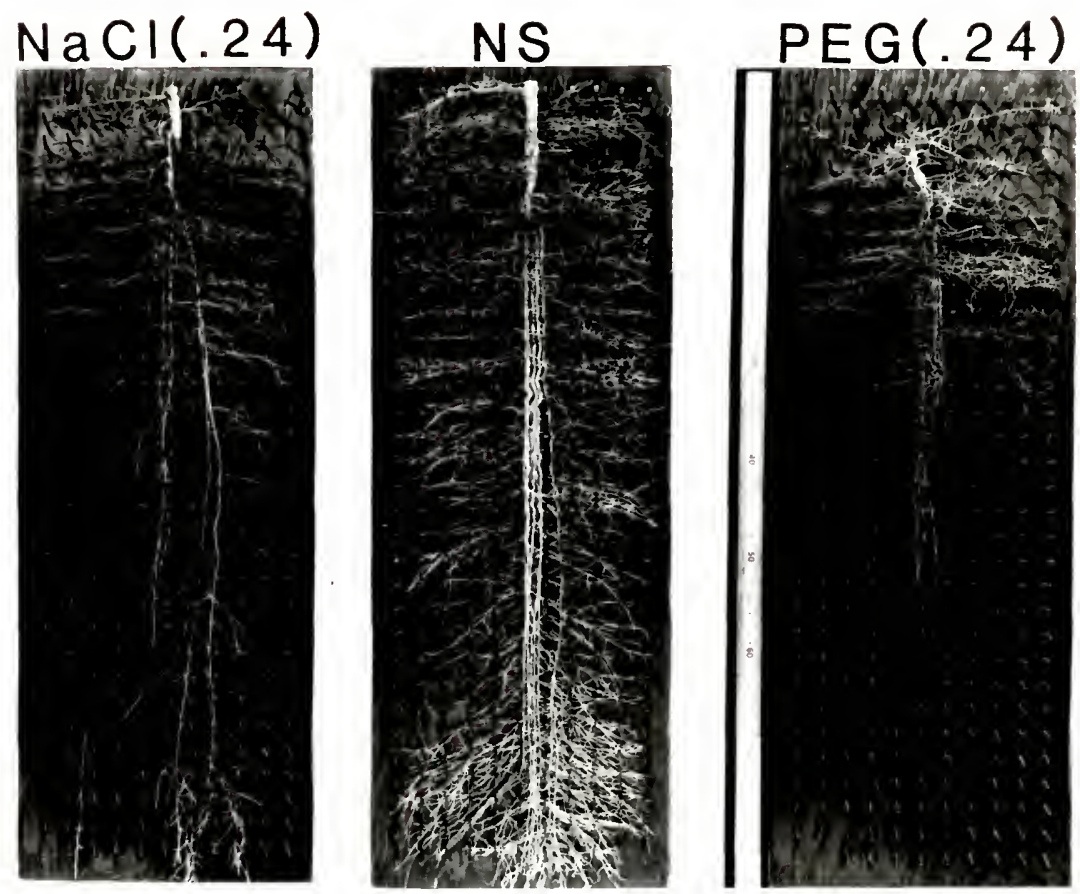

Fig. 14. Root density and distribution of sour orange seedlings growing in root boxes under non-stressed (NS) and stressed ( $\mathrm{NaCl}, \mathrm{PEG}$ ) conditions. $\mathrm{NaCl}$ and PEG treatments were at $-0.24 \mathrm{MPa}$ osmotic potential. 
bottom section, only 5 to $16 \%$ of the roots developed in the stressed chambers as compared to $26 \%$ in the controls.

Fibrous root length at the plexiglas face, measured from tracings made on acetate sheets with colored pencils, was compared to the total fibrous root length measured at the end of the experiment. Root length against the plexiglas represented 3 to 48,2 to 38 , and 4 to 58 of the total root length in the top, middle, and bottom of the root boxes, respectively. From the comparison of root lengths at the plexiglas and in the box, it was concluded that growth and distribution of citrus roots at the plexiglas-soil interface correlated satisfactorily with growth and distribution of roots in the bulk soil.

Experiment 4: Response of Split-Root Sour Orange Seedlings to Salinity

Uniform salinity was significantly more damaging to sour orange seedlings than non-uniform salinity (Table 16; Fig. 15). Shoot dry weight was reduced only slightly ( 9 to $21 \%$ ) when half of the root rystem was irrigated with saline solutions. When both halves of the root system were irrigated with saline solutions, shoot dry weight was reduced 45 to 818 (Table 16). The trend was similar with root dry weight in that stressing one-half of the root system resulted in only a moderate reduction (16 to 318) in root dry weight. Stressing both halves gave a much larger reduction in root dry weight (43 to 798 ).

In the split-root test, shoot growth did not correlate well with the average salt stress of the total root system. The average osmotic potential of the NS/NaCl $(0.20)$ treatment was $-0.12 \mathrm{MPa}$. Even though this was slightly greater than the average osmotic potential of the NaCl $(0.10) / \mathrm{NaCl}(0.10)$ treatment, shoot dry weight was $35 \%(10.7 \mathrm{~g})$ less in the $\mathrm{NaCl}(0.10) / \mathrm{NaCl}(0.10)$ treatment. Similarly, shoot dry weight in the $\mathrm{NaCl}(0.20) / \mathrm{NaCl}(0.20)$ treatment was $50 \%(14.5 \mathrm{~g})$ less than that in 


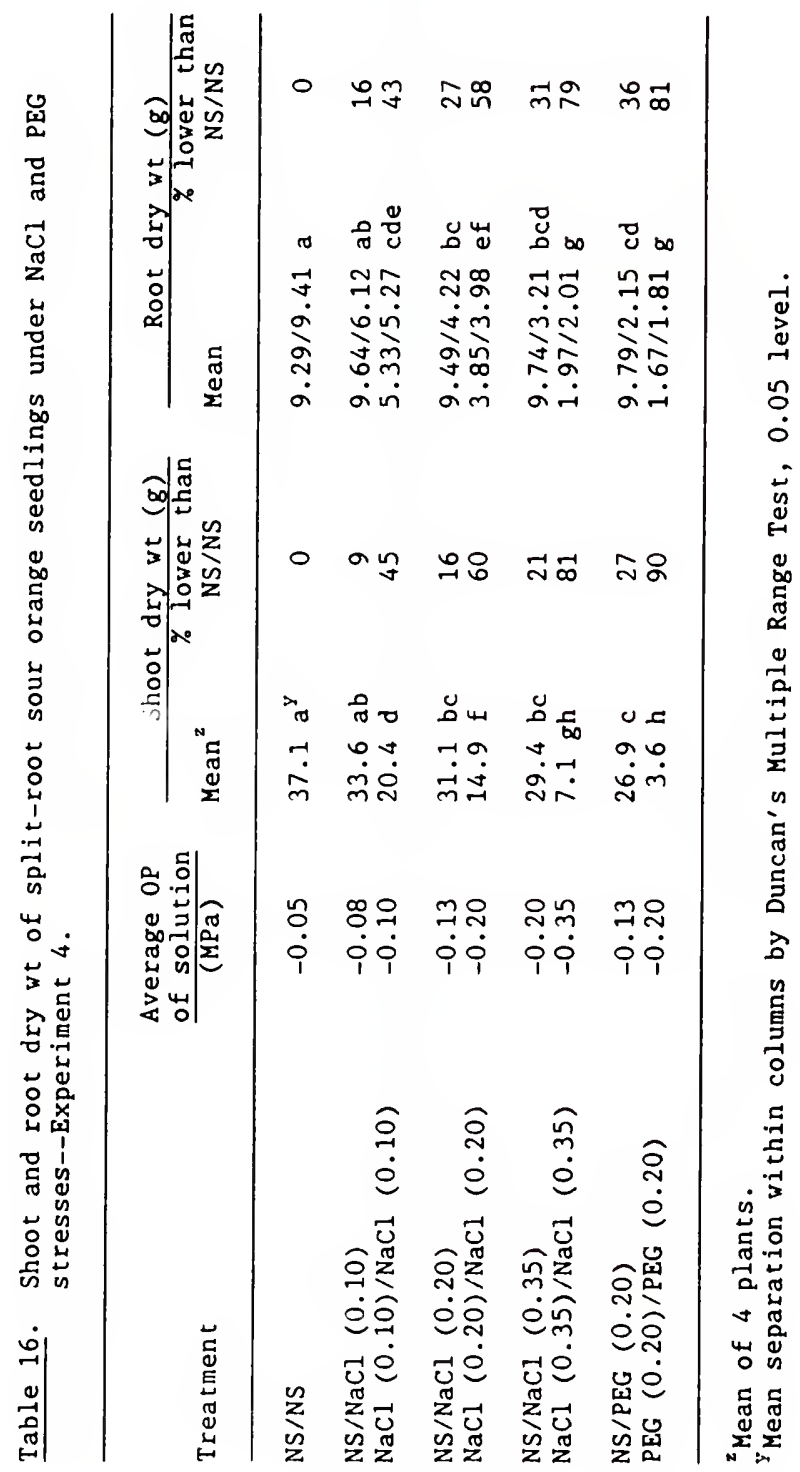



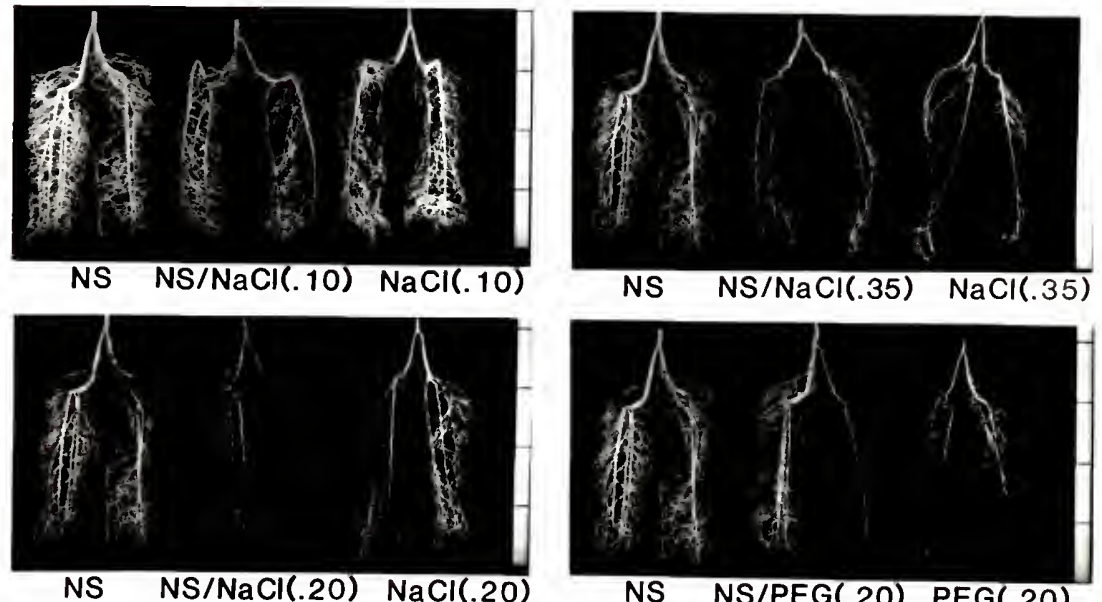

Fig. 15. Split-root treatment of sour orange seedlings under uniform and non-uniform $\mathrm{NaCl}$ and PEG stresses. $\mathrm{NaCl}$ treatments were at $-0.10,-0.20$, and $-0.35 \mathrm{MPa}$ osmotic potentials. PEG treatments were at $-0.20 \mathrm{MPa}$ osmotic potential. 
the NS/NaCl (0.35) treatment, even though both of these treatments had the same average $\mathrm{NaCl}$ stress $(-0.20 \mathrm{MPa})$.

Under uniform salinity similar to Experiments 1, 2, and 3, shoot growth was more reduced than root growth. However, under non-uniform salinity, root dry weight on a percentage basis appeared to be more reduced than shoot dry weight (Table 16).

Partial leaf burn occurred after 4 weeks in the $\mathrm{NaCl}(0.35) / \mathrm{NaCl}$ (0.35) treatment and after 5 weeks in the $\mathrm{NaCl}(0.20) / \mathrm{NaCl}(0.20)$ treatment. No leaf damage symptoms were noticed in the remaining treatments until the end of the experiment.

Water relations variables were monitored on 4 successive days during the fourth month of salt treatment. Data were combined because no significant differences were found from day to day. Similar to growth, water relations variables were also significantly more disturbed under uniform salinity than under non-uniform salinity conditions. With uniform salinity, leaf water and turgor potentials decreased significantly from morning to midday, but leaf osmotic potential did not (Fig. 16). Leaf water potential, osmotic potential, stomatal conductance, and transpiration decreased with increasing $\mathrm{NaCl}$ and PEG concentrations in the irrigation water (Tables 17, 18). Turgor potential significantly increased in response to $\mathrm{NaCl}$ treatments particularly during the morning. A significant positive correlation was found between stomatal conductance and transpiration (Fig. 17). Similar to findings of the preceding experiments, PEG at $-0.20 \mathrm{MPa}$ was more damaging than $\mathrm{NaCl}$ at the same osmotic potential.

Cross sections of leaves from control (NS/NS) and from NaCl $(0.35) / \mathrm{NaCl}(0.35)$ treatments, compared by light microscopy, showed that the number of cell layers in the epidermis, the palisade, and the spongy 


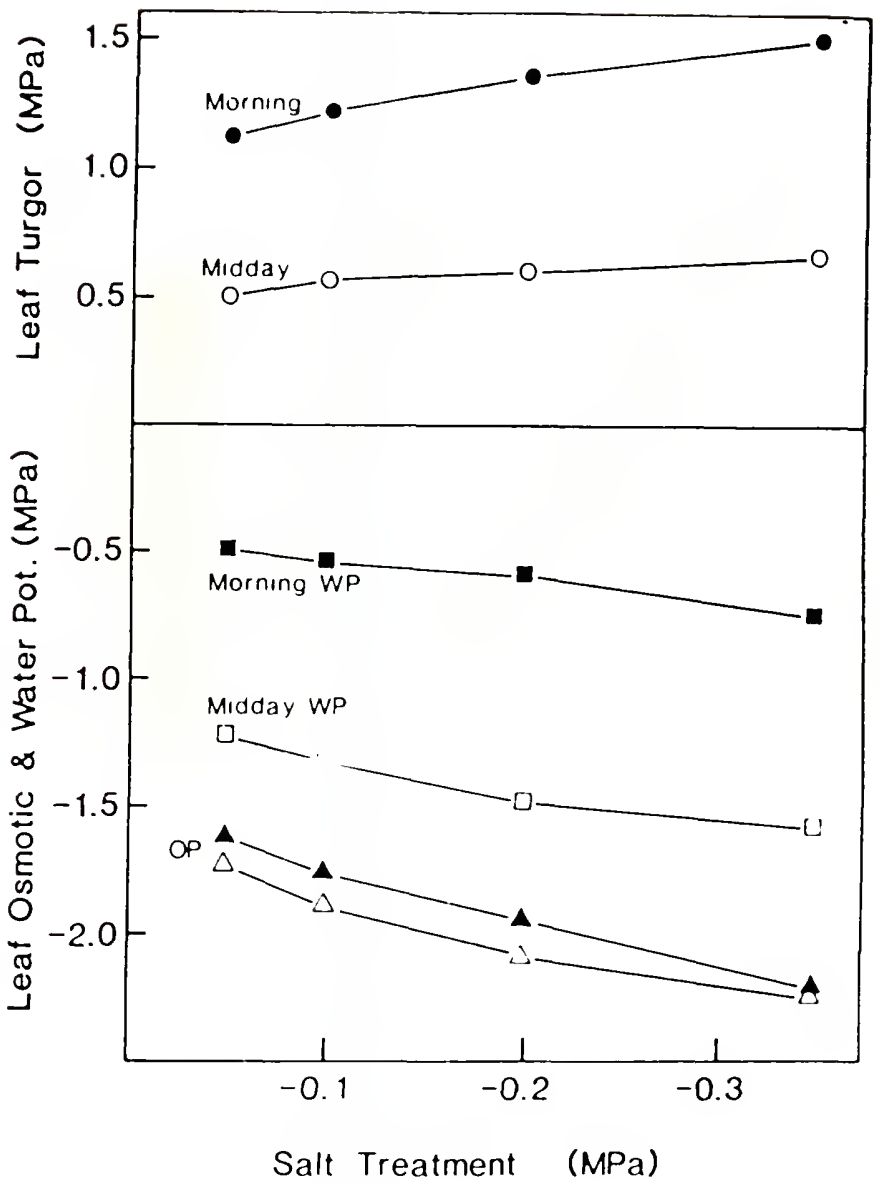

Fig. 16. Leaf water, osmotic, and turgor potential of sour orange seedlings irrigated with nutrient solution containing no salt (NS) or with $\mathrm{NaCl}$ added to both root halves. Solid figures are morning values and open figures are midday values. 


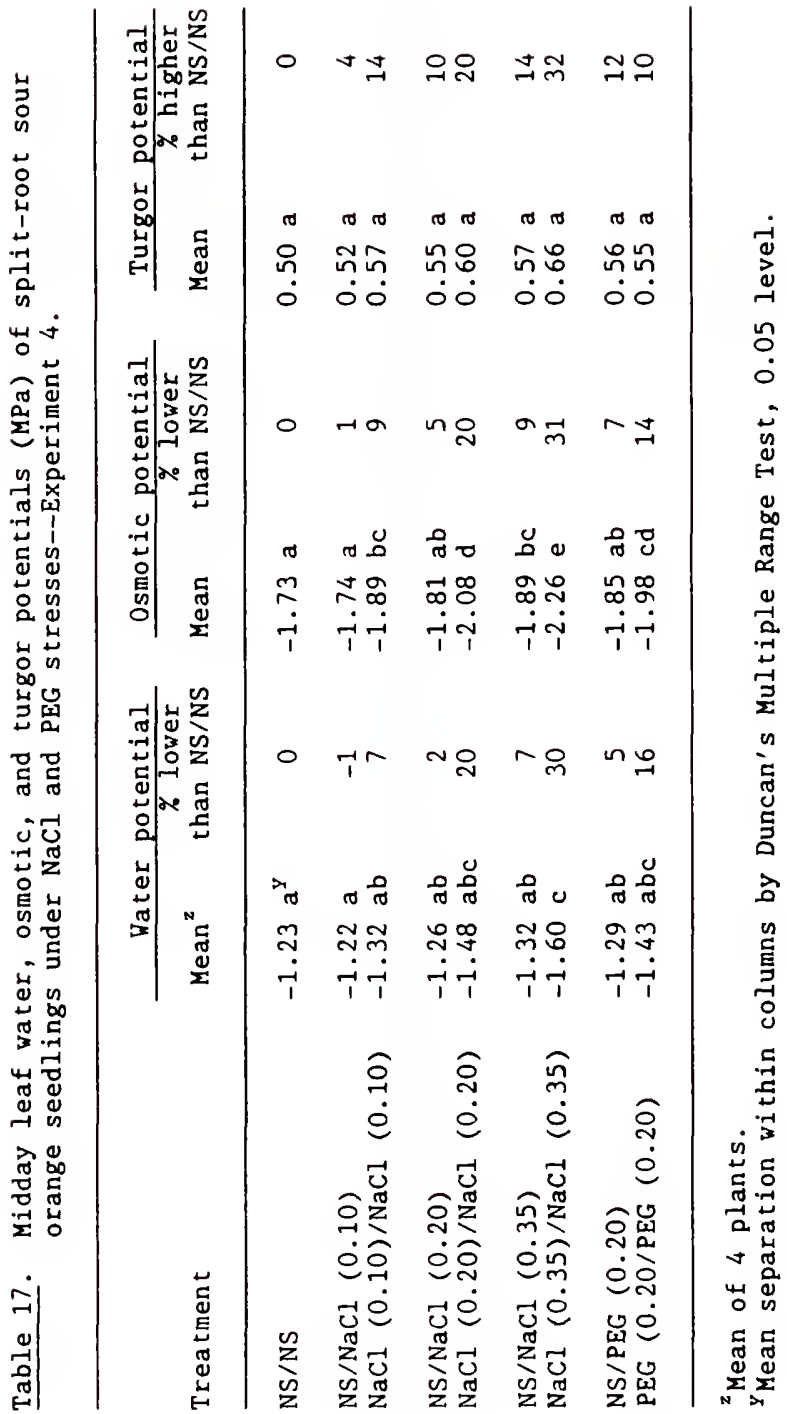




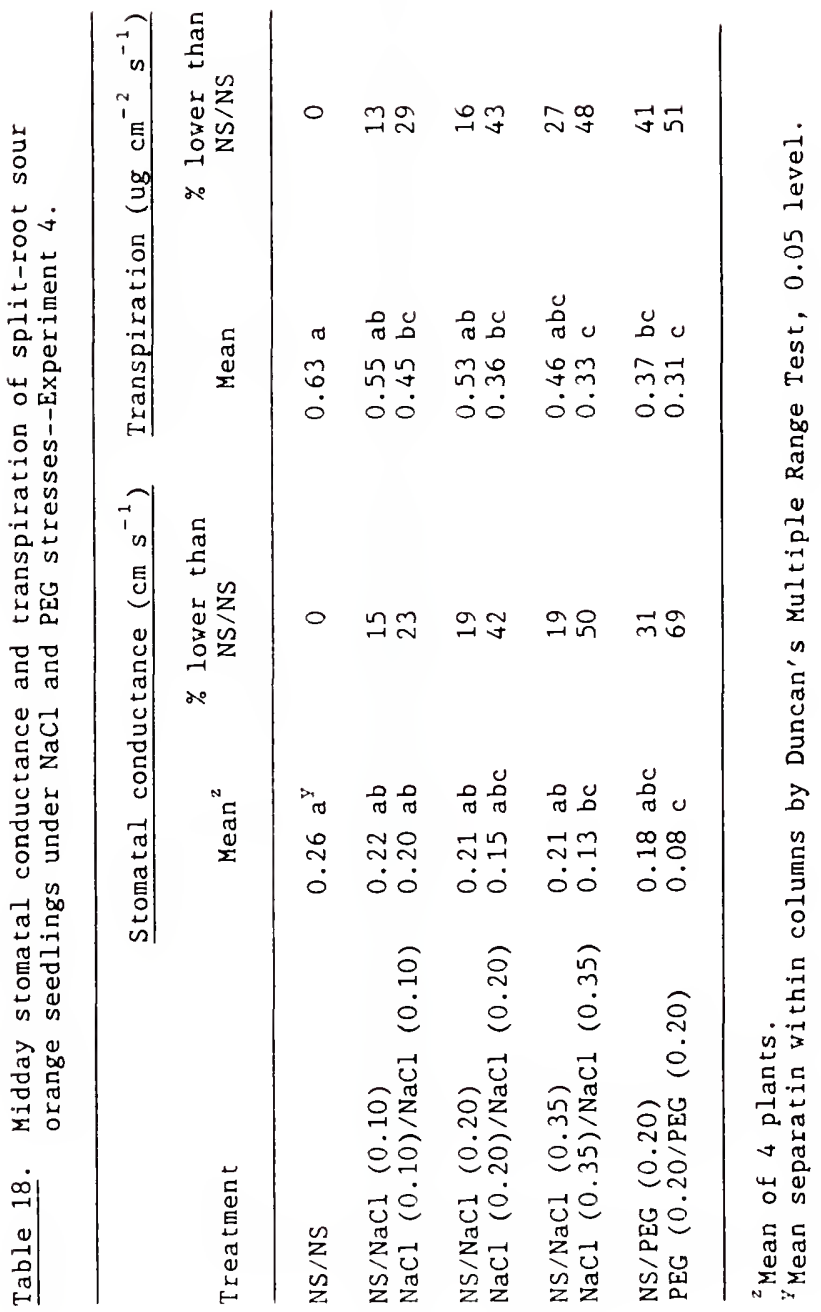




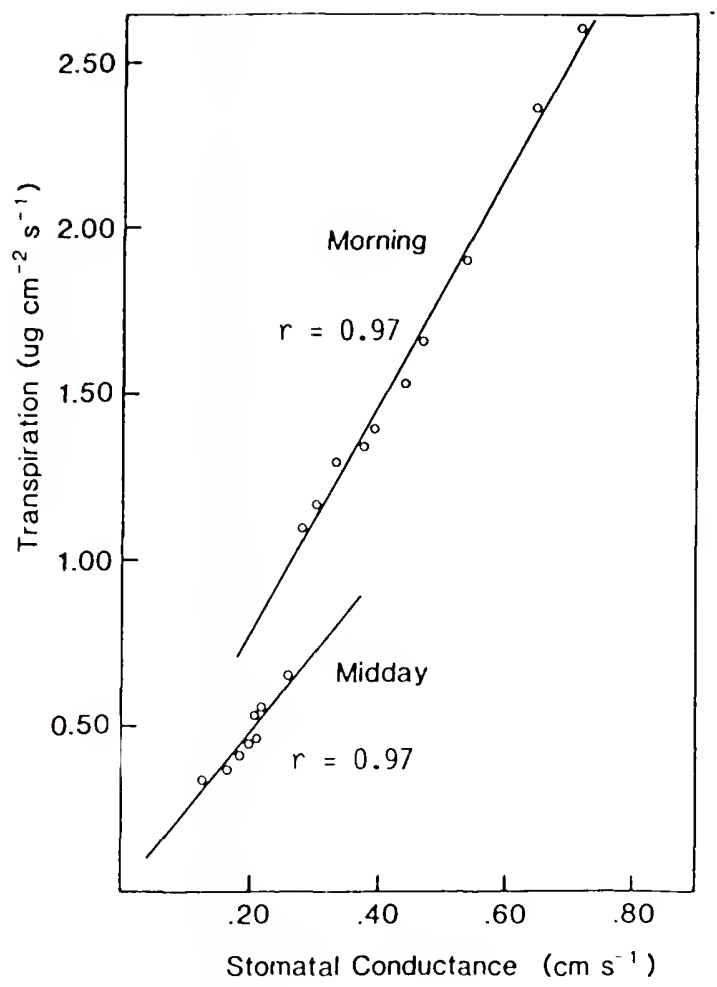

Fig. 17. Relationship between transpiration and stomatal conductance of sour orange seedlings. 
mesophyll in control leaves and NaCl-treated leaves were similar. Epidermal and palisade cells of the control and NaCl-grown leaves were also similar in size; however, the spongy mesophyll cells of the . $\mathrm{NaCl}$-treated leaves were about 3 times larger than those of the control (Fig. 18). The overall increase in leaf thickness due to $\mathrm{NaCl}$ was relatively small (238) because the enlarged cells of the spongy mesophyll were tightly packed with much less intercellular space. Cells of the spongy mesophyll in NaCl-treated leaves also had fewer chloroplasts than those in the control leaves.

Experiment 5: Effects of Calcium on Sour Orange Seedlings Grown under Saline Conditions

Addition of NaCl to half strength Hoagland's solution significantly reduced growth of sour orange seedlings. Shoot, root, and total plant dry weights were reduced by about $30 \%$ (treatments 2 and 10) when $40 \mathrm{mM}$ $\mathrm{NaCl}$ was added to the nutrient solution (Tables 19, 20). However, addition of $7.5 \mathrm{mM} \mathrm{CaSO} \mathrm{C}_{4}$ (treatment 3 ) to the salty solution decreased the adverse effect of $\mathrm{NaCl}$ on growth. Furthermore, addition of only $5 \mathrm{mM} \mathrm{CaSO}{ }_{4}$ (treatment 12) completely inhibited the adverse effect of $\mathrm{NaCl}$. Addition of either $\mathrm{KCl}$ (treatments 6 and 7 ) or $\mathrm{CaCl}_{2}$ (treatments 5 and 8 ) to the salty solution did not improve plant growth.

In the leaves of the sour orange seedlings, addition of $\mathrm{NaCl}$ to the nutrient solution significantly increased sodium and chloride, decreased calcium, magnesium, and potassium but had little or no effect on phosphorus, zinc, manganese, copper, and iron (Table 21). Sodium and chloride accumulation in the leaves usually reduces growth. Addition of $\mathrm{CaSO}_{4}$ (treatments $3,4,11$, and 12) to the saline solution reduced sodium and chloride content and, therefore, improved plant growth. Addition of $\mathrm{KCl}$ (treatment 6 ) did not reduce sodium and chloride; hence, 

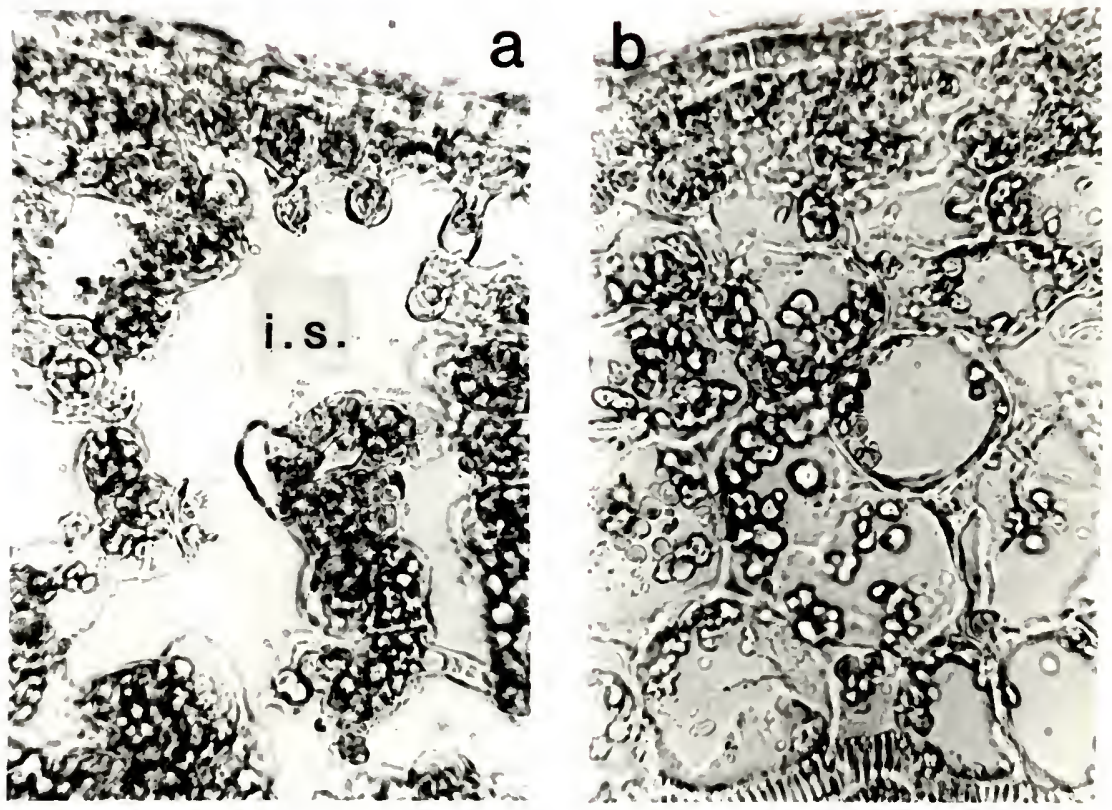

Fig. 18. Cross sections of sour orange leaves.

a. Leaf cross section of non-stressed seedling.

b. Leaf cross section of $\mathrm{NaCl}$-stressed seedling.

i.s. = intercellular space. 


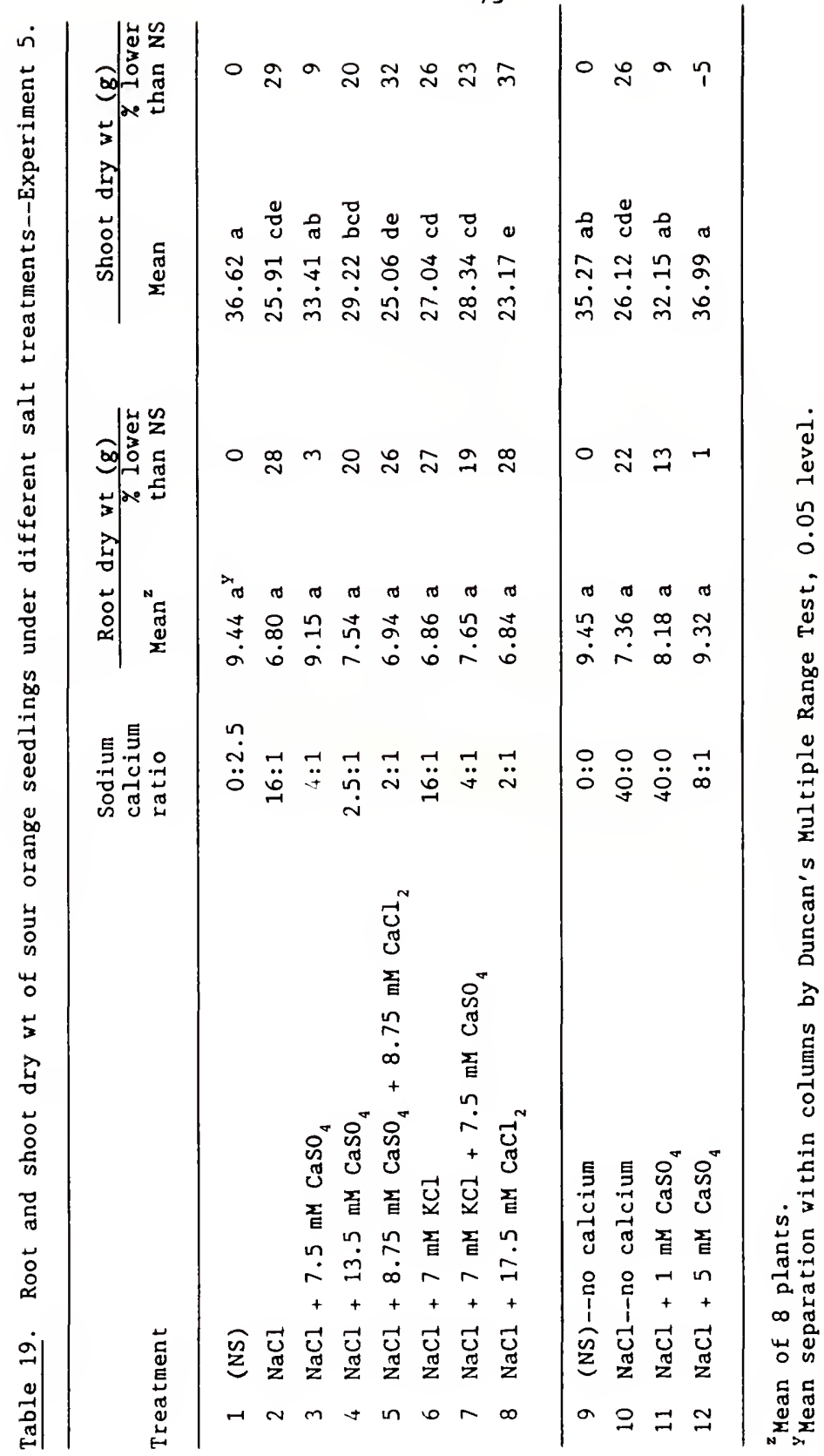


76

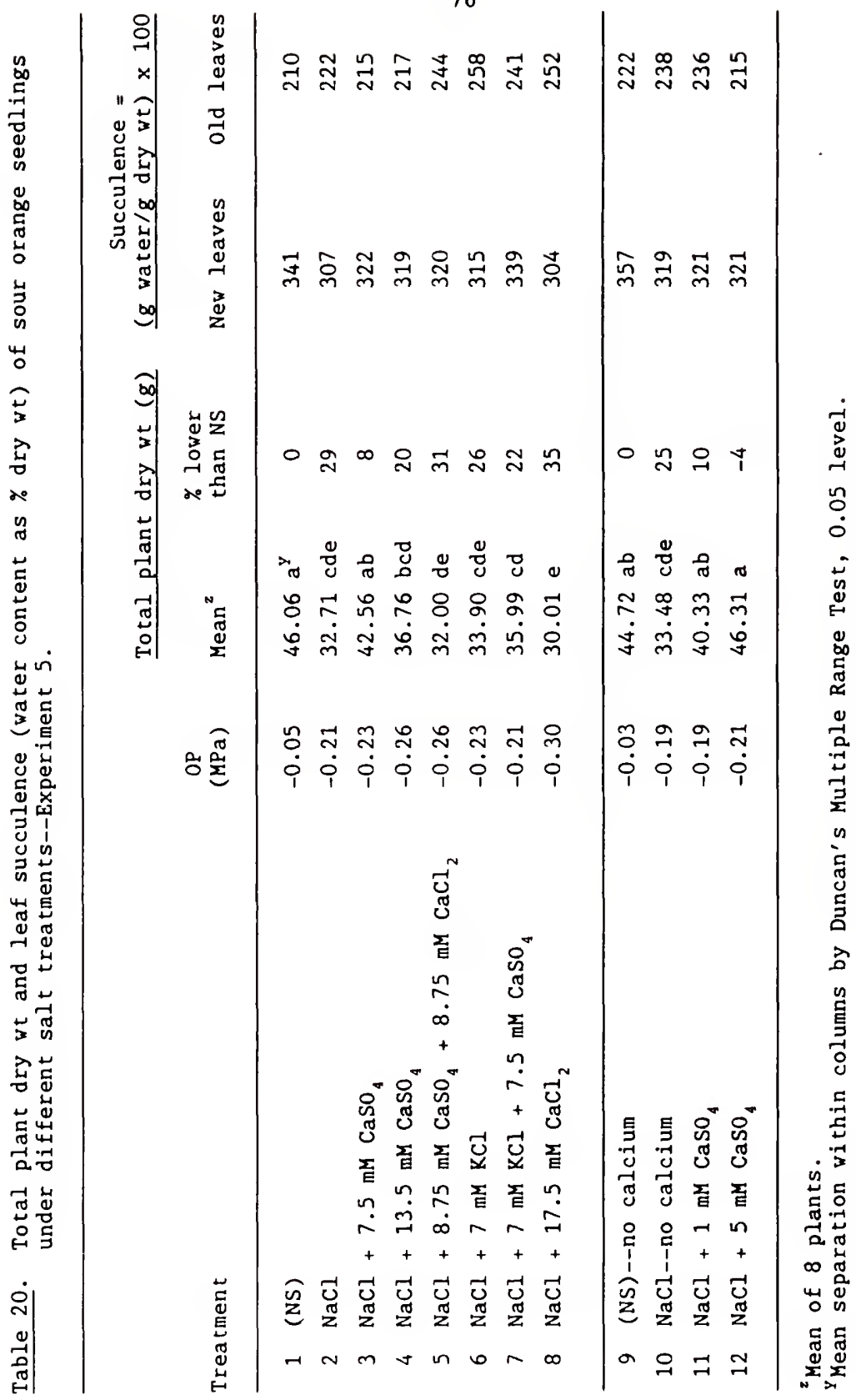




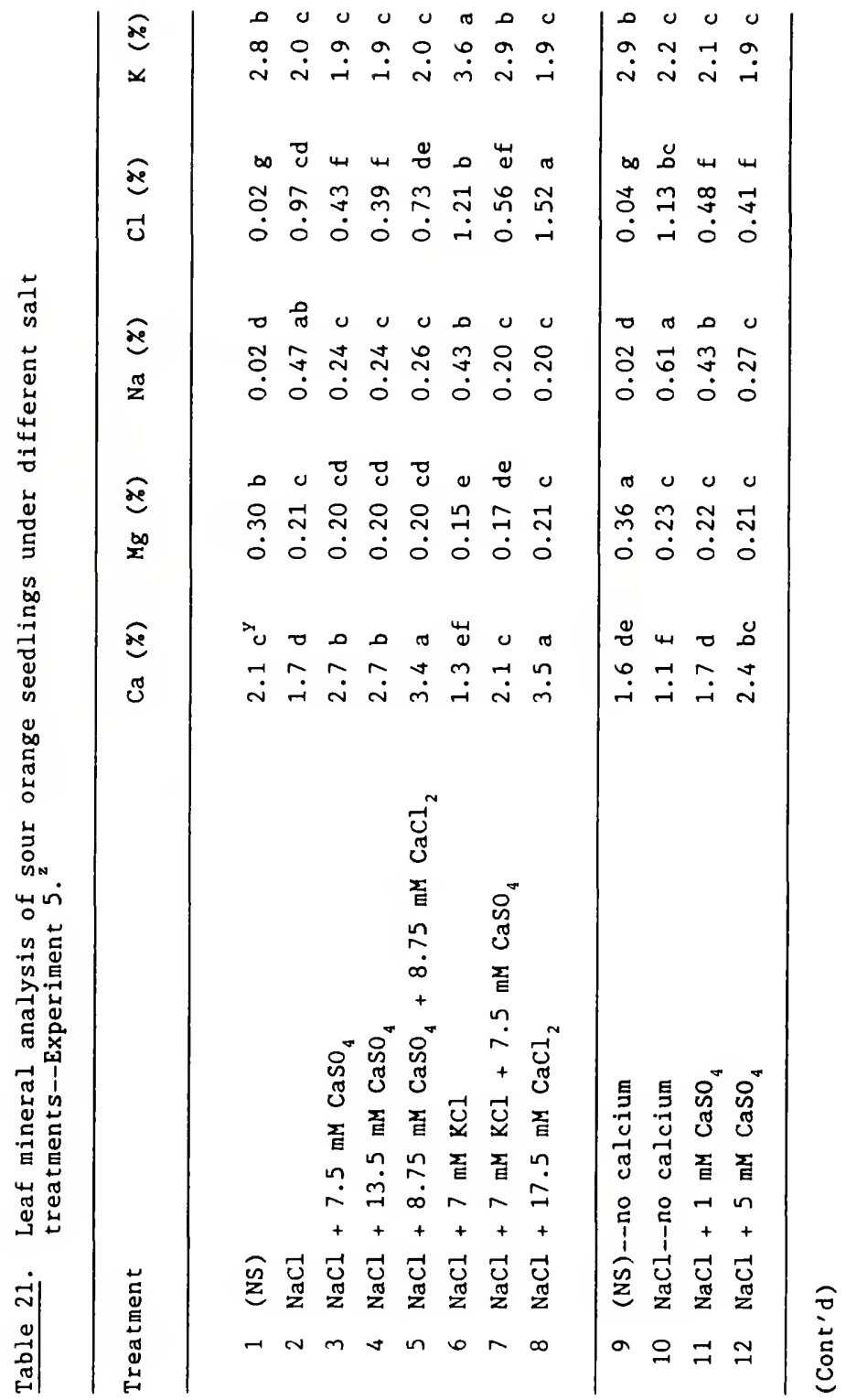




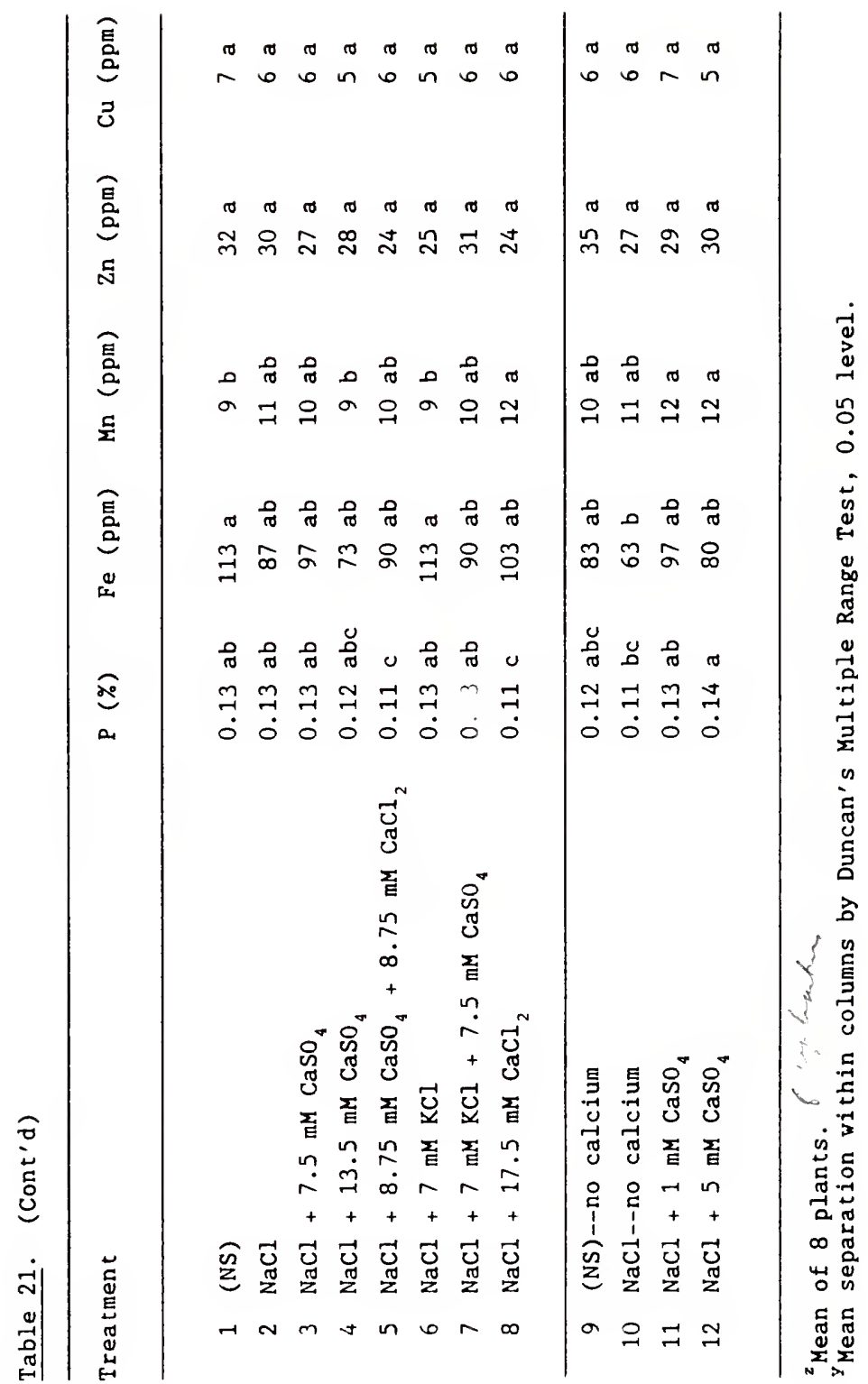


growth was not improved. Addition of $\mathrm{CaCl}_{2}$ (treatments 5 and 8) reduced sodium but did not reduce chloride sufficiently to improve growth.

Significant growth reduction occurred without any visible symptoms of salt damage. Although total plant dry weight was reduced by more than 288 in some treatments after 4 months of salinity stress, none of these treatments caused any apparent leaf damage symptoms.

Comparison of Citrus Seedling Responses to NaCl and PEG Treatments

The effects of $\mathrm{NaCl}$ and PEG on citrus seedlings differed in the degree and the type of damage. When considering $\mathrm{NaCl}$ and PEG at similar osmotic potentials, the damaging effects on all measured variables generally appeared to be larger in the PEG treatment than in the $\mathrm{NaCl}$ treatment. Citrus seedling responses to NaCl and PEG compared to the no salt control are summarized in Table 22 . The higher salinity damage occurring in Experiment 2 in comparison to Experiment 1 was thought to be mainly due to the more rapid onset of salt treatment and to the longer duration of salt treatment.

Differences in damage and leaf burn symptoms were also found between $\mathrm{NaCl}$ and PEG. Leaves from NaCl-treated seedlings appeared abnormally thickened. Leaf symptoms in the $\mathrm{NaCl}$ treatment were initially similar to nitrogen dificiency (uniform loss of the green color over the entire leaf). Later, leaf burn occurred as large spots merged together. Leaf scorch and areas of dead tissue extended inward from the margins of the leaf. Sodium chloride-damaged leaves readily abscised and dropped as soon as visual burn symptoms appeared. Sometimes leaves fell off before they reached this stage. Leaf symptoms in PEG treatment first appeared similar to iron-manganese deficiency (intervenal chlorosis). Then, leaf burn appeared at the edges and particularly at the tip of the leaf. Later, the dead area extended inward from the tip (Fig. 19). 
Table 22. Summary of citrus rootstock responses to $\mathrm{NaCl}$ and PEG as. compared to the no salt control.

Variable
$\mathrm{NaCl}$

PEG

\section{Growth}

Total fibrous root length

Leaf number

New shoot growth

Total root dry weight

Total shoot dry weight

Seedling height

Stem cross sectional area

Total leaf area

decrease

decrease

decrease

decrease

decrease

decrease

decrease

decrease

Water Relations

Root conductivity

Water flow rate

$O P$ of root exudate

Stomatal conductance

Transpiration

Water use

Leaf water potential

Leaf osmotic potential

Leaf turgor potential

Leaf succulence

Leaf Mineral Analyses

Chloride

Sodium

Calcium

Magnesium

Potassium

Phosphorus

Zinc

Manganese

Copper

Iron

Other Variables

Shoot root ratio

Specific root weight

Specific leaf wt (Dry wt basis)

Specific leaf wt (Fresh wt basis)

Leaf chlorophyll decrease

decrease

decrease

decrease

decrease

decrease

decrease

decrease

increase

increase

increase

increase

decrease

decrease

decrease

increase

decrease

increase

no change

no change decrease

increase

increase

increase

decrease decrease

decrease

decrease

decrease

decrease

decrease

decrease

decrease

decrease

decrease

decrease

decrease

decrease

decrease

decrease

decrease

increase

decrease

no change

no change

increase

decrease

decrease

increase

increase

increase

no change

no change

decrease

increase

increase

decrease 


\section{Sour orange}
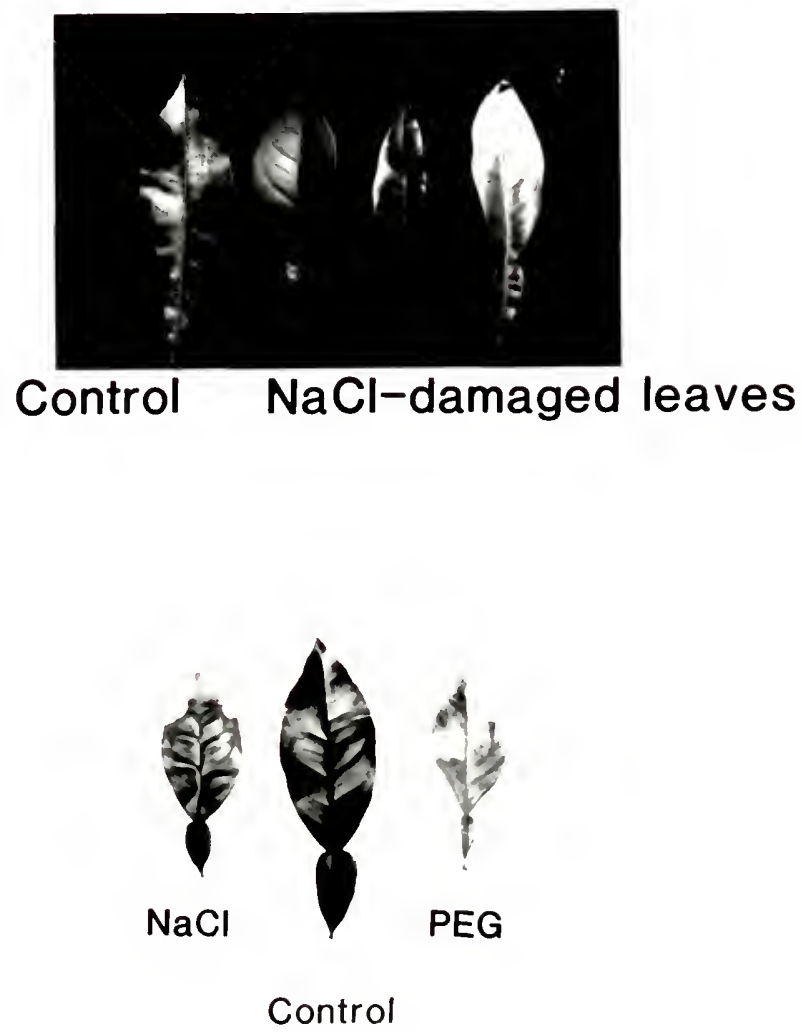

Fig. 19. Sour orange leaves from non-stressed (control) and stressed ( $\mathrm{NaCl}, \mathrm{PEG)}$ seedlings. 


\section{DISCUSSION}

\section{Leaf Ion Content and Salinity Tolerance}

\section{Rootstock Tolerance}

Important differences in salt tolerance among citrus rootstocks were demonstrated in this study. Based on various measurements of plant growth (shoot, root, and total plant dry weight), on plant water relations factors (root hydraulic conductivity, water flow rate, and osmotic potential of root exudate), and on seedling appearance and performance (leaf burn, leaf drop, and dieback), SO and CM seedlings were the least affected while the most damage occurred in ML and PT seedlings. Rough lemon, SC, and $\mathrm{CC}$ had an intermediate response. From these results, SO as well as CM were classified as relatively tolerant rootstocks, RL, SC, and CC were sensitive, and ML and PT were very sensitive rootstocks to $\mathrm{NaCl}$. Cooper et al. (1951) and Ream and Furr (1976), who based their conclusions on visual leaf burn symptoms and leaf chloride content, found that $C M$ appeared to be more salt tolerant than so. The current study, which was mainly based on growth and water relations measurements, showed that So was as tolerant as CM. This overall classification agreed with Cooper et al. (1951) who reported that PT was a very salt sensitive rootstock and with others who found that $\mathrm{CC}$ was a salt sensitive rootstock when compared to CM (Joolka and Singh, 1979; Patil and Bhambota, 1978). 
Ion Exclusion and Accumulation

Sour orange seemed to behave differently from the other rootstocks. Even though So accumulated higher amounts of sodium and chloride-than PT and its hybrids ( $\mathrm{SC}$ and $\mathrm{CC}$ ) at the first salinity level (Tables 7,8 ), plant growth and physiological activities of so were relatively unaffected as compared with those of RL, ML, SC, CC, and PT. Rough lemon and ML were sodium and chloride accumulators similar to so. However, salt damage was more severe and tree growth and appearance were poorer in RL and ML than in SO. Since excess accumulation of both chloride and sodium in so leaves caused relatively minor damage to this rootstock, so might have the ability to partially exclude these ions from the cytoplasm where they could inhibit metabolic functions. Salinity studies at the cellular level could further clarify ion exclusion and compartmentalization ability in citrus.

The citrus rootstocks tested in this study are considered to be salt sensitive because no rootstock has the ability to exclude both chloride and sodium. Rough lemon, ML, and SO are chloride and sodium accumulators. Poncirus trifoliata, SC, and CC are chloride accumulators but sodium excluders. Cleopatra mandarin is a chloride excluder but a sodium accumulator. Furthermore, sodium exclusion capacity in PT, SC, and $\mathrm{CC}$ and chloride exclusion capacity in CM are limited. This study (Tables 7,8) showed the inability of PT, SC, and CC to exclude sodium and the inability of $\mathrm{CM}$ to exclude chloride at moderate salinity levels $(-0.2 \mathrm{MPa})$. It is suggested that in any program where plants are being screened for salt tolerance on the basis of salt exclusion, chloride exclusion as well as sodium exclusion should be considered because the chloride and sodium accumulating properties of a particular species are quite different (Grieve and Walker, 1983). 
$\underline{\text { Leaf Ion Content and Ion Toxicity }}$

Sodium chloride was found to reduce potassium in So, CM, RL, and ML but not in SC, CC, and PT leaves (Table 27, Appendix). Sour orange, CM, RL, and ML are sodium accumulators (Table 9). Sodium accumulation in these rootstocks might be the main factor which depressed leaf potassium. Poncirus trifoliata, SC, and CC are sodium excluders (Table 9). The unaffected leaf potassium in these rootstocks might be attributed to sodium exclusion.

There was an inverse relationship between chloride ion accumulation in the leaves and salt tolerance. Usually chloride accumulation was associated with more damage. Since PT and its hybrids (SC and CC) accumulated large amounts of chloride, their ability to exclude sodium (particularly at $-0.10 \mathrm{MPa}$ ) and to maintain adequate potassium did not help prevent these rootstocks from showing severe growth reduction and water relation disturbances. Furthermore, although CM accumulated excess sodium in its leaves, growth and water relations of CM were not as severely affected at $-0.10 \mathrm{MPa}$ since it was a chloride excluder.

The levels of chloride and sodium accumulation at which leaf burn symptoms developed were found to be higher than the upper limits set by earlier investigators. Such differences are mainly attributed to different experimental conditions. Comparison between leaf chloride content (Table 8 ) and visual symptoms (Table 6) shows that a leaf chloride content of about $1 \%$ in SC and CC and even $1.7 \%$ in S0 did not cause any leaf burn symptoms. Similarly, when comparing leaf sodium content (Table 7) to visual symptoms (Table 6), leaf sodium content up to $1.9 \%$ in CM did not cause visible leaf burn. However, growth and water relations were severely altered. 
Leaf chloride and sodium analysis is thought to provide useful information on toxicity limits as well as on rootstock tolerance. Harding and Chapman (1951) recommended that a leaf chloride content exceeding $0.25 \%$ be considered indicative of chloride toxicity. Bernstein (1969) stated that although $0.25 \%$ might not lead to obvious chloride toxicity symptoms, it might affect the longevity of leaves and reduce the yield. Chapman et al. (1969) suggested that $0.30 \%$ chloride in the dry matter was regarded as the threshold value of injury and leaf levels over $0.75 \%$ chloride would be indicative of serious growth retardation and yield reduction. According to Abdel-Messih et al. (1979), sodium leaf content higher than $0.36 \%$ would be critical for developing burn symptoms in citrus leaves. These threshold values were lower than those found in this study because of the higher degree of stress under field and dry climate conditions.

Importance of Calcium under Saline Conditions

Under salinity conditions, addition of calcium to irrigation waters resulted in different responses in citrus. The present study on S0 seedlings showed that the beneficial effect of calcium depended on the anion associated with the calcium salt. Calcium sulfate was found to be significantly more effective than calcium chloride in reducing the deleterious effect of $\mathrm{NaCl}$ on growth (Tables 19, 20). Walker and Douglas (1983) did not observe any improvement in citrus growth by increasing calcium chloride in the growth medium. However, the earlier work on citrus by others showed the effectiveness of calcium sulfate, calcium nitrate, and calcium carbonate on reducing sodium concentrations in plant tissues, in preventing the deflocculation effect of sodium and in improving tree appearance and growth (Cooper, 1961; Harding et al., 1958b; Jones et al., 1952). LaHaye and Epstein (1969, 1971) 
demonstrated that an increase in calcium levels by adding either calcium sulfate or calcium chloride protected bean plants from salt injury by restricting sodium absorption and translocation to the leaves. Failure in effectiveness of calcium chloride in our work might have been due to the chloride accompanying the calcium and to the sensitivity of citrus to chloride.

\section{Physiological Effects of $\mathrm{NaCl}$ and PEG}

\section{Effect of $\mathrm{NaCl}$ on Root Conductivity}

The present study showed that root hydraulic conductivity in citrus seedlings was severely reduced due to $\mathrm{NaCl}$ stress and that root conductivity varied significantly among rootstocks under stressed and non-stressed conditions. Under non-stressed conditions, these results were consistent with data obtained by others (Graham and Syvertsen, 1985; Syvertsen and Graham, 1985; Syvertsen et al., 1981). Under salinity stress, root conductivity of different citrus rootstocks has not been thoroughly studied.

Reduced hydraulic conductivity of roots has been attributed to several factors. Bielorai et al. (1983) suggested that reduced water uptake by mature citrus trees irrigated with saline water was a result of soil solute potential reduction and to root suberization. Hayward and Blair (1942) observed a condition resembling dormancy caused by suberization of epidermal and root cap cells of Valencia orange seedlings irrigated with $\mathrm{NaCl}$ solutions. They also noted reductions in water uptake and development of lateral roots and root hairs as salinity increased. Walker et al. (1984) studied the anatomy and the ultrastructure of roots from two citrus genotypes (Rangpur lime and Etrog citron) with different abilities for chloride exclusion. They found that $\mathrm{NaCl}$ increased suberization of the hypodermis and endodermis 
closer to the root tip. This increase in suberization associated with the lower extension rate of the root tips might be of prime importance in reducing root permeability and root hydraulic conductivity.

0'Leary (1974) found that the reduction in root conductivity of beans could be reversed after a 2-day exposure to high $\mathrm{NaCl}$ by removing the NaCl. This short time reversibility suggested that biochemical or membrane changes were responsible for the reduced conductivity because root suberization may not have yet occurred. Thus, differences in root hydraulic conductivity may arise from anatomical and biochemical features.

Effect of PEG on Root Conductivity

Polyethylene glycol was found to reduce root hydraulic conductivity more severely than $\mathrm{NaCl}$. Similar to $\mathrm{NaCl}$, reduction in root conductivity due to PEG was attributed to reduced root permeability. Reduction in root permeability might result from root suberization, inhibited root hair formation, and oxygen deficiency around the roots. Growth of root hairs in redtop grass seedlings and in Vicia faba was completely inhibited by a PEG concentration of $-0.2 \mathrm{MPa}$ (Jackson, 1962; Zahran and Sprent, 1986). It was suggested by Mexal et al. (1975) that the main damage of PEG to plants was caused by low oxygen solubility and slow oxygen transport to the roots. In the present study, after the termination of the first 4 experiments when the roots were removed and washed from the soil, there was an indication that the root system in PEG treatments suffered aeration deficiency since PEG-treated soil was found to be firmer and sticky. Furthermore, under osmotic stress, citrus roots exhibited early suberization of the endodermis and root hairs were directly affected by soil water conditions (Cossmann, 1940). 


\section{Effect of $\mathrm{NaCl}$ on Stomatal Conductance}

In all experiments, stomatal conductance was reduced significantly with an increase in $\mathrm{NaCl}$ or PEG concentrations. It is apparent from Fig. 8 that there is a strong correlation $(R=0.99)$ between stomatal conductance and root conductivity. Even though there was a strong correlation, closure of stomata might not be caused entirely by salinity-induced water stress. This possibility was based on the data presented in Table 17 which showed leaf turgor maintenance in salt treated plants. Stomatal closure was similarly reported in certain glycophytes when grown under saline conditions, even when leaf turgor was maintained (Gale et al, 1967; Meiri and Poljakoff-Mayber, 1970). 0'Leary (1969) also found that stomatal conductance of beans grown in salinized solutions was also lower than that of control plants. He suggested that the increase in resistance (or decrease in conductance) in the water flow pathway could result in the bean leaves experiencing physiological drought even if osmotic adjustment occurred.

The work of Walker and his coworkers showed more clearly the importance of sodium concentration in affecting stomata of citrus under salinity stress. Stomatal recovery occurred in leaves of stress-relieved Etrog citron ( $\underline{C}$. medica) even though the leaves retained high chloride concentrations and low sodium concentrations (Walker et al., 1982). There was a failure of stomatal recovery of Valencia leaves on other citrus rootstocks which was associated with retention of high sodium concentration (Walker et al., 1983). It is possible that high amounts of sodium replaced potassium in the vacuoles and guard cells and caused stomata to close (Behbondian et al., 1986). 
Stomatal behavior in citrus under $\mathrm{NaCl}$ stress is mainly affected by ion accumulation and therefore, better associated with the leaf osmotic potential and not the bulk turgor potential of the leaves.

\section{Effect of PEG on Stomatal Conductance}

Stomatal conductance in citrus was more reduced under PEG stress than under $\mathrm{NaCl}$ stress (Figs. 9, 10). These results agreed with those of Plaut and Federman (1985) and with Sanchez-Diaz et al. (1982) who found that PEG decreased leaf conduction and carbon dioxide fixation rate in tomato and legume plants more severely than did $\mathrm{NaCl}$. Reduction in stomatal conductance due to PEG might be attributed to several factors such as drought stress caused by reduced water flow to the shoots and to translocation of PEG to the leaves. It was suggested by Lawlor (1970) that PEG blocked the water pathway and induced desiccation in plants. It was also concluded that PEG damage was due to its uptake and translocation throughout the plant (Emmert, 1974; Kaufmann and Eckard, 1971; Lagerwerff et al., 1961; Lawlor, 1970). It is possible that PEG was absorbed and translocated in leaves of citrus seedlings since PEG caused leaf necrosis. Effect of $\mathrm{NaCl}$ and PEG on Chlorophyll

Leaf chlorophyll content was the only variable more significantly affected in So than in CM (Table 14). For SO seedlings, chlorophyll reduction due to $\mathrm{NaCl}$ was similar to that due to PEG. However, for CM, chlorophyll reduction was more severe under PEG than under $\mathrm{NaCl}$ treatments. Since $\mathrm{NaCl}$ did not reduce chlorophyll as much in $\mathrm{CM}$, and since $C M$ is a chloride excluder, chlorophyll reduction could be mainly attributed to chloride accumulation in the leaves. Contrary to this, Bhambota and Kanwar (1970) attributed salt induced chlorophyll reduction in sweet orange to sodium uptake and to a reduction in magnesium and 
iron uptake. Leaf chlorophyll content has also been found to be reduced in many other crops such as beans (Seemann and Critchley, 1985) and spinach (Downton et al., 1985; Robinson et al., 1983). In other photosynthetic related processes, $\mathrm{NaCl}$ was found to inhibit the Hill reaction (Sivtsev, 1973) and increase the hydrolytic activity of chlorophyllase (Sivtsev et al., 1973) in tomato leaves. Effect of $\mathrm{NaCl}$ on Leaf Thickness and Succulence

Increases in leaf succulence and thickness have been attributed to changes in cell size, cell layer number, or a combination of both. In the present study, examination of leaf sections by light microscopy (Fig. 18) suggested that an increase in spongy mesophyll cell size rather than an increase in cell number caused the greater leaf thickness and succulence. Similar conclusions were made with tobacco (Flowers et al., 1986), spinach (Robinson et al., 1983), and beans (Wignarajah et a 1, 1975). However, in Atriplex, cotton, and Salicornia herbacea, leaf thickness and succulence increased not only due to a development of larger cells but also to an increase in cell layers of the mesophyll. In most circumstances, increase in succulence was accompanied by an increase in sodium and chloride concentrations in the leaves.

\section{Growth of Citrus Rootstock Seedlings under NaCl and PEG Stresses}

The results of this study are consistent with those of other investigators who classified citrus as a salt sensitive crop. Growth was reduced at least $20 \%$ in the rootstocks ranked as tolerant when irrigated with a nutrient solution containing as little as $1 \mathrm{~g} \mathrm{NaCl/L}$ $(-0.1 \mathrm{MPa})$. The higher salinity damage occurring in Experiment 2 in comparison to Experiment 1 was thought to be mainly due to the more rapid onset of salt treatment and to the longer duration of salt treatment . 
Relationship of Leaf Damage Symptoms to Growth Reduction

Significant growth reduction and physiological disturbances were found to precede visible leaf symptoms. When comparing shoot dry weight (Table 2) to visual symptoms (Table 6), growth reduction up to $30 \%$ occurred without being accompanied by visible leaf damage symptoms. Similar to this, the use of saline irrigation water decreased grapefruit and orange yields from 18 to $54 \%$ without apparent toxicity symptoms (Bielorai et al., 1978, 1983: Bingham et al., 1974; Francois and Clark, 1980). Salinity effects develop slowly so that leaf injury symptoms appear only after a certain period of time. Leaf symptoms are, therefore, a poor parameter for evaluating salt damage. Root Growth and Distribution under $\mathrm{NaCl}$ and PEG Stresses

The present study showed that root growth of citrus was severely reduced even at relatively low concentrations of $\mathrm{NaCl}$ and PEG in the nutrient solution. The average daily root growth rate was reduced by 30 to $50 \%$ at $-0.12 \mathrm{MPa} \mathrm{NaCl}$ and PEG, respectively (Table 15).

Nevertheless, these results showed that citrus roots were able to grow slowly at an osmotic potential of $-0.24 \mathrm{MPa}$. Bevington and Castle (1985) reported that citrus root growth was significantly reduced at a soil matric potential of $-0.05 \mathrm{MPa}$ and Monselise (1947) reported that citrus root growth was very limited at soil water potentials of -0.75 to $-0.80 \mathrm{MPa}$. Within the limited range of $\mathrm{NaCl}$ and $\mathrm{PEG}$ used in the current study, it is not possible to specify a water potential value at which growth stopped completely.

Root distribution of stressed seedlings was altered in comparison to root distribution of control seedlings. Stressed seedlings had a higher percentage of the total root system in the top and a much lower percentage at the bottom of the root boxes (Table 15). Seedlings 
receiving $\mathrm{NaCl}$ or $\mathrm{PEG}$ treatments produced, therefore, a shallow root system.

Root and shoot growth was found to be cyclic (2-month cycle). in young citrus seedlings even when the plants were under $\mathrm{NaCl}$ or PEG stress (Fig. 13). It was observed that immediately following the cessation of shoot elongation, a rapid increase in root growth occurred and continued until the initiation of the next shoot growth flush. Alteration of root and shoot growth activity in citrus has been described earlier under non-stressed conditions by other investigators (Bevington and Castle, 1982, 1985; Marloth, 1949).

\section{Effect of Non-Uniform Salinity and Water Stress}

Soil water content and salinity levels are seldom uniform in the field, particularly with the use of microsprinklers which may irrigate only a portion of the root zone. A split-root experiment was designed to determine if non-stressed portions of the root system compensated for the decrease in water and nutrient uptake by the stressed portions so that plants could withstand substantial amounts of stress.

The non-stressed roots were found to partially compensate for the decrease in water by the stressed roots. Water uptake from each of the 2 sides was estimated since the amount of water added each time was based on bringing the soil to slightly above field capacity. Water uptake by the unsalinized half of the root system increased when the other half of the root system was subjected to salinity stress. Similar results were obtained on corn (Bingham and Garber, 1970) and alfalfa (Shalhevet and Bernstein, 1968). Watering one part of the root system of wheat (Lawlor, 1973) and tomato (Tan et al., 1981) resulted in a compensatory increase in water uptake by other parts of the root system so that plant water relations remained relatively unaffected. However, 
compensation was not seen in beans and barley because plants with half their roots in saline solutions had growth and water relations values intermediate between those of plants grown in non-saline solutions and plants grown in saline solutions (Kirkham et al., 1969, 1972). Only partial compensation occurred in so seedlings since plants with half their root systems in either $\mathrm{NaCl}$ or PEG solutions had shoot and root dry weight and leaf water and osmotic potential values closer to those of the non-stressed control than to those with completely stressed root system (Tables 16,17 ).

No soil water measurements were recorded in the split-root experiment. However, the root dry weight data (Table 16) might indicate that some water could have been transported through roots from the non-stressed half to the stressed half. Several investigators have demonstrated that plant roots can absorb water from a wet soil, transport the water, and build up the moisture of a dry soil. In a study using wheat plants with roots split between soil and nutrient solution, Kirkham (1980) showed transport of water from the solution to the soil suggesting that roots were acting like wicks.

While the present study was carried out under greenhouse conditions, it provided several useful observations which are relevant to field conditions. Citrus as a deep and dense rooted crop may tolerate certain levels of salinity as long as a portion of the root system remains in a relatively non-saline soil.

\section{Comparative Effects Between $\mathrm{NaCl}$ and $\mathrm{PEG}$}

Although PEG-induced water stress is osmotic in nature and may not be exactly the same as the water stress occurring in soils, it is a sensitive method that can create small degrees of vater stress on a continuous basis not easily induced in soils (Gergely et al., 1980). 
Polyethylene glycol was used satisfactorily by several investigators for various species (Janes, 1966; Kaufmann and Eckard, 1971; Kaul, 1966) in which the response to PEG was attributed to a decrease in osmotic. potential with no obvious toxic effects.

Injuries to citrus rootstock seedlings by PEG were greater than the osmotic effects per se. Damage due to ionic effects of sodium and chloride were less than the damage from non-ionic PEG. Excess damage might be attributed to insufficient transport of oxygen to the root system due to high PEG viscosity and its effect on soil stickiness and firmness. Damage could also be caused by PEG uptake and transport to the leaves where it caused dehydration and leaf damage. 0xygen availability could be significantly reduced at relatively low PEG concentrations (Mexal et al., 1975). Absorption and secretion of PEG 4000 and 6000 by Solanaceae species was observed (Yaniv and Verker, 1983), as well as the appearance of white material on the upper surface of bean leaves grown in PEG 20000 (Lagerwerff et al., 1961).

Studies with other species have shown $\mathrm{NaCl}$ to be either more damaging or less damaging than PEG. Similar to results of the present investigation, the damaging effect of PEG was found to be higher than $\mathrm{NaCl}$ at equal osmotic potentials in tobacco (Heyser and Nabors, 1981) and tomato (Plaut and Federman, 1985). However, growth of beans, maize, and barley was substantially better with PEG than isosmotic salt solutions (Lagerwerff and Eagle, 1961; Storey and Wyn Jones, 1978). The matter of separating toxic ion effects from osmotic effects of salts on citrus was not clearly determined in this study. This important question merits continued investigation involving the testing of other non-ionic compounds or nutrient solutions at different concentrations. 
SUMMARY AND CONCLUSIONS

The conclusions from this study are summarized below:

1. Differences in sodium and chloride exclusion capacity were found among citrus rootstocks. This study was the first to show that ML was a chloride and sodium accumulator while SC and CC were chloride accumulators but sodium excluders.

2. Citrus rootstocks were found to be sensitive to $\mathrm{NaCl}$ since none of these rootstocks was able to exclude both chloride and sodium. Furthermore, sodium and chloride exclusion capacities were lost at a concentration of $-0.20 \mathrm{MPa}$. Differences in $\mathrm{NaCl}$ sensitivity among rootstocks were also found. Cleopatra mandarin and so were the least sensitive, ML and PT were the most sensitive, and RL, SC, and CC were intermediate in sensitivity.

3. This study was also the first to show that salt tolerance in citrus rootstocks was not strongly correlated with chloride and sodium exclusion. Even though so accumulated higher amounts of chloride and sodium than PT, SC, and CC at an osmotic potential of $-0.10 \mathrm{MPa} \mathrm{NaCl}$, growth of SO was as good as CM and significantly better than the remaining rootstocks. Water relations measurements also showed that so was similar to $C M$ but less stressed than the other rootstocks. Sour orange and $C M$ acted through 2 different mechanisms to tolerate salinity stress. Cleopatra mandarin tolerated high concentrations of $\mathrm{NaCl}$ by partial exclusion of chloride. Sour orange tolerated $\mathrm{NaCl}$ by possible 
compartmentation of sodium and chloride and their exclusion from the cytoplasm where they could inhibit metabolic processes.

4. Sodium chloride usually caused less damage than PEG to seedlings of 7 citrus rootstocks. Both $\mathrm{NaCl}$ and PEG caused significant growth depression and physiological disturbances even at a concentration of $-0.10 \mathrm{MPa}$. The response of citrus rootstocks to the 2 compounds was different suggesting that $\mathrm{NaCl}$ and $\mathrm{PEG}$ acted through different mechanisms. Addition of PEG to the irrigation water probably reduced aeration and also moved to the shoots where it caused plant dehydration and leaf damage. Addition of $\mathrm{NaCl}$ reduced water uptake but increased leaf sodium and chloride concentrations. This increased leaf thickness and succulence and caused leaf burn.

5. Growth reduction and physiological disturbances were found to precede visible damage. Growth was reduced up to $30 \%$ without being accompanied by visible leaf injury symptoms. Leaf burn symptoms developed only after a threshold value of chloride accumulation (1q) was reached. Leaf burn symptoms developed too slowly to accurately evaluate salt damage.

6. In all $\mathrm{NaCl}$ and PEG treatments, growth was depressed and water balance was disturbed. Growth depression was shown by plants that had lower dry weight, fewer leaves per plant, smaller area of individual leaves, shorter height, smaller stem cross sectional area, and smaller root systems. Disturbance in water balance was shown by reductions in root hydraulic conductivity, stomatal conductance, transpiration, water use, and leaf water and osmotic potentials.

7. Root observation boxes were used to follow root growth and distribution under stressed and non-stressed conditions. Root growth usually alternated with shoot growth but this alternating pattern was 
not shifted by $\mathrm{NaCl}$ and PEG stresses. However, root growth and distribution were significantly affected. Seedlings receiving $\mathrm{NaCl}$ or PEG treatments, produced smaller and shallower root systems with the majority of the roots occurring in the top layer.

8. Although roots were in direct contact with $\mathrm{NaCl}$ and PEG solutions, shoot growth was more reduced than root growth. The monthly or daily amount of new flush area was found to be a sensitive measure of the effects of $\mathrm{NaCl}$ on plants. Root conductivity correlated better with salinity tolerance among rootstocks than did total fibrous root length.

9. Stomatal conductance was greatly reduced even though leaf turgor was maintained. This reduction was attributed to a decrease in water flow to the shoots and to a suggested lack of osmotic adjustment of the guard cells. Reduction in stomatal conductance correlated with an accumulation of sodium and chloride in the leaves and depressed transpiration and water use. Reduction in water consumption of the stressed seedlings was attributed to lower transpiration rate per leaf and also to smaller total transpiring area per plant.

10. Examination of leaf sections by light microscopy suggested that an increase in cell size rather than cell number was responsible for the increased leaf thickness. Leaf succulence and thickness increased due to the development of larger cells in the spongy mesophyll in response to ion accumulation. Microscopic examination also showed a decrease in leaf intercellular space and the number of chloroplasts under $\mathrm{NaCl}$ stress. Leaf chlorophyll content decreased in salt-treated seedlings which agreed with microscopic observations. Chlorophyll reduction was mainly attributed to chloride accumulation in the leaves.

11. The split-root experiment demonstrated that citrus shoot growth did not correlate with the average osmotic potential of the 2 root 
halves. It demonstrated also that citrus could withstand substantial amounts of stress as long as half of the root system was growing in a non-stressed environment.

12. Sodium chloride reduced calcium and magnesium contents but increased phosphorus content in the leaves. Sodium chloride decreased leaf potassium content only in sodium-accumulator rootstocks (so, cM, $R L$, and $\mathrm{ML}$ ).

13. This study showed that the beneficial effect of adding calcium to saline irrigation water depended on the anion accompanying the salt. Calcium sulfate but not calcium chloride was found to overcome the detrimental effects of $\mathrm{NaCl}$ by decreasing the concentrations of sodium and chloride in the leaves. 
APPENDIX 


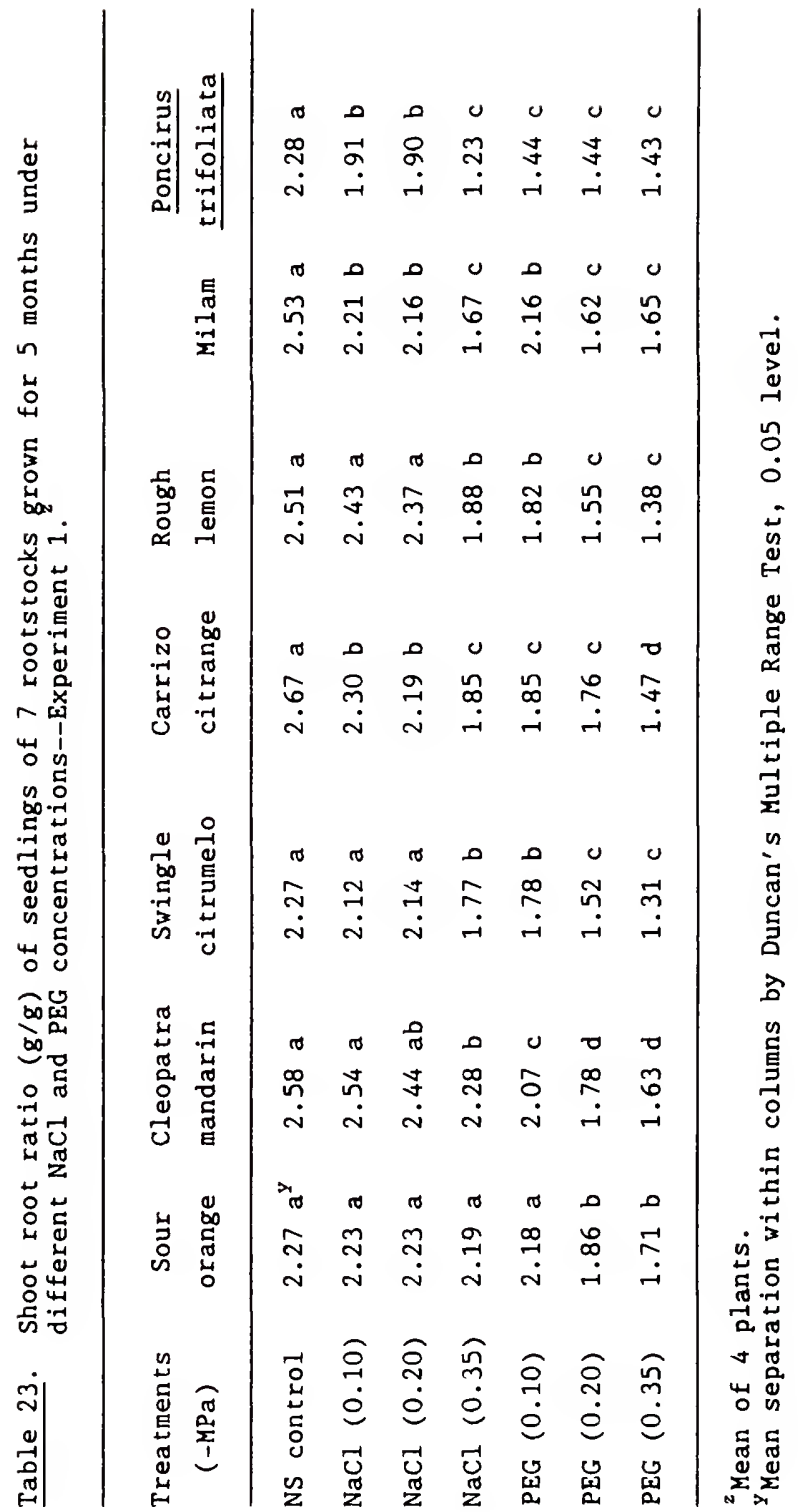




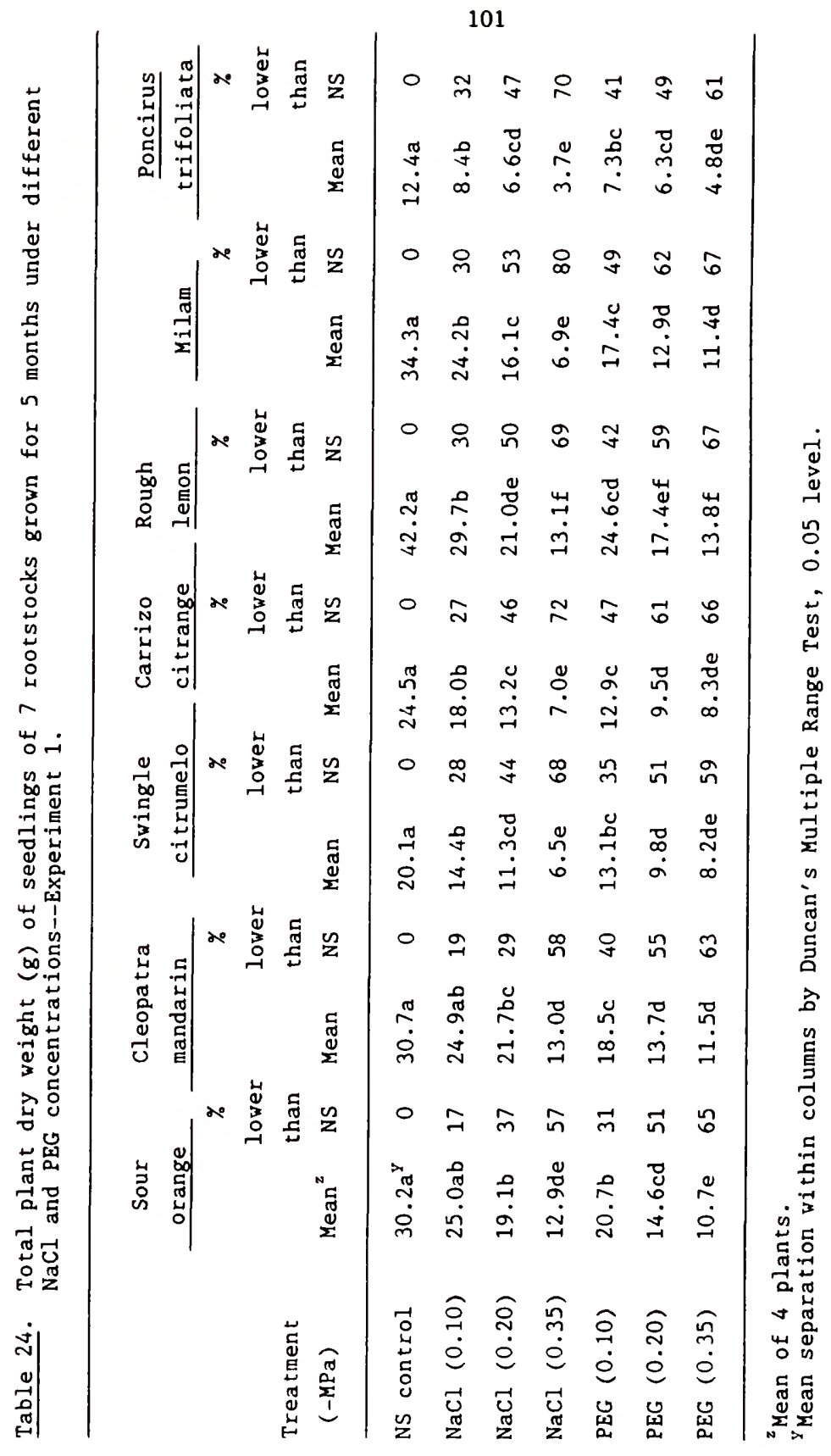




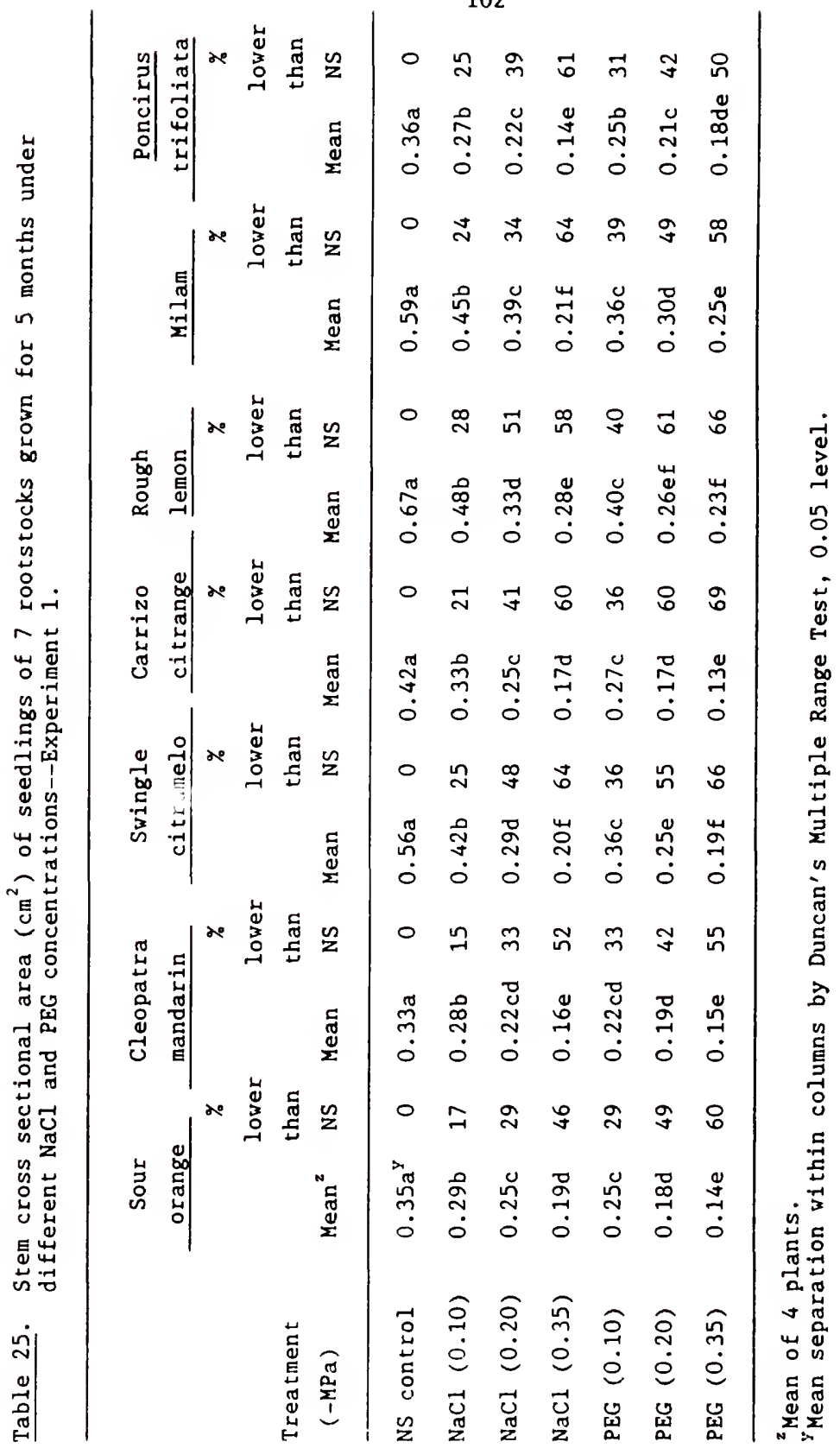




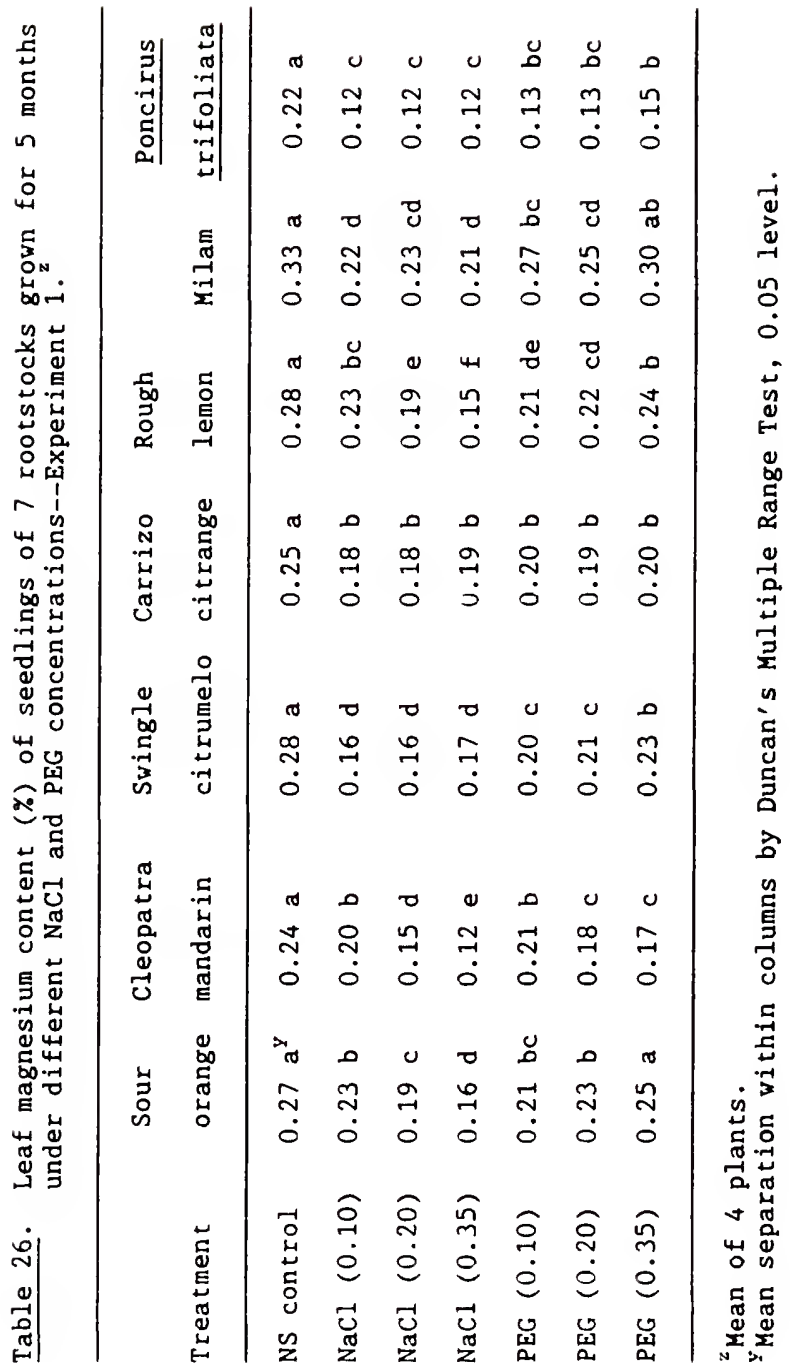




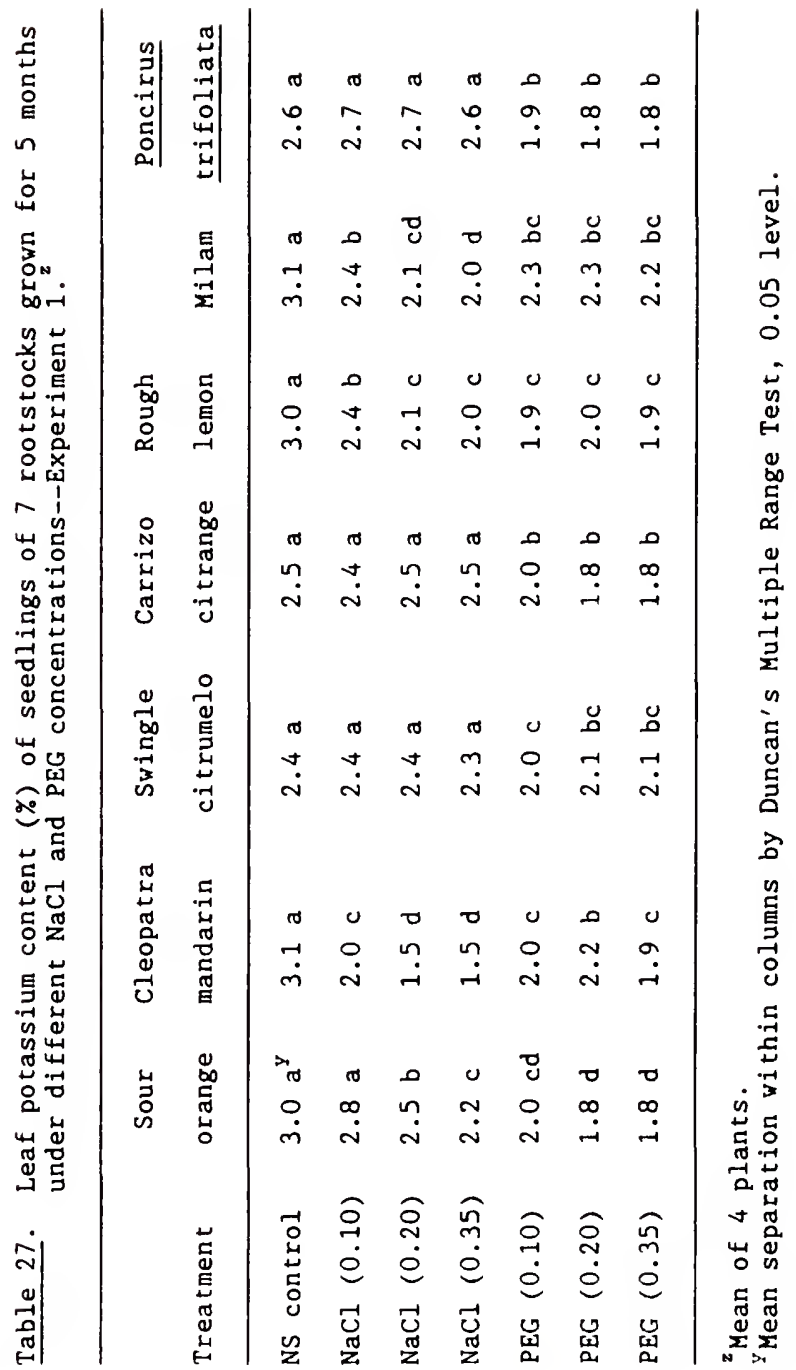




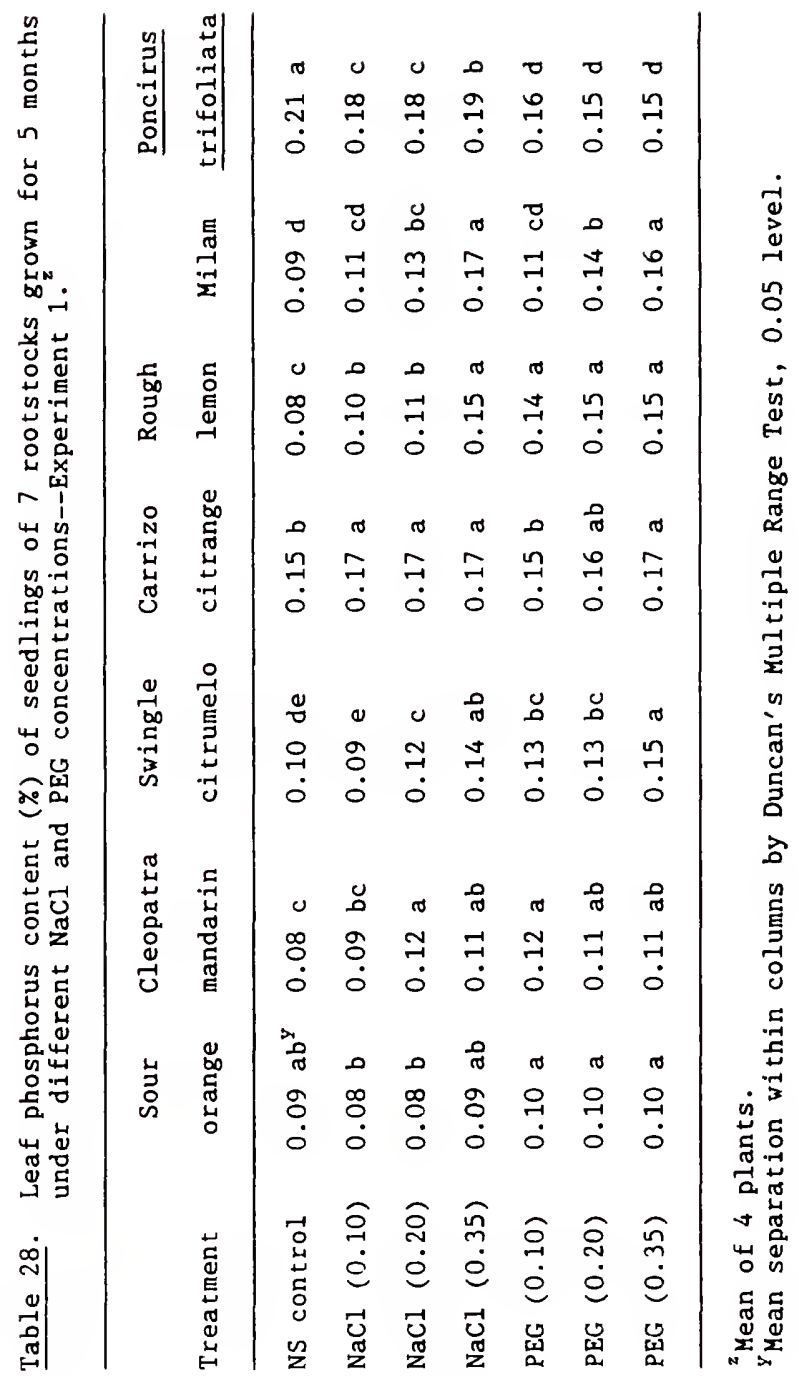




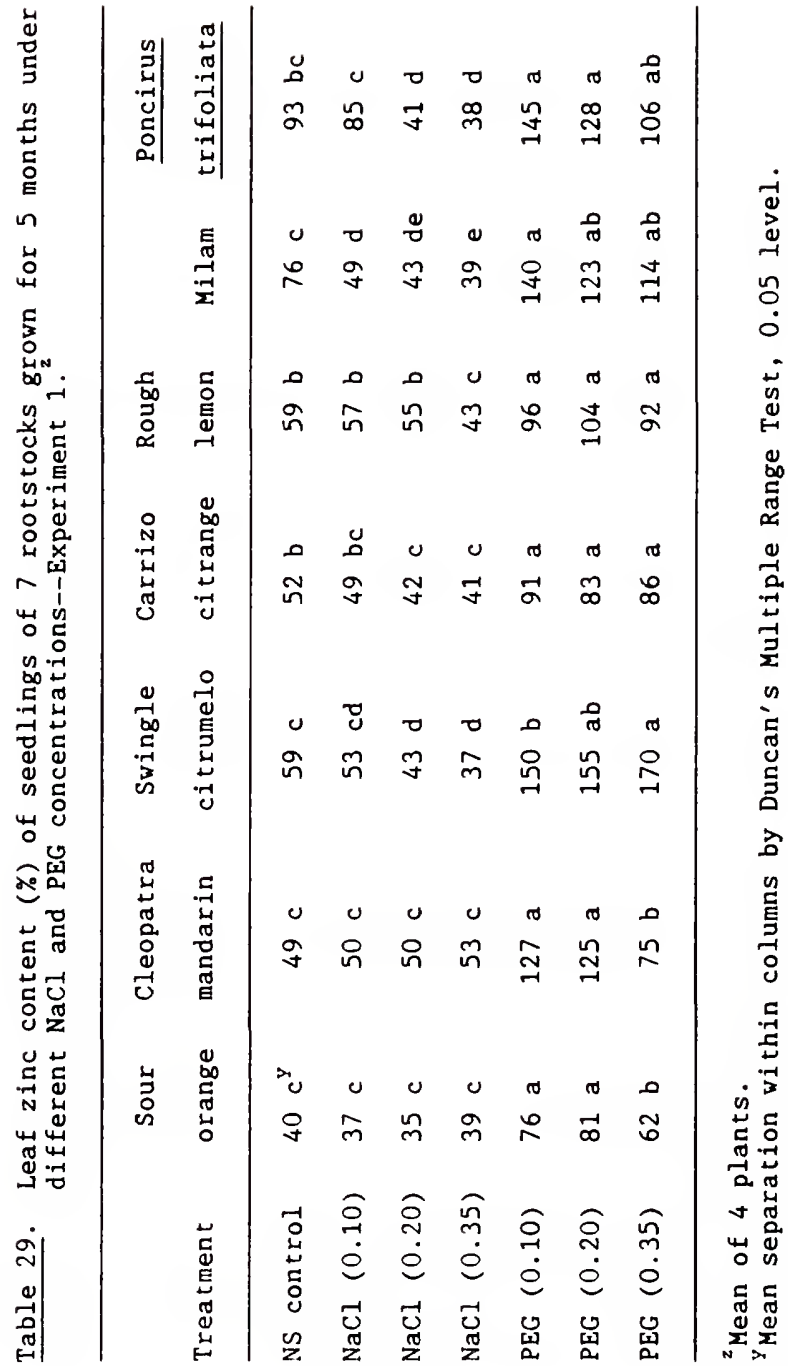




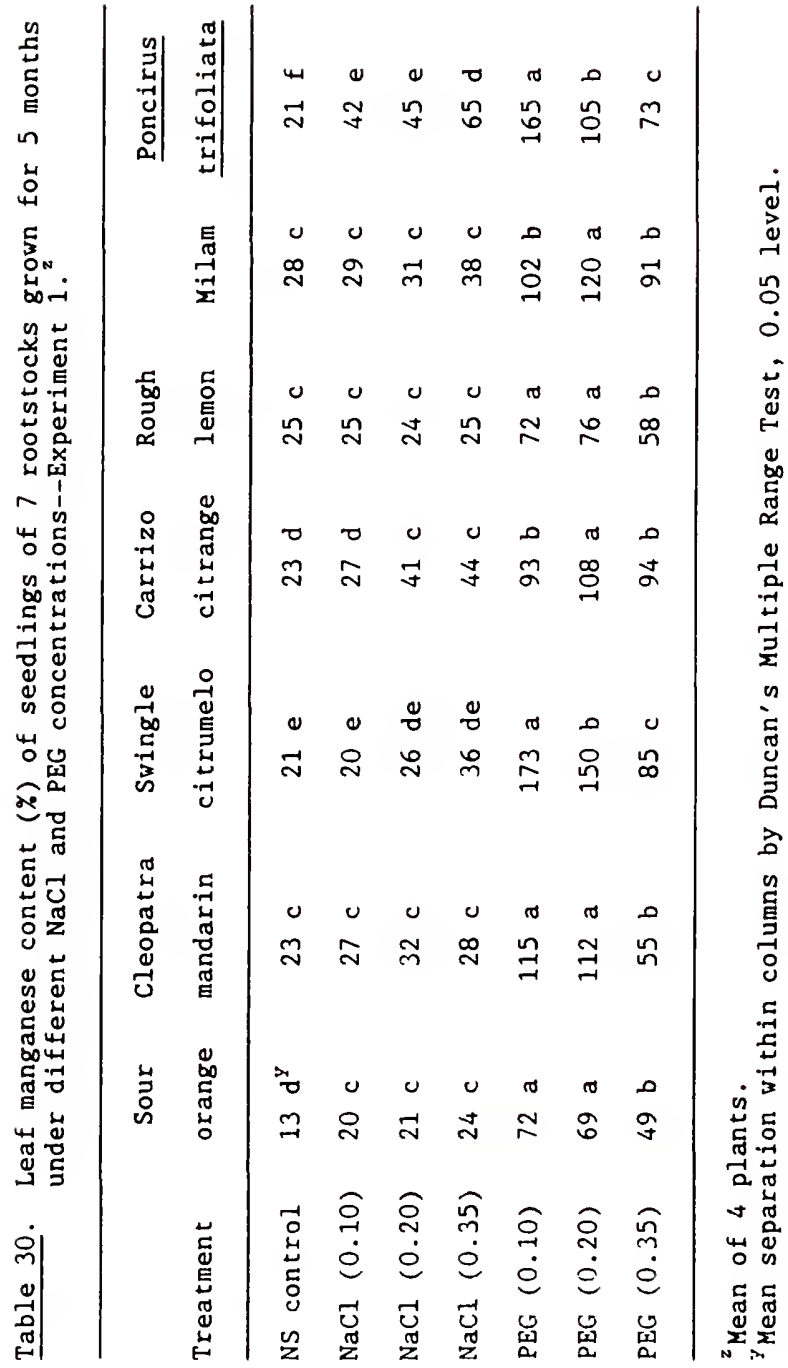


Table 31. Seedling height $(\mathrm{cm})$ of seedlings of 2 rootstocks grown for 6 months under different $\mathrm{NaCl}$ and PEG concentrations--Experiment 2 .

\begin{tabular}{|c|c|c|c|c|}
\hline \multirow[b]{2}{*}{$\begin{array}{l}\text { Trea tment } \\
(-\mathrm{MPa})\end{array}$} & \multicolumn{2}{|c|}{ Sour orange } & Cleopatra & \multirow{2}{*}{$\begin{array}{l}\text { mandarin } \\
\text { \% lower } \\
\text { than NS }\end{array}$} \\
\hline & $\operatorname{Mean}^{2}$ & $\begin{array}{l}\text { \% lower } \\
\text { than NS }\end{array}$ & Mean & \\
\hline NS control & $104 a^{y}$ & 0 & 106 a & 0 \\
\hline $\mathrm{NaCl}(0.10)$ & $64 \mathrm{~b}$ & 39 & $79 \mathrm{~b}$ & 26 \\
\hline $\mathrm{NaCl}(0.20)$ & $52 \mathrm{c}$ & 50 & $71 \mathrm{c}$ & 33 \\
\hline $\mathrm{NaCl}(0.35)$ & $48 \mathrm{~cd}$ & 54 & $55 \mathrm{~d}$ & 48 \\
\hline PEG $(0.10)$ & $60 \mathrm{~b}$ & 42 & $63 c$ & 41 \\
\hline PEG $(0.20)$ & 41 de & 61 & $54 d$ & 49 \\
\hline PEG (0.35) & $38 \mathrm{e}$ & 64 & $43 \mathrm{e}$ & 59 \\
\hline
\end{tabular}

${ }^{z}$ Mean of 7 plants.

${ }^{Y}$ Mean separation within columns by Duncan's Multiple Range Test, 0.05 level. 
Table 32. Total leaf area $\left(\mathrm{cm}^{2}\right)$ of seedlings of 2 rootstocks grown for 6 months under different $\mathrm{NaCl}$ and PEG concentrations--Experiment 2 .

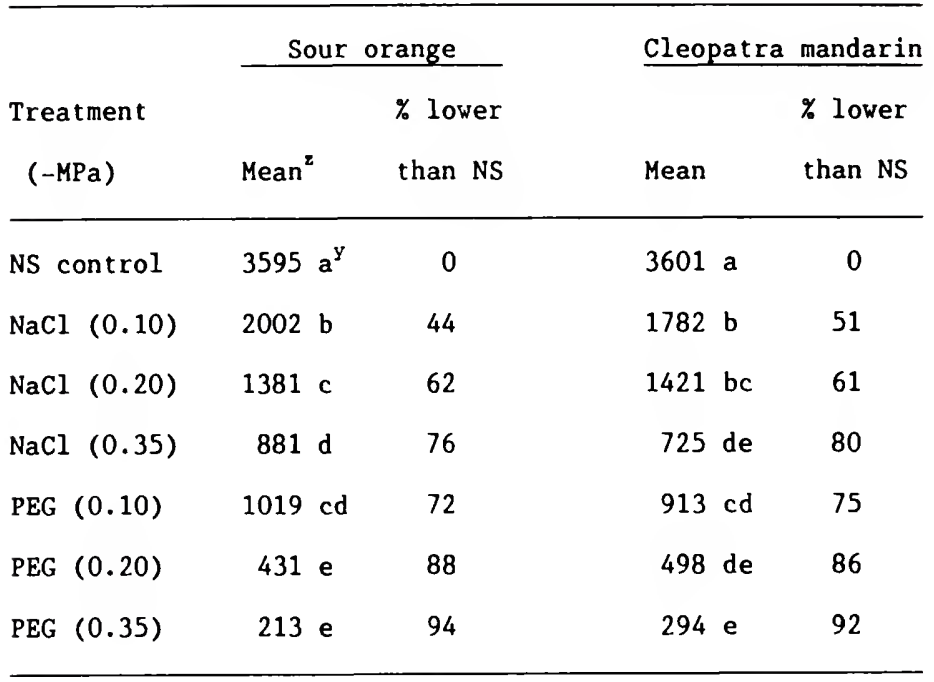

${ }^{2}$ Mean of 7 plants.

YMean separation within columns by Duncan's Multiple Range Test, 0.05 level. 
Table 33. Specific leaf weight $\left(\mathrm{mg} / \mathrm{cm}^{2}\right)$ of seedlings of 2 rootstocks grown for 6 months under different $\mathrm{NaCl}$ and PEG concentrations--Experiment 2."

\begin{tabular}{lccccc}
\hline & \multicolumn{2}{c}{ Sour orange } & & \multicolumn{2}{c}{ Cleopatra mandarin } \\
\cline { 2 - 4 } & Fresh wt & Dry wt & & Fresh wt & Dry wt \\
Treatment & basis & basis & & basis & basis \\
\hline NS control & $25.1 \mathrm{a}^{\mathrm{y}}$ & $9.0 \mathrm{~b}$ & $18.7 \mathrm{~b}$ & $8.3 \mathrm{c}$ \\
$\mathrm{NaCl}(0.10)$ & $27.5 \mathrm{a}$ & $9.5 \mathrm{~b}$ & $18.9 \mathrm{~b}$ & $8.4 \mathrm{c}$ \\
NaCl (0.20) & $27.9 \mathrm{a}$ & $9.6 \mathrm{~b}$ & $19.1 \mathrm{~b}$ & $8.5 \mathrm{c}$ \\
NaCl (0.35) & $28.2 \mathrm{a}$ & $9.6 \mathrm{~b}$ & $21.1 \mathrm{a}$ & $8.7 \mathrm{c}$ \\
PEG (0.10) & $18.2 \mathrm{~b}$ & $11.2 \mathrm{a}$ & $18.3 \mathrm{~b}$ & $10.1 \mathrm{~b}$ \\
PEG (0.20) & $17.4 \mathrm{bc}$ & $11.5 \mathrm{a}$ & $18.2 \mathrm{~b}$ & $12.1 \mathrm{a}$ \\
PEG (0.35) & $14.4 \mathrm{c}$ & $11.3 \mathrm{a}$ & $18.1 \mathrm{~b}$ & $11.9 \mathrm{a}$ \\
\hline
\end{tabular}

${ }^{z}$ Mean of 7 plants.

'Mean separation within columns by Duncan's Multiple Range Test, 0.05 level. 


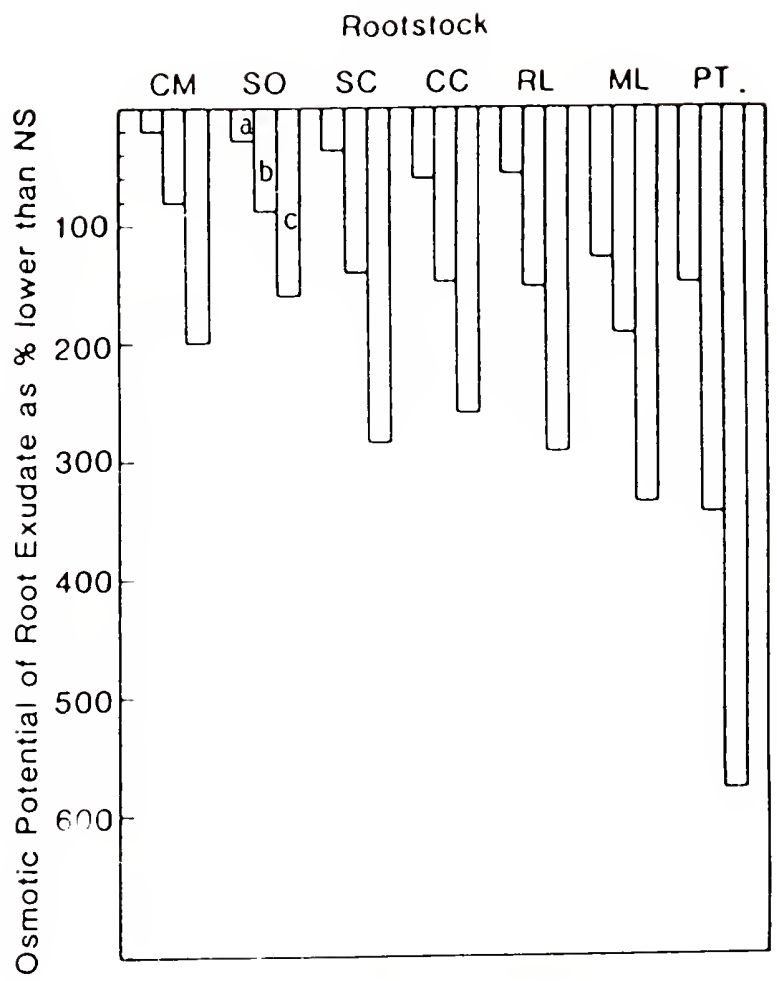

Fig. 20. Effect of $3 \mathrm{NaCl}$ concentrations ( $\mathrm{a}=-0.10 \mathrm{MPa}$, $\mathrm{b}=-0.20 \mathrm{MPa}, \mathbf{c}=-0.35 \mathrm{MPa}$ ) on the osmotic potential of root exudate collected from seedlings of 7 citrus rootstocks. 


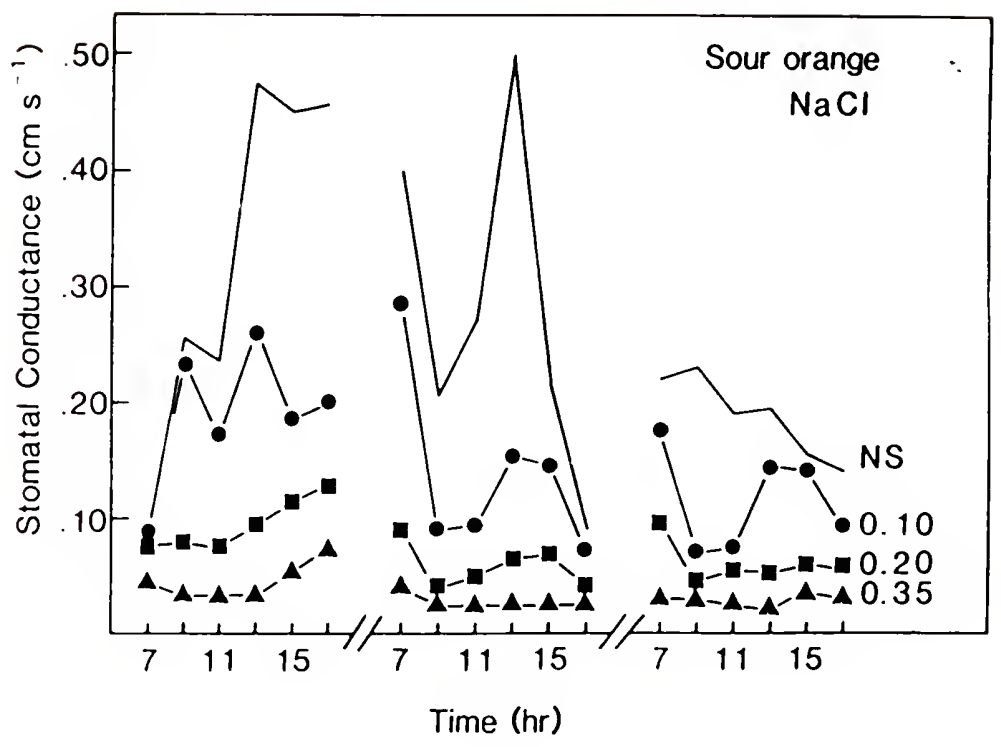

Fig. 21. Relationship of time of day to stomatal conductance of sour orange seedlings irrigated with nutrient solution containing no salt (NS) or with added $\mathrm{NaCl}$ during 3 consecutive days. Measurements were started on April 9, 1986. 


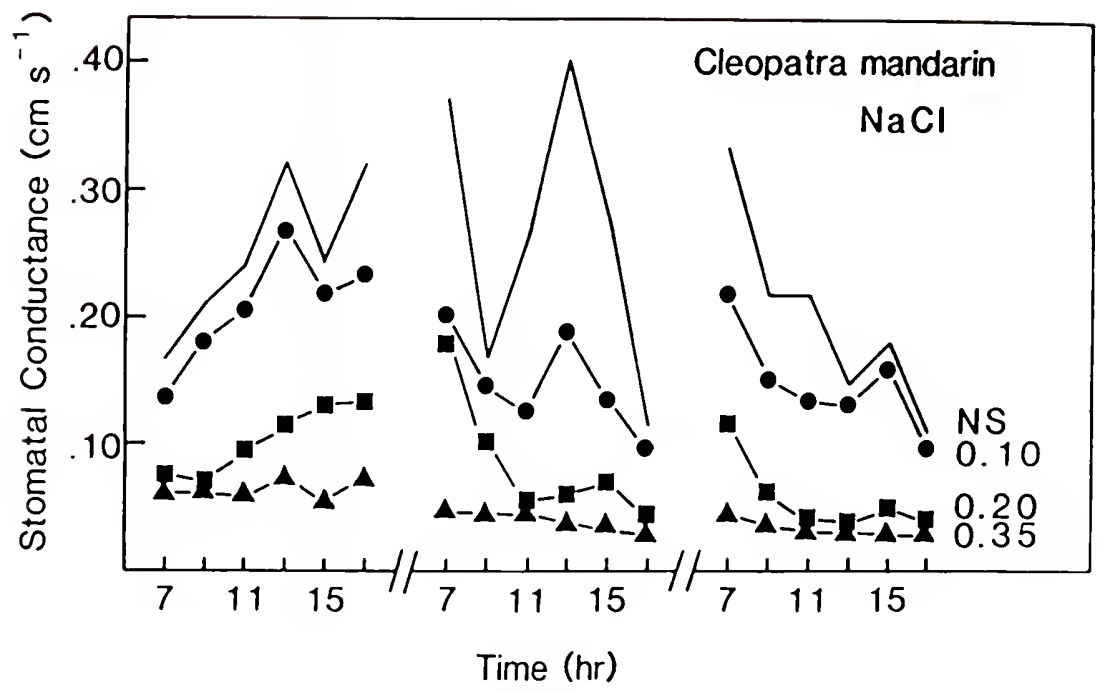

Fig. 22. Relationship of time of day to stomatal conductance of Cleopatra mandarin seedlings irrigated with nutrient solution containing no salt (NS) or with added $\mathrm{NaCl}$ during 3 consecutive days. Measurements were started on April 9, 1986. 


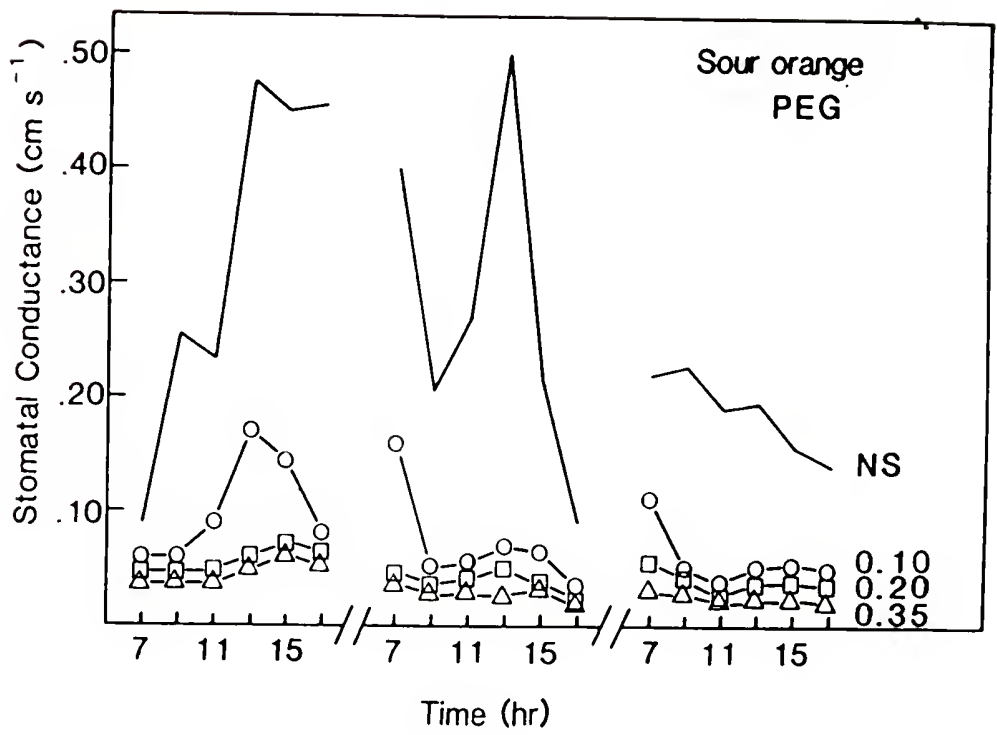

Fig. 23. Relationship of time of day to stomatal conductance of sour orange seedlings irrigated with nutrient solution containing no salt (NS) or with added PEG during 3 consecutive days. Measurements were started on April 9, 1986. 


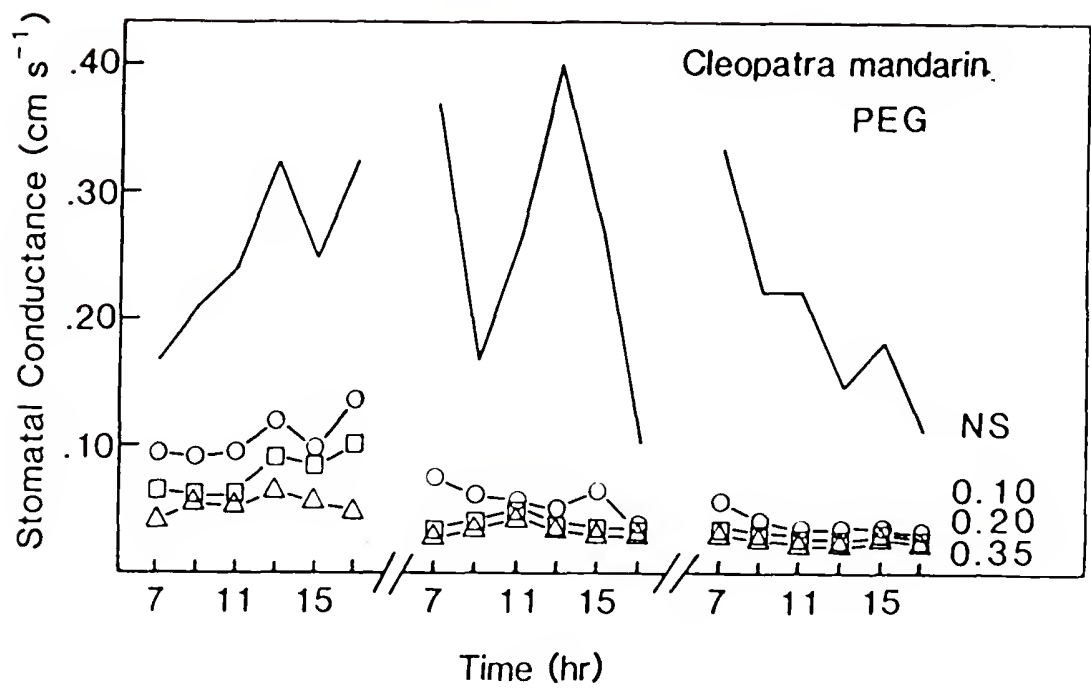

Fig. 24. Relationship of time of day to stomatal conductance of Cleopatra mandarin seedlings irrigated wi th nutrient solution containing no salt (NS) or with added PEG during 3 consecutive days. Measurements were started on April 9, 1986. 


\section{LITERATURE CITED}

Abdel-Messih, M.N., A.M. Rokba, M.A. El-Shourbagy and M.A.

El-Nokrashy. 1979. Effect of different salinity levels on leaf mineral composition of some citrus stock seedlings. Egypt. J. Hort. 6(1):81-89.

Aldrich, D.G., E.R. Parker and H.D. Chapman. 1945. Effects of several nitrogenous fertilizers and soil amendments on the physical and chemical properties of an irrigated soil. Soil Sci. 59:299-312.

Arnon, D.I. 1949. Copper enzymes in isolated chloroplasts. Polyphenol-oxidase in Beta vulgaris. Plant Phyiol. 24:1-15.

Babaeva, Z.A., R.G. Butenko and B.P. Strogonov. 1968. Influence of salinization of the nutrient medium on the growth of isolated carrot tissues. Soviet Plant Physiol. 15:75-82.

Behboudian, M.H., E. Torokfalvy and R.R. Walker. 1986. Effects of salinity on ionic content, water relations and gas exchange parameters in some citrus scion-rootstock combinations. Scientia Horticulturae 28:105-116.

Ben-Hayyim, G. and J. Kochba. 1983. Aspects of salt tolerance in a NaCl-selected stable cell line of Citrus sinensis. Plant Physiol. 72:685-690.

Ben-Hayyim, G., P. Spiegel-Roy and H. Neumann. 1985. Relation between ion accumulation of salt-sensitive and isolated stable salt-tolerant cell lines of Citrus aurantium. Plant Physiol. 78:144-148.

Bernstein, L. 1961. Osmotic adjustment of plants to saline media. I. Steady state. Amer. J. Bot. 48:909-918.

Bernstein, L. 1963. Osmotic adjustment of plants to saline media. II. Dynamic phase. Amer. J. Bot. 50:360-370.

Bernstein, L. 1969. Salinity factors and their limits for citrus culture. Proc. First Int. Citrus Symposium 3:1779-1782.

Bernstein, L. and H.E. Hayward. 1958. Physiology of salt tolerance. Ann. Rev. Plant Physiol. 9:25-46.

Bevington, K.B. and W.S. Castle. 1982. Development of the root system of young valencia orange trees on rough lemon and Carrizo citrange rootstocks. Proc. Fla. State Hort. Soc. $95: 33-37$. 
Bevington, K.B. and W.S. Castle. 1985. Annual root growth pattern of young citrus trees in relation to shoot growth, soil temperature, and soil water content. J. Amer. Soc. Hort. Sci. $110(6): 840-845$.

Bhambota, J.R. and J.S. Kanwar. 1969. Salinity tolerance of some rootstocks and scions of citrus species. Proc. First Int. Citrus Symposium 3:1833-1836.

Bhambota, J.R. and J.S. Kanwar. 1970. Effect of different salt concentrations on sweet-orange (Citrus sinensis L) Osbeck, Indian J. Agric. Sci. 40(6):485-494.

Bielorai, H. 1977. The effect of drip and sprinkler irrigation on grapefruit yield, water use and soil salinity. Proc. Int. Soc. Citriculture 1:99-103.

Bielorai, H. 1985. Moisture, salinity and root distribution of drip irrigated grapefruit. Proc. Third Int. Drip/Trickle Irrig. Congress $2: 562-567$.

Bielorai, H. and J. Levy. 1971. Irrigation regimes in a semi-aird area and their effects on grapefruit yield, water use and soil salinity. Israel J. Agric. Res. 21:3-12.

Bielorai, H., J. Levy and J. Shalhevet. 1973. The effect of irrigation frequency and water quality on grapefruit yield, water use and soil salinity. Proc. Int. Soc. Citriculture $1: 257-263$.

Bielorai, H., J. Shalhevet and Y. Levy. 1978. Grapefruit response to variable salinity in irrigation water and soil. Irrig. Sci. $1: 61-70$.

Bielorai, H., J. Shalhevet and Y. Levy. 1983. The effect of high sodium irrigation water on soil salinity and yield of mature grapefruit orchard. Irrig. Sci. 4:255-266.

Bingham, F.T. and M.J. Garber. 1970. Zonal salinization of the root system with $\mathrm{NaCl}$ and boron in relation to growth and water uptake of corn plants. Proc. Soil Sci. Soc. Amer. $34: 122-126$.

Bingham, F.T., R.J. Mahler, J. Parra and L.H. Stolzy. 1974. Long-term effects of irrigation-salinity management on a valencia orange orchard. Soil Sci. 117:369-377.

Bingham, F.T., R.J. Mahler and L.H. Stolzy. 1973. Irrigation-salinity effects on mature orange trees: growth and production. Proc. Int. Soc. Citriculture 1:293-298.

Boaz, M. 1978. Salinity management in citrus. Proc. Int. Soc. Citriculture 233-234.

Bohn, H.L., B.L. MCNeal and G.A. O'Connor. 1979. Soil Chemistry. pp.217-246. John Wiley and Sons, New York. 
Calvert, D.V. and H.J. Reitz. 1966. Salinity of water for sprinkler irrigation of citrus. Proc. Fla. State Hort. Soc. 79:73-78.

Carter, D.L. 1975. Problems of salinity in agriculture. In.Plants in Saline Environments. (A. Poljakoff-Mayber and J. Gale, eds.), pp. 25-35. Springer-Verlag, Berlin and Heidelberg.

Cerda, A., F.G. Fernandez, M. Caro and M.G. Guillen. 1979. Growth and mineral composition of two lemon varieties irrigated with saline waters. Agrochimica 23:387-396.

Chapman, v.J. 1975. The salinity problem in general, its importance and distribution with special reference to natural halophytes. In Plants in Saline Environments.

(A. Poljakoff-Mayber and J. Gale, eds.), pp.7-21. Springer-Verlag, Berlin and Heidelberg.

Chapman, H.D., H. Joseph and D.S. Rayner. 1969. Effects of variable maintained chloride levels on orange growth, yield and leaf composition. Proc. First Int. Citrus Symposium $3: 1811-1817$.

Cherif, D., E. Zid, A. Ayadi and M. Thellier. 1981. Effect du chlorure de sodium sur la croissance et l'alimentation minerale de Citrus aurantium L. (Bigaradier) et de l'hybride Poncirus trifoliata $\times$ Citrus sinensis (Citrange troyer). C. R. Acad. Sci., Paris 292:879-882.

Cherif, D., E. Zid, H. Ghorbal and A. Ayadi. 1982. Reponse de tres jeunes plants de Citrus a $\mathrm{NaCl}$ : etude comparative de deux porte-greffes Citrange Troyer et Bigardier. Oecol. Plant., 3(17): 79-85.

Cole, P.J. and M.R. Till. 1977. Evaluation of alternatives to overhead sprinklers for citrus irrigation. Proc. Int. Soc. Citriculture 1:103-106.

Cooper, w.C. 1948. A progress report for 1948 on the Texas citrus rootstock investigations. Proc. Ann. Rio Grande Valley Hort. Inst. $3: 128-154$.

Cooper, w.C. 1961. Toxicity and accumulation of salts in citrus trees on various rootstocks in Texas. Proc. Fla. State Hort. Soc. $74: 95-104$.

Cooper, W.C., W.R. Cowley and A.V. Shull. 1952a. Selection for salt tolerance of some subtropical fruit plants. Yrbk. Tex. Avocado Soc. 24-36.

Cooper, w.C. and C. Edwards. 1950. Salt tolerance of Shary Red grapefruit and Valencia orange on sour orange and cleopatra mandarin rootstocks. Proc. Ann. Rio Grande Valley Hort. Inst. $4: 58-79$. 
Cooper, W.C. and B.S. Gorton. 1952. Toxicity and accumulation of chloride salts in citrus on various rootstocks. Proc. Amer. Soc. Hort. Sci. 59:143-146.

Cooper, W.C., B.S. Gorton and C. Edwards. 1951. Salt tolerance of various citrus rootstocks. Proc. Rio Grande valley Hort. Inst. 5:46-52.

Cooper, W.C., B.S. Gorton and E.O. Olson. 1952b. Ionic accumulation in citrus as influenced by rootstock and scion and concentration of salts and boron in the substrate. Plant Physiol. 27:191-203.

Cooper, W.C. and A. Peynado. 1953. A comparison of sour orange and cleopatra mandarin seedlings on salty and calcareous nursery soils. Proc. Rio Grande Valley Hort. Inst. pp. 95-101.

Cooper, W.C. and A. Peynado. 1959. Chloride and boron tolerance of young-line citrus trees on various rootstocks. Proc. Rio Grande Valley Hort. Soc. 13:89-96.

Cooper, W.C., A. Peynado and E.O. Olson. 1958. Response of grapefruit on two rootstocks to calcium additions to high-sodium, boron-contaminated, and saline irrigation water. Soil Sci. 86:180-189.

Cooper, w.C. and A.V. Shull. 1953. Salt tolerance of and accumulation of sodium and chloride ions in grapefruit on various rootstocks grown in a naturally saline soil. Proc. Rio Grande Valley Hortic. Inst. 7:107-117.

Cossmann, K.F. 1940. Citrus roots: their anatomy, osmotic pressure and periodicity of growth. Palest. J. Bot. $3: 65-103$.

Crider, F.J. 1927. Root studies of citrus trees with practical applications. Citrus Leaves $7(4): 1-3,27-30$.

Croughan, T.P., S.J. Stavarek and D.W. Rains. 1981. In vitro development of salt-resistant plants. Environmental and Experimental Botany 21:317-324.

Deo, R. and J.S. Kanwar. 1969. Effect of saline irrigation waters on the growth and chemical composition of wheat. J. Indian. Soc. Soil Sci. 16:365-370.

Douglas, T.J. and R.R. Walker. 1983. 4-Desmethylsterol composition of citrus rootstocks at different salt exclusion capacity. Physiol. Plant. 58:69-74.

Downton, W.J.S., W.J.R. Grant and S.P. Robinson. 1985. Photosynthetic and stomatal responses of spinach leaves to salt stress. Plant Physiol. 77:85-88. 
Downton, W.J.S. and J. Millhouse. 1985. Chlorophyll fluorescence and water relations of salt-stressed plants. Plant Sci. Letters 37:205-212.

Eaton, F.M. and R.B. Harding. 1959. Foliar uptake of salt . constituents of water by citrus plants during intermittent sprinkling and immersion. Plant Physiol. 34:22-26.

Ehlig, C.F. 1964. Salt tolerance of raspberry, boysenberry and blackberry. Proc. Amer. Soc. Hort. Sci. 85:318-324.

Ehlig, C.F. and L. Bernstein. 1959. Foliar absorption of sodium and chloride as a factor in sprinkler irrigation. Proc. Amer. Soc. Hort. Sci. 74:661-670.

El-Azab, E.M., M.A. Barakat, F.A. Minessy and A. Ismail. 1973. Effect of salt source on the nutritional status of Cleopatra mandarin and sour orange seedlings. Proc. Int. Soc.

Citriculture 1:317-320.

Elgazzar, A., A. Wallace and N. Hemaidan. 1965. Sodium distribution in rough lemon and trifoliate orange seedlings. Soil Sci. 99:387-391.

Embleton, T.W., C.K. Labanauskas and W.P. Bitters. 1962. The influence of certain rootstocks on the concentration of boron, iron, manganese, and other elements in lemon leaves, and on boron toxicity symptoms. Proc. Amer. Soc. Hort. Sci. $80: 285-290$.

Emmert, F.H. 1974. Inhibition of phosphorus and water passage across intact roots by polyethylene glycol and phenylmercuric acetate. Plant Physiol. 53:663-665.

Epstein, E. 1972. Mineral Nutrition of Plants. Principles and Perspectives. John Wiley and Sons, New York.

Epstein, E., J.D. Norlyn, D.W. Rush, R.W. Kingsburg, D.B. Kelley, G.A. Cunningham and A.F. Wrona. 1980. Saline culture of crops: a genetic approach. Science 210:399-404.

Fernandez, F.G., M. Caro, A. Cerda and M.G. Guillen. 1977. Chloride sodium distribution in citrus rootstocks irrigated with saline waters. Abstract \#B-23. Int. Soc. Citriculture pp. 29.

Flowers, T.J., E. Duque, M.A. Hajibagheri, T.P. McGonigle and A.R. Yeo. 1985. The effect of salinity on leaf ultrastructure and net photosynthesis of two varieties of rice: further evidence for a cellular component of salt-resistance. New phytol. 100:37-43.

Flowers, T.J., S.A. Flowers and H. Greenway. 1986. Effects of sodium chloride on tobacco plants. plant, Cell and Envi ronment 9:645-651. 
Flowers, T.J., P.F. Troke and A.R. Yeo. 1977. The mechanism of salt tolerance in halophytes. Ann. Rev. Plant Physiol. 28:89-121.

Ford, H.W. 1964. The effect of rootstock, soil type, and soil pH on citrus root growth in soils subject to flooding. Proc. Fla. State Hort. Soc. 77:41-45.

Francois, L.E. and R.A. Clark. 1980. Salinity effects on yield and fruit quality of Valencia orange. J. Amer. Soc. Hort. Sci. 105:199-202.

Francois, L.E. and D.W. West. 1982. Reduction in yield and market quality of celery caused by soil salinity. J. Amer. Soc. Hort. Sci. 107:952-954.

Furr, J.R., J.B. Carpenter and A.A. Hewitt. 1963. Breeding new varieties of citrus fruits and rootstocks for the southwest. J. Rio Grande Valley Hort. Sci. 17:90-107.

Furr, J.R. and C.L. Ream. 1968. Shoot growth of 'Valencia' orange in relation to salinity and salt accumulation. Proc. Amer. Soc. Hort. Sci. 93:153-158.

Furr, J.R. and C.L. Ream. 1969. Breeding citrus rootstocks for salt tolerance. Proc. First Int. Citrus Symposium $1: 373-380$.

Gale, J., H.C. Kohl and R.M. Hagan. 1967. Changes in the water balance and photosynthesis of onion, bean and cotton plants under saline conditions. Physiol. Plant. 20:408-420.

Gergely, I., R.F. Korcak and M. Faust. 1980. Polyethylene glycol induced water stress effects on apple seedlings. I. Methodology, water consumption, and dry matter production. J. Amer. Soc. Hort. Sci. 105:854-857.

Goell, A. 1969. Salinity effects on citrus trees. Proc. First Int. Citrus Symposium 3:1819-1824.

Goldberg, D., B. Gornat and D. Rimon. 1976. Drip Irrigation. Drip Irrig. Scientific Publications Kfar Shmaryaha, Israel.

Goldberg, D. and M. Shmueli. 1971. Sprinkle and trickle irrigation of green pepper in an arid zone. HortScience 6:559-562.

Gollek, B. 1973. Structure and Function of Plant Cells in Saline Habitats. Israel Program for Scientific Translations. John Wiley, New York.

Graham, J.H. and J.P. Syvertsen. 1984. Influence of vesicular-arbuscular mycorrhiza on the hydraulic conductivity of roots of two citrus rootstocks. New Phytol. 97:277-284. 
Graham, J.H. and J.P. Syvertsen. 1985. Host determinants of mycorrhizal dependency of citrus rootstock seedlings. New Phytol. 101:667-676.

Greenway, H. 1962. Plant response to saline substrates. I. -Growth and ion uptake of several varieties of Hordeum during and after sodium chloride treatment. Aust. J. Biol. Sci. $5: 16-38$.

Greenway, H. and R. Munns. 1980. Mechanisms of salt tolerance in nonhalophytes. Ann. Rev. Plant Physiol. 31:149-190.

Grieve, A.M. and R.R. Walker. 1983. Uptake and distribution of chloride, sodium and potassium ions in salt-treated citrus plants. Aust. J. Agric. Res. 34:133-143.

Guillen, M.G., M. Caro, F.G. Fernandez and A. Cerda. 1978. Foliar composition of citrus seedlings irrigated with saline waters. Commu. In Soil Sci. and Plant Analysis 9(7):595-606.

Harding, R.B. and H.D. Chapman. 1951. Progress report on a study of soil characteristics in forty high-performance orange orchards in California. Soil Sci. Soc. Amer. Proc. $15: 243-248$.

Harding, R.B., M.P. Miller and M. Fireman. 1958a. Absorption of salts by citrus leaves during sprinkling with water suitable for surface irrigation. Proc. Amer. Soc. Hort. Sci. $71: 248-256$.

Harding, R.B., P.F. Pratt and W.W. Jones. 1958b. Changes in salinity, nitrogen, and soil reaction in a differentially fertilized irrigated soil. Soil Sci. 85:177-184.

Hartz, T.K. 1984. Salination-A threat to valley agriculture. J. Rio Grande Valley Hort. Soc. 37:123-125.

Hayward, H.E. and W.M. Blair. 1942. Some response of Valencia orange seedlings to varying concentrations of chloride and hydrogen ions. Amer. J. Bot. 29:148-155.

Helal, M.H. and K. Mengel. 1981. Interaction between light intensity and $\mathrm{NaCl}$ salinity and their effects on growth, $\mathrm{CO}_{2}$ assimilation, and photosynthate conversion in young broad beans. Plant Physiol. 67:999-1002.

Heller, J., J. Shalhevet and A. Goell. 1973. Response of a citrus orchard to soil moisture and soil salinity. In Physical Aspects of Soil, Water, and Salt in Ecosystems. Ecological Studies. (A. Hadas, D. Swartzendruber, P.E. Rijtema, M. Fuchs and B. Yaron, eds.), pp. 409-419. Springer-Verlag, Berlin.

Hewitt, A.A. and J.R. Furr. 1965a. Influence of salt source on the uptake of chlorides by selected citrus seedlings. Proc. Amer. Hort. Sci. 86:201-204. 
Hewitt, A.A. and J.R. Furr. 1965b. Uptake and loss of chloride from seedlings of elected citrus rootstock varieties. Proc. Amer. Soc. Hort. Sci. 86:194-200.

Hewitt, A.A., J.R. Furr and J.B. Carpenter. 1964. Uptake and distribution of chlorides in citrus cuttings during a short-term salt test. Proc. Amer. Soc. Hort. Sci. $84: 165-169$.

Heyser, J.W. and M.W. Nabors. 1981. Growth, water content, and salute accumulation of two tobacco cell lines cultured on sodium chloride, dextran and polyethylene glycol. Plant Physiol. 68:1454-1459.

Hoagland, D.R. and D.I. Arnon. 1950. The water-culture method for growing plants without soil. California Agriculture Exp. station. Circular $347: 1-32$.

Hoffman, G.J., J. Shalhevet and A. Meiri. 1980. Leaf age and salinity influence water relations of pepper leaves. physiol. Plant. 48:463-469.

Hoffman, G.J., M.C. Shannon and J.A. Jobes. 1985. Influence of rain on soil salinity and lettuce yield. Proc. Third Int. Drip/Trickle Irrig. Congress 2:659-665.

Hyder, S.z. and H. Greenway. 1965. Effects of Ca++ on plant sensitivity to high $\mathrm{NaCl}$ concentrations. Plant and Soil $23: 258-260$.

Jackson, W.T. 1962. Use of carbowaxes (polyethylene glycols) as osmotic agents. Plant Physiol. 37:513-519.

Janes, B.E. 1966. Adjustment mechanisms of plants subjected to varied osmotic pressures of nutrient solution. Soil Sci. $101: 180-188$.

Jones, W.W., J.P. Martin and W.P. Bitters. 1957. Influence of exchangeable sodium and potassium in the soil on the growth and composition of young lemon trees on different rootstocks. proc. Amer. Soc. Hort. Sci. 69:189-196.

Jones, W.W., H.E. Pearson, E.R. Parker, and M.R. Huberty. 1952. Effect of sodium in fertilizer and in irrigation water on concentration in leaf and root tissues of citrus trees. Proc. Amer. Soc. Hort. Sci. 60:65-70.

Joolka, N.K. and J.P. Singh. 1979. Effect of soil salinity on the growth of cirus rootstocks. Indian J. of Agric. Sci. $49(11): 858-861$.

Kanwar, J.S. and J.R. Bhambota. 1969. Variable salinity and water table level effects on the growth of sweet orange (C. sinensis) under Punjab conditions. Proc. First Int. Citrus Symposium 3:1783-1791. 
Kaufmann, M.R. and A.N. Eckard. 1971. Evaluation of water stress control with polyethylene glycols by analysis of guttation. plant Physiol. 47:453-456.

Kaul, R. 1966. Relative growth rate of spring wheat, oats and barley under polyethylene glycol induced water stress. Can. J. Plant Sci. 46:611-617.

Kawasaki, T., T. Akiba and M. Moritsugu. 1983a. Effects of high concentrations of sodium chloride and polyethelene glycol on the growth and ion absorption in plants. I. Water culture experiments in a greenhouse. Plant and Soil 75:75-85.

Kawasaki, T., G. Shimizu and M. Moritsugu. 1983b. Effects of high concentrations of sodium chloride and polyethylene glycol on the growth and ion absorption in plants. II.

Multi-compartment transport box experiment with excised roots of barley. Plant and Soil 75:87-93.

Keck, T.J., R.J. Wagenet, W.F. Campbell and R.E. Knighton. 1984. Effects of water and salt stress on growth and acetylene reduction in alfalfa. Soil Sci. Soc. Amer. J. 48:1310-1316.

Kirkham, M.B. 1980. Movement of cadmium and water in split-root wheat plants. Soil Sci. 129:339-344.

Kirkham, M.B., W.R. Gardner and G.C. Gerloff. 1969. Leaf water potential of differentially salinized plants. Plant Physiol. 44 :1378-1382.

Kirkham, M.B., W.R. Gardner and G.C. Gerloff. 1972. Stomatal conductance of differentially salinized plants. Plant Physiol. 49:345-347.

Kirkpatrick, J.D. and W.P. Bitters. 1969. Physiological and morphological response of various citrus rootstocks to salinity. Proc. First Int. Citrus Symposium 1:391-399.

Koch, K.E. and C.R. Johnson. 1984. Photosynthate partitioning in split-root citrus seedlings with mycorrhizal and nonmycorrhizal root systems. Plant Physiol. 75:26-30.

Kramer, P.J. 1969. Plant and Soil Water Relationships: A Modern Synthesis. McGraw-Hill, New York.

Kramer, P.J. 1983. Water Relations of Plants. Academic Press, New York.

Kriedemann, P.E. and H.D. Barrs. 1981. Citrus orchards. In Water Deficits and Plant Growth (T.T. Kozlowski, ed.), Vol. VI pp. 325-417. Academic Press, New York.

Lagerwerff, J.V. and H.E. Eagle. 1961. Osmotic and specific effects of excess salts on beans. Plant Physiol. $36: 472-477$. 
Lagerwerff, J.V., G. Ogata and H.E. Eagle. 1961. Control of osmotic pressure of culture solutions with polyethylene glycol. Science 133:1486-1487.

LaHaye, P.A. and E. Epstein. 1969. Salt toleration by plants: enhancement with calcium. Science 166:395-396.

LaHaye, P.A. and E. Epstein. 1971. Calcium and salt toleration by bean plants. Physiol. Plant. 25:213-218.

Lawlor, D.W. 1970. Absorption of polyethylene glycols by plants and their effects on plant growth. New Phytol. 69:501-513.

Lawlor, D.W. 1973. Growth and water absorption of wheat with parts of the roots at different water potentials. New Phytol. $72: 297-305$.

Levitt, J. 1980. Responses of Plants to Environmental Stresses. Volume II. Academic Press, New York.

Levy, Y., J. Shalhevet and H. Bielorai. 1979. Effect of irrigation regime and water salinity on grapefruit quality. J. Amer. Soc. Hort. Sci. 104:356-359.

Levy, Y., J.P. Syvertsen and S. Nemec. 1983. Effect of drought stress and Vesicular-arbuscular mycorrhiza on citrus transpiration and hydraulic conductivity of roots. New Phytol. 93:61-66.

Lunin, J. and M.H. Gallatin. 1965. Zonal salinization of the root system in relation to plant growth. Proc. Soil Sci. Soc. Amer. 29:608-612.

Lyons, Jr. C.G. 1977. Water management in Texas citrus. Proc. Int. Soc. Citriculture 1:117.

Maas, E.V. and G.J. Hoffman. 1977. Crop salt tolerance-Current assessment. J. Irrig. Drainage Div. 103:115-134.

Marloth, R.H. 1949. Citrus growth studies. I. Periodicity of root-growth and top-growth in nursery seedlings and budlings. J. Hort. Sci. 25:50-59.

Marsh, A.W. 1973. Irrigation. In The Citrus Industry (W. Reuther, ed.), Vol. 3. pp. 230-279. University of California, Berkeley.

Matar, Y., H.W. Doering and H. Marschner. 1975. Effect of $\mathrm{NaCl}$ and $\mathrm{Na}_{2} \mathrm{SO}_{4}$ on dry matter production, mineral content and organic compounds of spinach and lettuce. z. Pflanzenernaehr. Bodenkd. 3:295-307.

Meiri, A. and A. Poljakoff-Mayber. 1970. Effect of various salinity regimes on growth, leaf expansion and transpiration rate of bean plants. Soil Sci. 109:26-34. 
Mexal, J., J.T. Fisher, J. Osteryoung and C.P. Patrick Reid. 1975. Oxygen availability in polyethylene glycol solutions and its implications in plant-water relations. Plant Physiol. $55: 20-24$.

Minessy, F.A., E.M. El-Azab and M.A. Barakat. 1973. Effect of salinity and depth of water table on the mineral content of Washington Navel orange and Balady mandarin. Proc. Int. Soc. Citriculture 1:321-330.

Miwa, T., K. Gomi and S. Yamamoto. 1957. Studies on the briny wind injury of fruit trees. I. Spray injury caused by sea water to citrus leaves. Bull. Fac. Agric. Univ. Miyazaki. 2:96-105.

Mizrahi, Y. and D. Pasternak. 1985. Effect of salinity on quality of various agricultural crops. Plant and Soil 89:301-307.

Monselise, S.P. 1947. The growth of citrus and shoots under different cultural conditions. Palest. J. Bot. 6:43-54.

Moran, R. and D. Porath. 1980. Chlorophyll determination in intact tissues using $\mathrm{N}, \mathrm{N}$-dimethylformamide. Plant Physiol. 65: $478-479$.

Munns, R. and J.B. Passioura. 1984. Hydraulic resistance of plants. III. Effects of $\mathrm{NaCl}$ in barley and lupin. Aust. J. Plant Physiol. 11:351-359.

Nimbalker, J.D. and G.V. Joshi. 1975. Effect of increasing salinity on germination, growth and mineral metabolism of sugarcane var. Co. 740. J. Biol. Sci. 18:55-63.

O'Leary, J.W. 1969. The effect of salinity on permeability of roots to water. Israel J. Bot. 18:1-9.

O'Leary, J.W. 1974. Salinity induced changes in hydraulic conductivity of roots. In Structure and Function of Primary Root Tissues. (J. Kolek, ed.), pp. 309-314. Veda, Bratislava, Czechoslovakia.

Pair, C.H., W.W. Hinz, C. Reid, and K.R. Frost. 1975. Sprinkler Irrigation. Sprinkler Irrigation Association, Maryland.

Paricha, P.C., G.J. Patra and P. Sahoo. 1975. Effect of synthetic sea water on growth and chemical composition of rice at different stages of development. J. Indian Soc. Soil Sci. $23: 344-348$.

Patil, V.K. and J.R. Bhambota. 1978. Relationship between relative growth of different rootstock seedlings of citrus and levels of salinity in soil. Research Bull. Marathwada Agricultural Univ. $2(6): 71-74$. 
Patil, V.K. and J.R. Bhambota. 1980. Salinity studies in citrus: 1 - Effect of various levels of salinity on the macronutrient status of seedling rootstocks. J. Indian Soc. Soil Sci. 28(1):72-79.

Pearson, G.A. and J.A. Goss. 1953. Observations on the effects of salinity and water table on young grapefruit trees. Proc. Rio Grande Valley Hort. Inst. 7:1-6.

Pearson, G.A., J.A. Goss and H.E. Hayward. 1957. The influence of salinity and water table on the growth and mineral composition of young grapefruit trees. Proc. Amer. Soc. Hort. Sci. 69:197-203.

Pearson, H.E. and M.R. Huberty. 1959. Response of citrus to irrigation with water of different chemical characteristics. Proc. Amer. Soc. Hort. Sci. 73:248-256.

Peck, A.J. 1975. Effects of land use on salt distribution in the soil. In Plants in Saline Environments.

(A. Poljakoff-Mayber and J. Gale, eds.), pp. 77-90. Springer-Verlag, Berlin and Heidelberg.

Pehrson, J., N. O'Connell and J. Oster. 1985. Salinity management for San Joaquin valley citrus. Citrograph $71(1): 15-17$.

Peynado, A. and R.H. Young. 1964. Toxicity of three salts to greenhouse-grown grapefruit trees and their effects on ions accumulation and cold hardiness. Hort. Abst. 34:3595.

Plaut, Z, and E. Federman. 1985. A simple procedure to overcome polyethylene glycol toxicity on whole plants. Plant Physiol. $79: 559-561$.

Plessis, H.M. 1985. Evapotranspiration of citrus as affected by soil water deficit and soil salinity. Irrig. Sci. 6:51-61.

Ream, C.L. and J.R. Furr. 1976. Salt tolerance of some citrus species, relatives, and hybrids tested as rootstocks. J. Amer. Soc. Hort. Sci. 101(3):265-267.

Richards, L.A. 1954. In Diagnosis and Improvement of Saline and Alkali Soils. Agriculture Handbook \#60, pp. 4-5. U.S. Department of Agriculture. U.S. Government Printing office, Washington, D.C.

Robinson, S.P., W.J.S. Downton and J.A. Millhouse. 1983. Photosynthesis and ion content of leaves and isolated chloroplasts of salt-stressed spinach. Plant Physiol. 73: 238-242. 
Sanchez-Diaz, M., P. Aparicio-Tejo, C. Gonzalez-Murua and J.I. Pena. 1982. The effect of $\mathrm{NaCl}$ salinity and water stress with polyethylene glycol on nitrogen fixation, stomatal response and transpiration of Midicago sativa, Trifolium repens and Trifolium brachycalycinum (Subclover). Physiol plant. 54:361-366.

Schwarz, M. and J. Gale. 1983. The effect of heat and salinity stress on the carbon balance of Xanthium strumarium. In Effects of Stress on Photosynthesis. (R. Marcelle, $\mathrm{H}$. Clijsters and M. van Pouche, eds.) Martinus Nijhoff/Dr. W. Junk Publishers, The Hague.

Seemann, J.R. and C. Critchley. 1985. Effects of salt stress on the growth, ion content, stomatal behavior and photosynthetic capacity of a salt-sensitive species, Phaseolus vulgaris L. Planta $164: 151-162$.

Shainberg, I. 1975. Salinity of soils. Effects of salinity on the physics and chemistry of soils. In Plants in Saline Envi ronments. (A. Poljakoff-Mayber and J. Gale, eds.), pp. 39-55. Springer-Verlag, Berlin and Heidelberg.

Shalhevet, J. and L. Bernstein. 1968. Effects of vertically heterogeneous soil salinity of plant growth and water uptake. Soil Sci. 106:85-93.

Shalhevet, J., E.V. Maas, G.J. Hoffman and G. Ogata. 1976. Salinity and hydraulic conductance of roots. Physiol. Plant. $38: 224-232$.

Shalhevet, J., D. Yaron and U. Horowitz. 1974. Salinity and citrus yield-An analysis of results from a salinity survey. J. Hort. Sci. 49:15-27.

Shannon, M.C. and L.E. Francois. 1978. Salt tolerance of three muskmelon cultivars. J. Amer. Soc. Hort. Sci. 103:127-130.

Sharma, G. and P. Lal. 1975. Effect of nitrogen levels and leaching regimes on the use of saline waters for wheat crop grown on sandy and clay loam soils. J. Indian Soc. Soil Sci. 23:302-309.

Shaybany, B. and A. Kashirad. 1978. Effect of $\mathrm{NaCl}$ on growth and mineral composition of Acacia saligna in sand culture. J. Amer. Soc. Hort. Sci. 103:823-826.

Shmueli, M. and D. Goldberg. 1971. Sprinkle, furrow and trickle irrigation of muskmelon in an arid zone. Hort Science $6: 557-559$.

Siegal, S.M., B.Z. Siegal, J. Massey, P. Lahne and J. Chen. 1980. Growth of corn in saline waters. Physiol. Plant. 50:71-73. 
Sivtsev, M.V. 1973. Photochemical activity of chloroplasts and bond strength of chlorophyll in cultivated plants during action of herbicides, salinization and biologically active compounds. Fiziol. Rast. 20:1176-1181.

Sivtsev, M.V., S.A. Ponomareva and E.A. Kuznetsova. 1973. Éffect of salinization and herbicide on the activity of chlorophyllase in tomato leaves. Fiziol. Rast. 20:62-65.

Solov'ev, V.A. 1969. Distribution of cations in plants depending on the degree of salinization of the substrate. Fiziol. Rast. 14:1093-1103.

Steuter, A.A., A. Mozafar and J.R. Goodin. 1981. Water potential of aqueous polyethylene glycol. Plant Physiol. 67:64-67.

Stewart, E.H., R.R. Alberts and P.G. Orth. 1977. Water and salinity relationships in Perrine marl soils of south Florida. Proc. Fla. Soil and Crop Sci. Soc. 36:89-93.

Storey, R. and R.G. Wyn Jones. 1978. Salt stress and comparative physiology in the Gramineae. I. Ion relations of two salt and water stressed barley cultuvars. Aust. J. Plant Physiol. 5:801-806.

Strogonov, B.P. 1964. Physiological basis of salt tolerance of plants (as affected by various types of salinity). Israel Program for Scientific Translation. Daniel Davey and Co., New York.

Syvertsen, J.P. 1981. Hydraulic conductivity of four comercial citrus rootstocks. J. Amer. Soc. Hort. Sci. 106:378-381.

Syvertsen, J.P. and J.H. Graham. 1985. Hydraulic conductivity of roots, mineral nutrition, and leaf gas exchange of citrus rootstocks. J. Amer. Soc. Hort. Sci. 110(6):865-869.

Syvertsen, J.P. and M.L. Smith, Jr. 1984. Light acclimation in citrus leaves. I. Changes in physical characteristics, chlorophyll, and nitrogen content. J. Amer. Soc. Hort. Sci. $109(6): 807-812$.

Tagawa, T. and N. Ishizaka. 1963. Physiological studies on the tolerance of rice plants to salinity. II. Effects of salinity on the absorption of water and chloride ion. Proc. Jap. Crop Sci. Soc. 31:337-341.

Taha, M.W., E. El-Azab and Z. Fadiah. 1972. Ionic leaf concentration in grapes, guava and olive plants as affected by the salinity of irrigation water. Alexandria J. Agric. Res. 20:299-309.

Tan, C.S., A. Cornelisse and B.R. Buttery. 1981. Transpiration, stomatal conductance, and photosynthesis of tomato plants with various proportions of root system supplied with water. J. Amer. Soc. Hort. Sci. 106:147-151. 
Tennant, D. 1975. A test of a modified line intersect method of estimating root length. J. Ecol. 63:995-1001.

Waisel, Y. 1962. The effect of calcium on the uptake of monovalent ions by excised barley roots. Physiol. Plant 15:709-724.

Walker, R.R. 1986. Sodium exclusion and potassium-sodium selectivity in salt-treated trifoliate orange (Poncirus trifoliata) and Cleopatra mandarin (Citrus reticulata) plants. Aust. J. Plant Physiol. 13:293-303.

Walker, R.R. and T.J. Douglas. 1983. Effect of salinity level on uptake and distribution of chloride, sodium and potassium ions in citrus plants. Aust. J. Agric. Res. 34:145-153.

Walker, R.R., M. Sedgley, M.A. Blesing and T.J. Douglas. 1984. Anatomy, ultrastructure and assimilate concentrations of roots of citrus genotypes differing in ability for salt exclusion. J. Exp. Bot. 35:1481-1494.

Walker, R.R., E. Torokfalvy and W.J.S. Downton. 1982. Photosynthetic responses of the citrus varieties Rangpur lime and Etrog citron to salt treatment. Aust. J. Plant Physiol. 9:783-790.

Walker, R.R., E. Torokfalvy, A.M. Grieve and L.D. Prior. 1983. Water relations and ion concentrations of leaves on salt-stressed citrus plants. Aust. J. Plant Physiol. 10:265-277.

Ward, M.R., M. Aslam and R.C. Huffaker. 1986. Enhancement of nitrate uptake and growth of barley seedlings by calcium under saline conditions. Plant Physiol. 80:520-524.

Wignarajah, K., D.A. Jennings and J.F. Handley. 1975. The effect of salinity on growth of Phaseolus vulgaris L. I. Anatomical changes in the first trifoliate leaf. Ann. Bot. $39: 1029-1038$.

Wutscher, H.K., A. Peynado, W.C. Cooper and H. Hill. 1973. Method of irrigation and salt tolerance of citrus rootstocks. Proc. Int. Soc. Citriculture 1:299-306.

Yaniv, Z. and E. Werker. 1983. Absorption and secretion of polyethylene glycol by solanaceous plants. J. Exp. Bot. $34: 1577-1584$.

Yaron, B., J. Shalhevet and D. Shimshi. 1973. Pattern of salt distribution under trickle irrigation. In Physical Aspects of Soil Water and Salts in Ecosystems. (A. Hadas, D. Swartzendruber, P.E. Rijitema, M. Fuchs, and B. Yaron, eds.), pp. 339-394. Springer-Verlag, Berlin. 
Zahran, H.H. and J.I. Sprent. 1986. Effects of sodium chloride and polyethylene glycol on root-hair infection and nodulation of Vicia faba L. plants by Rhizobium leguminosarum. Planta 167:303-309.

Zid, E. 1975. Croissance et alimentation minerale du jeune bigaradier cultive' en presence de chlorure de sodium. Effect de variations de la concentration du potassium. Fruits $30(6): 403-410$.

Zid, E. and C. Grignon. 1985. Sodium-calcium interactions in leaves of Citrus aurantium grown in the presence of $\mathrm{NaCl}$. Physiol. veg. 23:895-903.

Zid, E. and C. Grignon. 1986. Effets compares de $\mathrm{NaCl}, \mathrm{KCl}$ et $\mathrm{Na}_{2} \mathrm{SO}_{4}$ sur la croissance et la nutrition minerale de jeunes Citrus aurantium L. Oecol. Plant. 7(21):407-416. 


\section{BIOGRAPHICAL SKETCH}

Mongi Zekri was born in Kerkennah, Tunisia, on December 3, 1955. He received his secondary education and graduated from Chott-Mariem High School, Sousse, in June 1972. He obtained the diplome of Baccalaureat of Science in September 1972.

He entered the National Institute of Agronomy in Tunis in October 1972 and graduated with the degree of Bachelor of Engineering in June 1976. Upon graduation, he was employed by the office of Cereals under the Ministry of Agriculture as an inspector and a researcher on wheat for two and a half years. He served in the Army from March 1977 to March 1978 and obtained the rank of lieutenant in August 1977.

He was awarded a scholarship to pursue graduate studies in the United States. He attended the Intensive English Program in the spring and summer of 1980 at the University of Missouri-Columbia. In the fall of 1980, he enrolled at the University of Florida as a graduate student in the Fruit Crops Department and earned the degree of Master of Science in April 1984.

He completed his work toward the degree of Doctor of Philosophy in December 1987.

He is married to the former Leila Atia. They have one daughter, Dhoha. 
I certify that I have read this study and that in my opinion it conforms to acceptable standards of scholarly presentation and is fully adequate, in scope and quality, as a dissertation for the degree of Doctor of Philosophy.

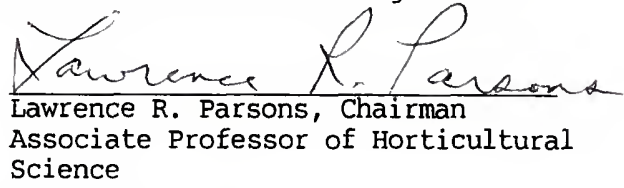

I certify that I have read this study and that in my opinion it conforms to acceptable standards of scholarly presentation and is fully adequate, in scope and quality, as a dissertation for the degree of Doctor of Philosophy.

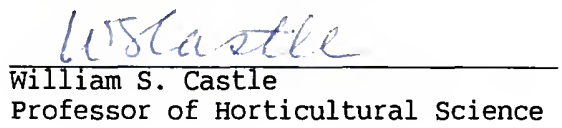

I certify that I have read this study and that in my opinion it conforms to acceptable standards of scholarly presentation and is fully adequate, in scope and quality, as a dissertation for the degree of Doctor of Philosophy.

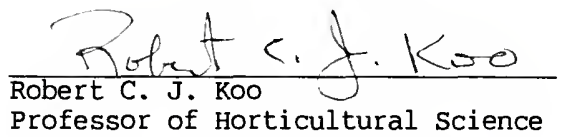

I certify that I have read this study and that in my opinion it conforms to acceptable standards of scholarly presentation and is fully adequate, in scope and quality, as a dissertation for the degree of Doctor of Philosophy.

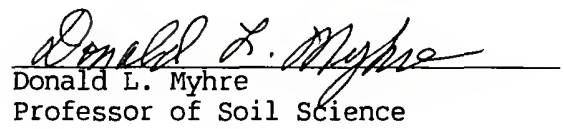

I certify that I have read this study and that in my opinion it conforms to acceptable standards of scholarly presentation and is fully adequate, in scope and quality, as a dissertation for the degree of Doctor of Philosophy.

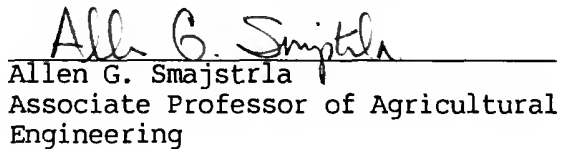


This dissertation was submitted to the Graduate Faculty of the College of Agriculture and to the Graduate School and was accepted as partial fulfillment of the requirements for the degree of Doctor of Philosophy.

December 1987

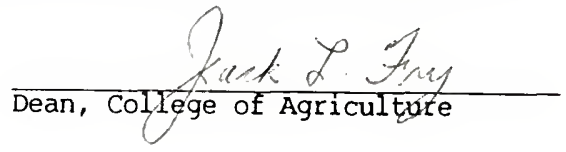

Dean, Graduate 
UNIVERSITY OF FLORIDA

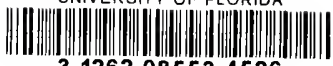

31262085534526 